Evaluating and Monitoring Environmental Exposure to Pesticide Residues in the Lake Naivasha River Basin (Kenya) 
Graduation committee:

\section{Chairman/Secretary}

Prof.dr. F.D. van der Meer

University of Twente

\section{Supervisor(s)}

A/Prof.dr.ir. C.M.M. Mannaerts

University of Twente

Co-supervisor(s)

\section{Members}

Prof.dr.Daphne van de Wal

Prof.dr.Justine Blanford

Prof.dr.ir. Voilette Geissen

Prof.dr.ing.Christian Renschler
University of Twente

University of Twente

Wageningen University (WUR)

State University of New York (SUNY)

ITC dissertation number 395

ITC, P.O. Box 217, 7500 AE Enschede, The Netherlands

ISBN 978-90-365-5174-8

DOI $10.3990 / 1.9789036551748$

Cover designed by Yasser Abbasi

Printed by CTRL-P Printing

Copyright (C) 2021 by Yasser Abbasi 
T- Faculty of gEO-INFORMATION SCIENCE AND EARTH OBSERVATION 


\title{
Evaluating and Monitoring Environmental Exposure to Pesticide Residues in the Lake Naivasha River Basin (Kenya)
}

\author{
DISSERTATION
}

to obtain

the degree of doctor at the University of Twente, on the authority of the rector magnificus, prof.dr.ir.A.Veldkamp,

on account of the decision of the graduation committee, to be publicly defended

on Thursday 27 May 2021 at 14.45 h

by

Yasser Abbasi

born on November $8^{\text {th }} 1984$

in Iran 
This thesis has been approved by

A/Prof.dr.ir. C.M.M. Mannaerts, supervisor 



\section{Acknowledgements}

Pursuing PhD program was always a dream for me since I was a bachelor student. My BSc (2004-2008) was in field of soil and water engineering and I remember that in some of the courses that I passed, there were many models that had been developed in the Netherlands. It was the time that I found that continuing my study in the country of Netherlands could be an interesting and big chance for me to develop my study. However it needed so much work to be prepared for admission in one of the Dutch Universities. I had to finish my MSc degree in a high rank University in Iran with a good resume. After achieving my MSc in university of Tehran and two years of working in some water resources management projects, I had a chance to get acceptance in University of Twente in 2014 which was the start of a new journey for me.

Starting PhD program in a new environment for me was a big challenge to put all the idea together and define an acceptable proposal. I started discussion about my proposal with prof. Bob Su and different academic members of department of water resources (ITC). After several meeting with Dr.ir. Chris Mannaerts, we agreed on a topic and he accepted to be my supervisor. I am sure during the long challenge that I had during my study, I could not succeed without his support. Along with the support that I received from my supervisor, I was supported by Prof. Bob Su, the secretaries of the department (Mrs. Anke de Koning, Mrs. Tina Butt - Castro and Mrs. Lindy Snijders - Nijkrake) and my friends in ITC. I appreciate all of their kind attentions. Besides this, I would like to thank to prof.dr.ir.A.Veldkamp and the ITC management team as well as the student affairs staff who all supported and facilitated the good conditions (e.g., visa applications, financial support like IFP, support letters, etc.) for completing the study.

Moreover, I did my fieldwork in Kenya for which I got much help from out of University of Twente. I got help from Deltares \& TNO/Utrecht by providing samplers and technical advice from Dr. Jasperien de Weert. In Kenya, I got support from WWF and the Water Resources Management Authority (WRMA). I did some of my analysis in Department of Chemistry at University of Nairobi. Additionally, I was helped by some friends in Kenya for collecting data during the fieldwork. I would like to thank all those kind people who supported me and enabled me to overcome all the difficulties during the data collection in Kenya.

Finally, I cordially appreciate my family for their support and motivating me during all of my life, especially during my stay in Netherlands. I am sure without them I could not succeed to finish this 
journey. Last but not least, I thank my lovely friends for their good feedbacks, support and happy times that we shared together. 


\section{Table of Contents}

\begin{tabular}{|c|c|}
\hline \multicolumn{2}{|c|}{ List of Tables } \\
\hline \multicolumn{2}{|r|}{ List of Abbreviations } \\
\hline \multicolumn{2}{|c|}{ 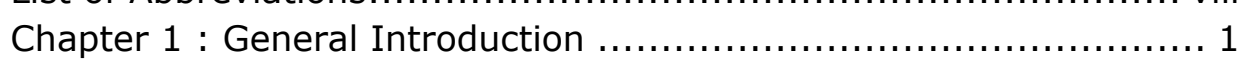 } \\
\hline 1.1 & Background . \\
\hline 1.2 & Literature review . \\
\hline 1.3 & Study area... \\
\hline 1.3 .1 & Hydrology and water balance \\
\hline 1.3 .2 & Water quality in the Naivasha ecosystem \\
\hline 1.3 .3 & e use in Naivasha basin... \\
\hline 1.4 & Objectives and research questions \\
\hline 1.4 .1 & Specific objectives ........... \\
\hline 5 & Thesis outline......... \\
\hline
\end{tabular}

Chapter 2 : Evaluating Organochlorine Pesticide Residues in the Aquatic Environment of the Lake Naivasha River Basin Using Passive

Sampling Techniques ................................................... 15

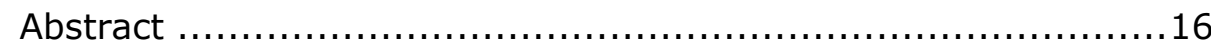

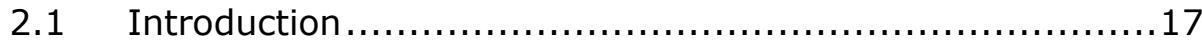

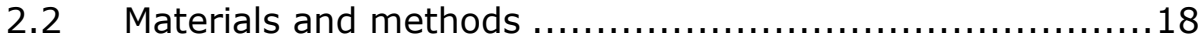

2.2 .1 Study area.................................................. 19

2.2.2 Sampler preparation and installation ....................... 19

2.2.3 Extraction and analysis..................................... 21

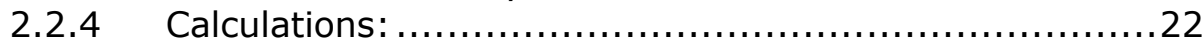

2.3 Results and discussion........................................ 23

2.4 Conclusions ................................................ 30

Chapter 3 : Modeling Pesticide and Sediment Transport in the Malewa

River Basin (Kenya) using SWAT ..................................... 33

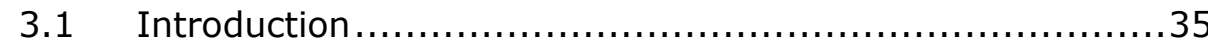

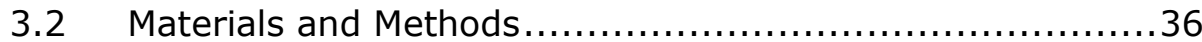

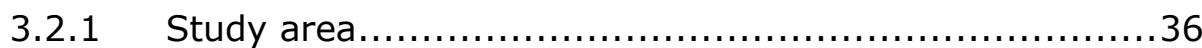

3.2.2 Data procurement........................................... 39

3.2.3 Model setup .............................................. 40

3.2.4 Model sensitivity analysis, calibration and validation ......43

3.3 Results ....................................................... 45

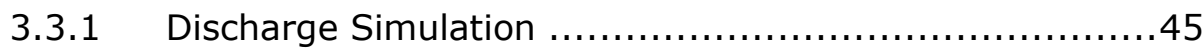

3.3.2 Suspended sediment transport simulation ..................50

3.3.3 Pesticides transport simulation ............................ 51

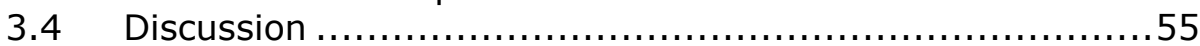

3.5 Conclusion ...................................................... 61

Chapter 4 : Exploring the Environmental Exposure of the Lake Naivasha (Kenya) to Pesticides Residues Using a Multimedia Fate Modelling Approach ......................................................65 


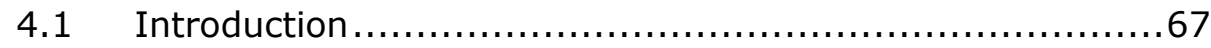

4.2 Materials and methods .......................................69

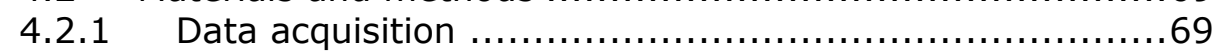

4.2.2 Environment characteristics ............................. 73

4.2.3 Pesticides properties ..................................... 74

4.2.4 Sensitivity analysis and calibration ........................ 75

4.3 Results and discussion..................................... 76

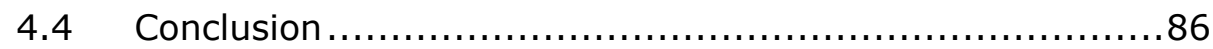

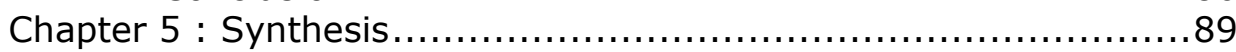

5.1 Organochlorine pesticides application ........................90

5.2 Pesticide monitoring by passive sampling ..................... 90

5.3 Modeling pollutants transport in the catchment ..............92

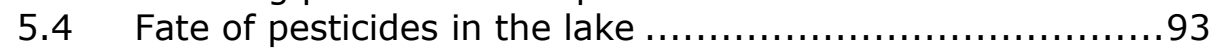

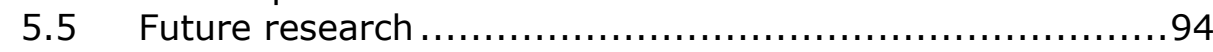

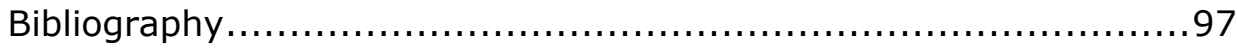

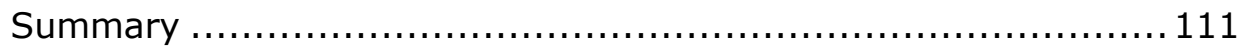

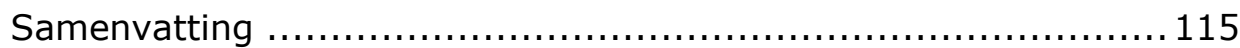

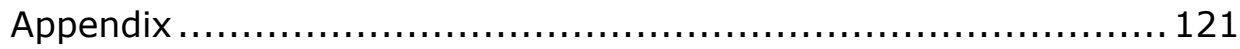




\section{List of Figures}

\section{Chapter 1:}

Figure 1-1 Typical fates and destinations of pesticides (Xu 1999)..... 3

Figure 1-2-Study are of the lake Naivasha catchment ................ 8 Figure 1-3-Toxicity classification of the pesticides applied within the L. Naivasha (Onyango et al. 2014) ....................................... 12

\section{Chapter2:}

Figure 2-1-The study area and locations of passive samplers (P1, P2 and P3 are Upper Malewa, Middle Malewa and the Lake sites, respectively) ......................................................... 19

Figure 2-2-Mounting Speedisk(SD, left) and Silicone Rubber sheet (SR, right) passive samplers for deployment............................. 21 Figure 2-3-Example diagram of logKpw versus Retained PRC fractions (left) and difference of calculated and measured (calc.) (Right). The drawn line represents the best non-linear square for two example sites. (RSA1 and RSA7 are example samples in the Lake and in Malewa river, respectively)........................................................... 25

Figure 2-4-Distribution of organochlorine pesticide residues on the Silicone Rubber (SR) and Speedisk (SD) Passive sampling media at the 3 sampling sites (based on June-July 2016 sampling campaign data)

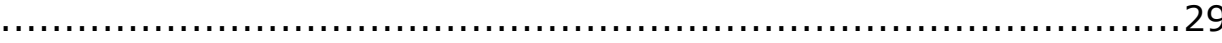

Figure 2-5- WHO drinking water standards and limits...................30

\section{Chapter3:}

Figure 3-1-Study area map showing the location of Malewa river basin and hydrological stations ............................................... 38 Figure 3-2-Daily discharge Calibration and Validation for different

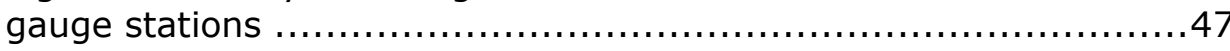
Figure 3-3-Monthly discharge Calibration and Validation for different

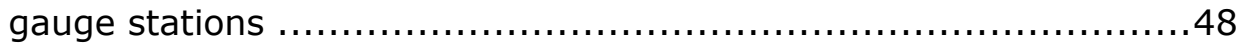
Figure 3-4-Observed and simulated daily (A) and monthly (B) suspended sediment in 2GB04 station (Upper Malewa basin) ........51 Figure 3-5- Comparing Observed and simulated monthly pesticides residues in the upstream and downstream Malewa river ...............54 Figure 3-6-Simulated and observed monthly discharge for calibration (2007-2012) and validation (2013-2017) periods against rainfall. No observed discharge data were available for the 2015 period...........56

\section{Chapter 4:}

Figure 4-1-Schematic profile of the lake Naivasha and representation of the QWASI model (reproduced partly from Whelan 2013) for different environmental compartments ...............................71 
Figure 4-2-Results of the sensitivity analysis for $\mathrm{a}-\mathrm{HCH}$ in Lake Naivasha ........................................................... 78 Figure 4-3-Results of the sensitivity analysis for Methoxychlor in Lake Naivasha ............................................................ 79 Figure 4-4-Results of the sensitivity analysis for Endosulfan-sulfate in Lake Naivasha ........................................................ 80 Figure 4-5-Comparison of the average measured and estimated concentrations of pesticides residues in the aquatic phase of Lake Naivasha .............................................................. 81 Figure 4-6-The D values of different process that affect the fate of contaminates ......................................................... 82 Figure 4-7-Mass balance diagram of $\mathrm{a}-\mathrm{HCH}$ residues in the lake Naivasha ............................................................ 83 Figure 4-8-Mass balance diagram of Endosulfan-Sulfate residues in the lake Naivasha........................................................ 84 Figure 4-9-Mass balance diagram of Methoxychlor residues in the lake Naivasha....

\section{Indices:}

Figure $0-1$ - Calculating the passive sampling

Figure $0-2-$ Outputs of the passive sampling calculations .............123

Figure 0-3- The modeling process algorithm in ArcSWAT ............ 124

Figure 0-4- Flow gauging stations in both all the basin (up) and Mallewa river basin (down) ............................................... 126

Figure 0-5-Rating curves coefficients based on $Q=a(H-b)^{c}$ equation

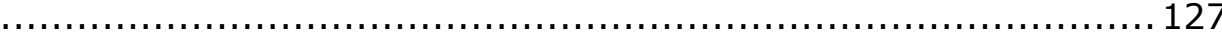

Figure 0-6-Land use-Land cover in Naivasha basin .................... 128

Figure 1-1- DEM of the L. Naivasha Basin used in modeling...........................126

Figure $0-7-$ Soil map of Naivasha basin .............................. 130 


\section{List of Tables}

\section{Chapter1:}

Table 1-1-List of some of banned pesticides in Kenya................11

Chapter 2:

Table 2-1-Physicochemical properties of water at the sampling sites

\section{Chapter3:}

Table 3-1-Parameters sensitivity of discharge simulations in SWAT .46

Table 3-2-Model performance measures for monthly and daily calibrations (2007-2012) and validations (2013-2017). The metrics were rated based on Moriasi et al. (2015) and Chen et al. (Chen et al. 2017; Moriasi et al. 2015)..............................................49

Table 3-3-Parameters sensitivity in sediment calibration...............50 Table 3-4-Sensitive parameters and their ranking in simulation of

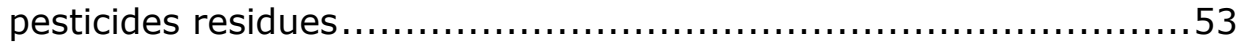

\section{Chapter4:}

Table 4-1- Physico-chemical properties of the pesticides used in the model calibration .................................................... 72 Table 4-2-Environmental properties used in the model calibration...73

Indices:

Table 0 -1- Rating coefficients of $Q=a(H-b)^{c}$ equation 123 


\section{List of Abbreviations}

\begin{tabular}{|c|c|}
\hline ANOVA & One-way analysis of variance \\
\hline AP_EF & Application efficiency \\
\hline $\mathrm{Cd}$ & Cadmium \\
\hline $\mathrm{CN} 2$ & Curve number \\
\hline $\mathrm{Cu}$ & Copper \\
\hline $\mathrm{Cw}$ & Concentrations in the water \\
\hline DDT & Dichlorodiphenyltrichloroethane \\
\hline DEM & Digital elevation model \\
\hline DTS & Digital turbidity sensor \\
\hline $\mathrm{EC}$ & Electric Conductivity \\
\hline EIA & Environmental impact assessment \\
\hline GC & $\begin{array}{l}\text { Gas chromatography } \\
\text { Gas chromatography electron capture }\end{array}$ \\
\hline GC-ECD & detection \\
\hline & Gas chromatography-double \\
\hline GC-MSMS & Spectrometry \\
\hline GIS & Geographic Information System \\
\hline $\mathrm{HCH}$ & Hexachlorocyclohexane \\
\hline HLIFE_F & Half-life in foliage \\
\hline HLIFE_S & Half-life in soil \\
\hline HPLC & High Performance Liquid Chromatography \\
\hline HRUs & Hydrological response units \\
\hline HSPF & Hydrology Simulation Program-FORTRAN \\
\hline IPM & Integrated Pest Management \\
\hline KAW & Air-water partitioning coefficient \\
\hline KOC & Organic carbon-water partition coefficient \\
\hline logKpw & Water partition coefficient \\
\hline LULC & Land use Land Cover \\
\hline $\mathrm{ng} / \mathrm{L}$ & Nano grams per liter \\
\hline $\mathrm{Ni}$ & Nickel \\
\hline NLSs & Non-linear least-squares \\
\hline NSE & Nash-Sutcliffe coefficient \\
\hline OAT & One At a Time \\
\hline OCPs & Organochlorine pesticides \\
\hline $\mathrm{P}$ & Phosphorus \\
\hline $\mathrm{Pb}$ & Lead \\
\hline PBIAS & Percent bias \\
\hline
\end{tabular}




$\begin{array}{ll}\text { PCB } & \text { Polychlorinated biphenyl } \\ \text { PERCOP } & \text { pesticide percolation coefficient } \\ \text { pH } & \text { Quantitative measure of the acidity } \\ \text { POP } & \text { Persistent organic pollutant } \\ \text { PRCs } & \text { Performance Reference Compounds } \\ & \text { Quantitative Water Air Sediment } \\ \text { QWASI } & \text { Interaction } \\ \text { Sal. } & \text { Salinity } \\ \text { Sat.O2 } & \text { Oxygen saturation } \\ \text { SCS } & \text { Soil Conservation Service } \\ \text { SD } & \text { Standard Deviation } \\ \text { SD } & \text { Speedisk } \\ \text { SKOC } & \text { Soil adsorption coefficient } \\ \text { SR } & \text { Silicone Rubber } \\ \text { SWAT } & \text { Soil \& Water Assessment Tool } \\ \text { TWA } & \text { Time-weighted average } \\ \text { WHO } & \text { World Health Organization } \\ \text { WOF } & \text { wash-off fraction } \\ \text { USLE } & \text { soil erodibility factor } \\ \text { Zn } & \text { Zinc } \\ \Sigma O C P s & \text { Total amount of organochlorine pesticide } \\ \text { HECD } & \text { residue } \\ \text { HS/cm } & \text { Micro electron capture detector } \\ & \text { Micro Siemens per centimetre }\end{array}$



Chapter 1 : General Introduction 


\subsection{Background}

Using pesticides and other agrochemicals is common in intensive agriculture. However, this can lead to environmental contamination through pesticide residues (Ware et al., 2004). Pesticides are liquid or solid chemicals that are intended to control pests that can damage agricultural products or reduce their quality. Pesticides can be categorized as fungicides (to control fungi), insecticides (to control insects), herbicides (to control weeds) and rodenticides (to kill rodents). Soil pollution by pesticides may happen by direct exposure or when they are used for crop spraying. The pollution of soil, water and aquatic ecosystems by pesticide application is a very problematic global environmental issue since years (Carson, 1962). Kim and Smith (2001) reported existing residues of organochlorine pesticides in the soils of South Korea, even though their use was banned in 1980. As agricultural lands are usually close to surface waters such as rivers and lakes together with runoff which travels through polluted lands, these surface waters are all at risk. Moreover, groundwater can be contaminated by drainage from irrigation practice or precipitation (Khodadadi 2009).

The pollution by pesticides comes from point and non-point sources. Point sources of pesticide usually include spills, waste water from cleaning sites and storage places and the improper disposal of pesticides (Tiryaki \& Temur 2010). Nonpoint sources of pesticides are usually agricultural areas in which huge amounts of pesticides is used through air and their residues can end up in surface and ground water resources by runoff (Toth and Buhler 2009). Toth and Buhler (2009) categorized environmentally-sensitive areas to seven sets: shallow ground water; surface waters; high populated areas; areas crowded with livestock and pets; near the habitats of endangered species and other wildlife; near honey bees; near food crops and ornamental plants. Any one of mentioned types, can be affected directly or indirectly. When a pesticide is used in an environment, its fate can be changed under various conditions. For example, leaching may help a herbicide to reach the roots of weeds and makes a better weed control. However, not all of the pesticide reaches the target point and as a result become harmful for environment (Cessna 2009).

The fate of pesticides is governed by pesticide properties (e.g. solubility, resistance to degradation, tendency to be adsorbed to soil), soil properties $(\mathrm{pH}$, clay and organic content of soil) and climate conditions (Anonymous 2009). With regards to these environmental characteristics, they may remain in the environment for a long time and thereby cause pollution. As to the long-term effects of pesticides, they can seep away and contaminate water resources. The evaporation of pesticide or the erosion of soil that is pesticide-polluted can be another route to environmental pollution by pesticides. It is remarkable 
that in addition to environmental contamination, movement of pesticides to non-target sites can also cause economic loss and the inefficient control of pests (Duttweiler, D.W. Malakhov 1977, Waite et al. 2002).

The movement of pesticides in environment is highly complex. After applying pesticide on the plants, many processes occur and govern its fate (Figure 1-1). The applied pesticide may be transported within the plant or it may just remain covering the plant's surface. Pesticides may even be transported through air by evaporation or through soil erosion by the wind. Pesticides are also applied directly to the soil surface and can be translocated by runoff, percolation and volatilization as well as being diluted in the soil water and leaching towards the groundwater. In addition to chemical processes, there are some physical processes such as advection, dispersion, diffusion and volatilization which are involved in the transport of the pesticides through the soils (Hounslow, 1995).

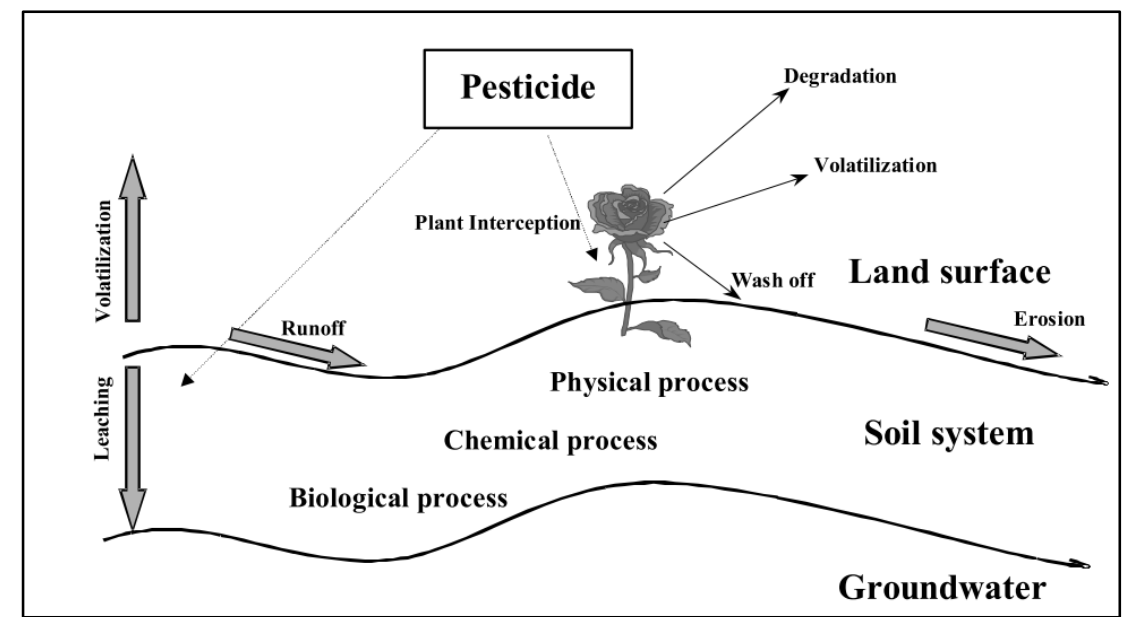

Figure 1-1 Typical fates and destinations of pesticides (Xu 1999)

This study is about the pollution of pesticides in the lake Naivasha basin in which intensive agricultural activities have caused worries about micro-pollutant contamination in the environment. The Naivasha lake which is fed by Gilgil, Karati and Malewa rivers is a fresh water lake in Kenya in the Rift Valley and is used mostly for irrigation purposes. Some of the biggest flower farms of the world are in the basin of this lake which is mostly covered by horticultural production (Oduory, 2000). Most of the agricultural products are exported to European countries such as the Netherlands, Germany and the UK. To achieve the high standard necessary for export, the use of pesticides for controlling weeds and pests is unavoidable and is common in Kenya. However, use of pesticides in an unsuitable way can cause high toxicity 
and create serious environmental risk in both the basin and the lake (Moncada 2001).

In the Naivasha lake basin, smallholders are still important parts of the agricultural and food producers for the local people, who generally have less information about the dangers of pesticides and other chemicals which are used by farmers in the upper catchment. As Naivasha lake has an important role in drinking water, irrigation water and fishery for the inhabitants, hydrologic transport of chemicals from upper catchment to the lake is possible, increasing thereby the risk of people's exposure to chemicals. This issue may not only endanger the public health in the area, but also has important economic impacts on the horticultural sector and the tourism industry which are the most important earners of foreign exchange for the Kenyan economy.

\subsection{Literature review}

As a result of the environmental and ecological importance of Lake Naivasha and its riparian area, there have been many studies which have focused on different quality aspects of lake Naivasha and basin. Kitaka et al. (2002) evaluated chemical characteristics of the rivers draining into Lake Naivasha. They found that the transfer of phosphorus from the basin to the lake was $0.2 \mathrm{~kg} / \mathrm{ha} /$ year of which $76 \%$ happened in normal climatic conditions (wet and dry). Moreover, by extreme precipitation which occurred around the 1997-1998 global El Niño climate event in the Pacific, this level increased to 1.8 $\mathrm{kg} / \mathrm{ha} /$ year. They found that total and particulate phosphorus was positively correlated with suspended solids and with discharge. This loss of phosphorus threated the quality of the Lake and the sustainable water resources in the catchment.

Moncada (2001) conducted a study on pesticide contamination potential around lake Naivasha. In this study most of effort was concentrated on the evaluation and geographic distribution of pesticides utilization around the Lake Naivasha. A noteworthy exertion was put into the detailed inventory and examination of the cultivating frameworks as for agrochemical utilization. Moreover, a preliminary environmental impact assessment (EIA) by using an environmental partitioning method was done by which an assessment of potential effects and residue accumulation of poisonous compounds in the environmental compartments could be possible which helped to understand the exposure risk to chemicals. Odada et al., (2003) initiated an appraisal of the East African Rift Valley lakes. The evaluation was done in aspect of water quality and quantity, related bio-differences and natural surroundings, utilization by society and social reasons for the territorially recognized issues. Moreover, the evaluation recognized the significant concerns about the East African Rift Valley lakes. Overall, contamination and unsustainable use of 
fisheries and other living assets came out as discriminating concerns attributable to human interventions.

Additionally, Tarras-Wahlberg et al. (2002) studied the geochemical and physical characteristics of river and lake sediments of Naivasha. Geochemical investigations of stream and lake silt demonstrated that these represent genuinely undisturbed foundation conditions. Higherthan-anticipated levels of cadmium, iron, nickel and zinc in both waterway and lake silt were considered to originate from volcanic rocks and/or lateritic soils and geothermal activity found in the lake basin. By concentrating on the contamination from the agricultural sector, $\mathrm{Xu}$ (1999) studied chemical pollution of the lake water. Conventional test examination strategy led to a general appraisal of the lake water quality. Distinguishing proof and appraisal of the contamination sources demonstrated the utilization of agrochemicals around the lake represented a potential danger to the lake water quality. Moreover, a modeling approach was applied to predict the fate of pesticides and explore the effective factors governing the fate of pesticides and attributed process. In view of the reported results and the particular site of the study area, the model outputs indicated the potential danger of the pesticides leaching down into soil and thereby creating a risk of polluting the water resources.

Gitahi et al. (2002) evaluated the pollution of Organochlorine and organophosphorus pesticides in different environmental compartments (water, sediments and organisms) in the Naivasha Lake. To meet this aim, they analyzed the collected samples of water, sediment and fish species from the Lake to determine the residue of organochlorine and organophosphorus pesticides. The results of their study showed that the concentration of measured pesticides were more than the amounts in previous records, indicating the widespread use of certain pesticides in the catchment of Naivasha. Moreover, they reported that mean concentrations of lindane, dieldrin, $\beta$-endosulfan and aldrin in black bass were 100.5, 34.6, 21.6 and $16.7 \mu \mathrm{g} . \mathrm{kg}^{-1}$, respectively.

Njogu (2011) evaluated the environmental risks of organochlorine pesticide residues on aquatic communities in the Lake Naivasha. The aim of the study was to evaluate environmental contamination of heavy metals and organochlorine pesticides in the Lake Naivasha basin and to predict environmental risks of organochlorine pesticides on aquatic species. The initial data was obtained from discussions, observations and sample collections while secondary data was obtained from published information. The pollutants were selected based on their toxicity to aquatic life and persistence. Sediment and water samples were collected from 10 sampling sites in the basin. The results of the study indicated that (i) The lake bed was polluted with cadmium, nickel and lead, (ii) The heavy metal and pesticide concentrations in the water samples and fish were within the range recommended by WHO, (iii) 
Fish consumption from the lake does not pose any risk to the consumers with respect to Methoxychlor, DDT, heptachlor and heptachlor epoxide, $\mathrm{Cd}, \mathrm{Pb}, \mathrm{Cu}, \mathrm{Zn}$ and $\mathrm{Ni}$, (iv) Important sources of contaminants are flower farms, river Malewa and the Naivasha Municipal Council, (v) Although organochlorine insecticides are only targeted to insects, they had adverse influences on other aquatic communities, (vi) The most used organochlorine pesticide in the catchment was Endosulfan-sulfate.

Kaoga, Ouma, and Abuom (2013) studied the effect of farm pesticides on water quality in Lake Naivasha. They investigated the residue of Organochlorine and organophosphate in the water of the lake catchment. They selected the sampling points based on their relevance as point sources of pesticides pollution. The results of 18 site sampling points and analysing by GC method revealed that the water samples were in the range of WHO and Kenya Bureau standards while organochlorine and organophosphate pesticide residues were not detected. They concluded that the conservation measures prevented water pollution in the lake, however, further exploration and continuous monitoring were recommended. Moreover, Mburu et al. (2013) studied the pesticide usage pattern and preferences in farms around the Lake. The aim of their study was to explore the pesticide preferences and pattern of use in farms along the shore of Lake Naivasha. In order to collect data for this study, interviewer administered questionnaires and researcher observation were used in 20 major horticultural farms around Lake Naivasha. After that data from journals, standards and materials safety data from pesticides providers were also used to determine pesticide properties and their toxicity. They found that there were $4.3 \%$ WHO class I and $14.3 \%$ class II pesticides of all the pesticides ( 141 kinds of pesticides) used along the shore of Lake Naivasha. Additionally, the pattern of pesticides used in the area was considered as moderate to high and all the farms used Integrated Pest Management (IPM) to control pests. They concluded that some pesticides like oxamyl, methomyl and fenamiphos of WHO Class I, that were being used along the shore of Lake Naivasha, were very toxic to human beings and aquatic organisms by deactivating the acetylcholinesterase enzyme.

Ndungu (2014) studied water quality in lake Naivasha. The specific objectives of this study were to assess the total water quality status; establish the trophic status; exploring the effect of succession of fish community; and examine the procedures that affect the water quality dynamics in Lake Naivasha. Field measurements, geo- information and earth observation, and system modelling were used to achieve these objectives. Some water properties like water temperature, $\mathrm{pH}$, conductivity, and turbidity were measured in- situ while others were analyzed from water samples in the laboratory. The outcome of the 
study represented spatial variations in physiochemical parameters, nutrients and main ions. Agricultural activities and domestic effluent around Lake Naivasha affected water quality parameters. For instance the Northern sector (close to the Malewa and Gilgil rivers input) was influenced by agricultural activities and the North East sector of the Lake was dominated by domestic waste and close association with the crescent lake which is influenced by natural mineral composition. Examination of the reasons behind the spatial variability in water quality revealed that streams which might have been responsible for the transport of sediment and other constituents from the input rivers, were mainly wind-driven in Lake Naivasha.

Onyango et al. (2014) explored pesticide residues pollution in lake Naivasha basin. Their study focused on the pesticides that are applied within Lake Naivasha catchment. They collected information on pesticide usage in the catchment from farms and agricultural offices within the region to monitor pesticides residue contamination of the water bodies in Lake Naivasha catchment including L. Naivasha, and Rivers Malewa, Karati and Gilgil. By this way they tried to answer the inquiry of whether pesticides of international concern - "the Dirty Dozen"- were still being used within the L. Naivasha catchment. The result of their study indicated that thirty two pesticide active ingredients were identified in the study area which consisted of insecticides, fungicides or herbicides. Moreover, they found that although most of the pesticides recognized were moderately toxic (WHO Toxicity Class II), extremely toxic to highly toxic pesticides were also identified. The study concluded that pesticides residues of international concern, including the "dirty dozen" were still found and regulatory mechanisms needed to be assessed.

\subsection{Study area}

\subsubsection{Hydrology and water balance}

Because of the Rift valley's floor geometry and tectonics, it is considered hydro-geologically complex. Lake Naivasha is the second largest freshwater resources in Kenya and has a vital role in the economy of the country. It is not only attractive for tourism, but also is one of the largest sources of irrigation for agriculture.

The aquifers typically occur as broken volcanic developments or along the weathered contacts between lithological units. The aquifers close to the lake are unconfined with high permeability. Indeed, even in areas far from the lake the aquifers are restricted or semi confined. The evaluated hydraulic conductivity is, high and about $10 \mathrm{~m} /$ day and the well outflows exceed 3 litres per second per meter in those regions that have high permeability (Clarke et al.,1990). 


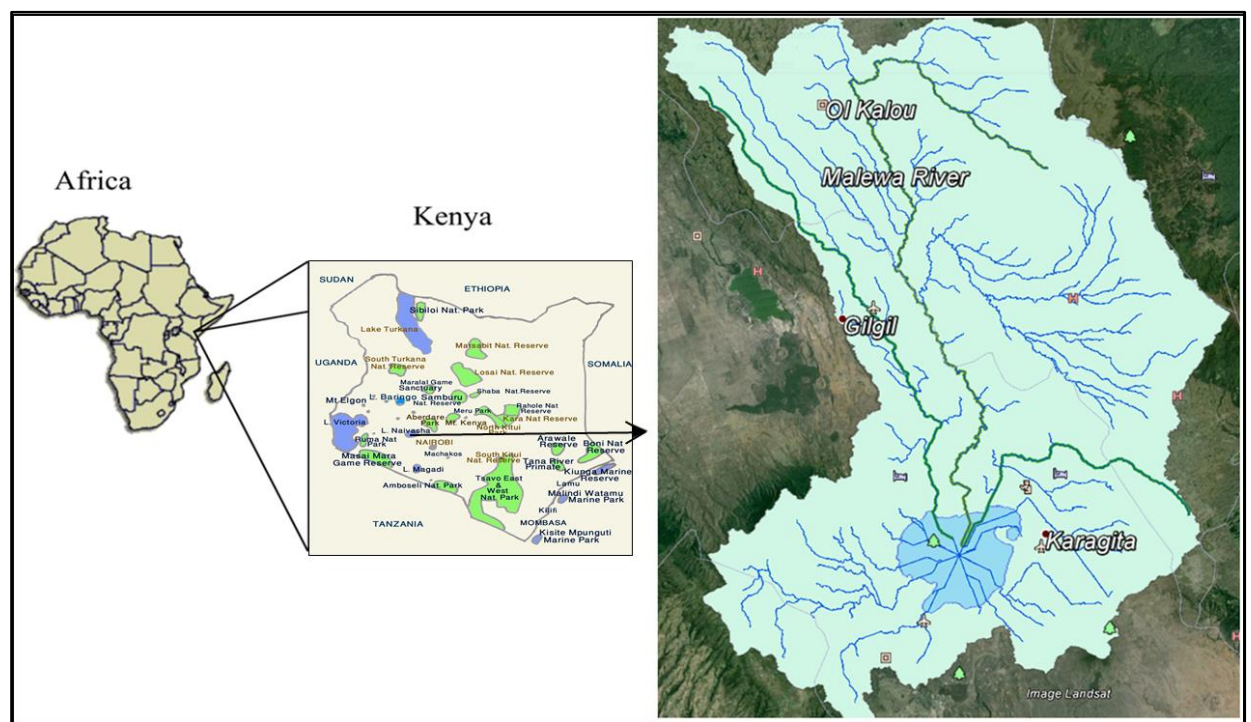

Figure 1-2-Study are of the lake Naivasha catchment

Based on the study by Becht et al., (2010) the Malewa and the Gilgil Rivers constitute $80 \%$ and $20 \%$, respectively, of the lake inflow. Both the Malewa and the Gilgil Rivers have excellent water quality with a low Electric Conductivity (EC) of $100 \mu \mathrm{S} / \mathrm{cm}$. Another river which feeds the lake is Karati but it mostly drains the eastern area of the lake, being ephemeral and flowing only about 2 months per year. The lake exhibits a dynamic behaviour, as during the past 100 years its water level has fluctuated around $12 \mathrm{~m}$ (Harper et al. 2011). However, the lake has no surface outflow while it still has a good water quality, with an EC value of approximately $300 \mu \mathrm{S} / \mathrm{cm}$. The reason for such a freshness has been related to underground outflow of the lake water. Moreover, there are a few contributors to the water balance of the lake. The inputs to the lake comprise precipitation, surface run off, rivers, and drainage inflow from the catchment area. The outflow includes evaporation from the lake and riparian wetland areas, deep percolation, water abstraction and leakage from the Lake.

\subsubsection{Water quality in the Naivasha ecosystem}

One of important factors in maintaining the ecological processes and preserving the biodiversity of aquatic environments is water quality. Its deterioration due to environmental disasters can endanger the stability of the biotic integrity and consequently may decrease the ecosystem resilience (Kitaka, et al., 2002). In the aquatic ecosystem of the Naivasha lake, Malewa and Gilgil and Karati rivers are the main inputs into the Lake. Apart from the contribution of these rivers to the Lake water quantity and the water level, they play an important role in 
the Lake water quality by transferring organic matter/detritus, inorganic matter/sediments like fine particles, nutrients and agrochemicals (e.g. P, N and pesticides) from riparian areas to the Lake. Organic matter/ detritus significantly has an important effect in the transfer of phosphorus $(P)$, since as the detritus decays, phosphorus is released into the water column (Kitaka, et al., 2002).

Based on the study of (Ndungu 2014) by which the concentrations of various physico-chemical variables, nutrients, and the main ions were determined by field measurements, water turbidity was high in the mouth of Malewa in comparison to other studied sites implying presence of more suspended particles around the river input region. The concentration of nutrients was high in the area around the Lake inputs and effluent of the waste water treatment (Mouth of Malewa, North East). Moreover, main ions were higher in Crescent Lake, which is a nearly an isolated volcanic crater lake, due to the effect of underlying volcanic rocks. It can be concluded that the nutrients and organic matter which both stem from upper catchment parts of the basin and are washed out by runoff, govern the quality of rivers and the lake water.

\subsubsection{Pesticide use in Naivasha basin}

Kenya imports annually more than 7000 tonnes of different kinds of pesticides containing insecticides, fungicides, herbicides, fumigants, rodenticides, growth regulators, defoliators, proteins, surfactants and wetting agents in which insecticides account for about $40 \%$ in terms of volume (2,900 metric tonnes) (Nyakundi \& Magoma 2012). Based on the survey by Mburu et al. (2013) about pesticide preferences and pattern of use around the Naivasha lake, more than 140 pesticides were used along the shore of Lake Naivasha that were categorized in classes (I-IV) given by WHO. Class I pesticides recognized in this study belonged to six chemical groups namely; carbamates, bipyridylium, strobilurin, tetranortriterpenoids, azole and organophosphates.

Most of the agricultural products which are produced in the Naivasha basin is exported to European countries. Therefore, the big horticultural supplier have to follow very strict rules concerning the use of pesticides. To meet these restrictions, farmers follow integrated pest management (IPM), combining chemical fungicides and pesticides and biological fungicides and pest control. Because of the restriction by the Kenyan authorities and the European or American buyers of their products, many of the pesticides have been blacklisted for use.

Table (1-1) shows a list of pesticides that have been forbidden by Kenyan authorities during the past years.

However, although utilizing pesticides in Kenya has faced some strict rules specially in large scale farms, the above mentioned studies showed that there is still a serious risk associated to pesticide use or 
at least residues are found, that remained from past use. Moreover, some of legal pesticides which are used by small holders may be expired or because of the lack of enough knowledge of the farmers about suitable application of the pesticides, they are not used for the exact target (Nyakundi \& Magoma 2012). Additionally, there are no (regular) examinations of the chemical stores of smallholder farmers that use pesticides in the upper catchment and consequently harmful chemicals are far more likely to originate from the small scale farms in upper part of the basin. On the other hand, in the last two decades, the Naivasha region has experienced a remarkable increase of population from 200,000 to 700,000 people (www.imarishanaivasha.wordpress.com/) and market demand for fresh products from the people that have moved to Naivasha because of the employment opportunities offered by the horticultural industries. This fact has caused a change from dairy farming to vegetable farming which has led to an increased need for the use of pesticides and consequently has increased the risk of pesticide pollution.

Based on the study by Onyango et al. (2014) pesticides recognized in the Naivasha basin were $52 \%$ insecticides, 33\% fungicides and $15 \%$ herbicides. The major type of pesticides applied within the catchment were pyrethroids $(19 \%)$, followed by organochlorines $(9 \%)$ and organophosphates with $(9 \%)$, conazoles $(6 \%)$ and dithiocarbamates $(6 \%)$. These five chemical types make approximately $50 \%$ of the pesticides applied within the catchment.

Additionally, more than $50 \%$ of applied pesticides were considered as moderately toxic (WHO toxicity class II), followed by those unlikely to cause acute hazard under normal use (WHO toxicity class $U$ ), whereas the extremely hazardous (class Ia), highly hazardous (class Ib) and slightly hazardous (class III) form minor proportions (Figure 1-3). 
Table 1-1-List of some of banned pesticides in Kenya

\begin{tabular}{|c|c|c|c|}
\hline No. & Common Name & Use & $\begin{array}{l}\text { Date } \\
\text { Banned }\end{array}$ \\
\hline 1 & $\begin{array}{l}2,4,5 \mathrm{~T}(2,4,5 \text { - Trichloro- } \\
\text { phenoxybutyric acid) }\end{array}$ & Herbicide & 1986 \\
\hline 2 & Chlordane & Insecticide & 1986 \\
\hline 3 & Chlordimeform & Insecticide & 1986 \\
\hline 4 & $\begin{array}{l}\text { DDT (Dichlorodiphenyl } \\
\text { Trichloroethane) }\end{array}$ & Agriculture & 1986 \\
\hline 5 & Dibromochloropropane & Soil Fumigant & 1986 \\
\hline 6 & Endrin & Insecticide & 1986 \\
\hline 7 & Ethylene dibromide & Soil Fumigant & 1986 \\
\hline 8 & Heptachlor & Insecticide & 1986 \\
\hline 9 & Toxaphene (Camphechlor) & Insecticide & 1986 \\
\hline 10 & $\begin{array}{l}5 \text { Isomers of } \\
\text { Hexachlorocyclo-hexane } \\
(\mathrm{HCH})\end{array}$ & Fungicide & 1986 \\
\hline 11 & Ethyl Parathion & Insecticide & 1988 \\
\hline 12 & Methyl Parathion & Insecticide & 1988 \\
\hline 13 & Captafol & Fungicide & 1989 \\
\hline 14 & Aldrin & Insecticide & 2004 \\
\hline 16 & Binapacryl & Miticide/Fumigant & 2004 \\
\hline 17 & Chlorobenzilate & Miticide & 2004 \\
\hline 18 & Dieldrin & Insecticide & 2004 \\
\hline 19 & Dinoseb and Dinoseb salts & Herbicide & 2004 \\
\hline 20 & $\begin{array}{l}\text { DNOC and its salts (such as } \\
\text { Ammonium Salt, Potassium } \\
\text { salt \& Sodium Salt) }\end{array}$ & Insecticide, Fungicide, Herbicide & 2004 \\
\hline 21 & Ethylene Dichloride & Fumigant & 2004 \\
\hline 22 & Ethylene Oxide & Fumigant & 2004 \\
\hline 23 & Fluoroacetamide & Rodenticide & 2004 \\
\hline 24 & Hexachlorobenzene (HCB) & Fungicide & 2004 \\
\hline 25 & Mercury Compounds & Fungicides, seed treatment & 2004 \\
\hline 26 & Pentachlorophenol & Herbicide & 2004 \\
\hline 27 & Phosphamidon & Insecticide, & 2004 \\
\hline 28 & Monocrotophos & Insecticide/Acaricide & 2009 \\
\hline 29 & All Tributylin Compounds & $\begin{array}{l}\text { All compounds including tributyltin oxide, tributyltin } \\
\text { benzoate, trybutyltin fluoride, trybutyltin lineoleate, } \\
\text { tributyltin methacrylate, tributyltin naphthenate, } \\
\text { tributylin chloride }\end{array}$ & 2009 \\
\hline 30 & Alachlor & Herbicide. & 2011 \\
\hline 31 & Aldicarb & Nematicide/Insecticide/Acaricide. & 2011 \\
\hline 32 & Endosulfan & Insecticide. & 2011 \\
\hline 33 & Lindane & Insecticide. & 2011 \\
\hline
\end{tabular}




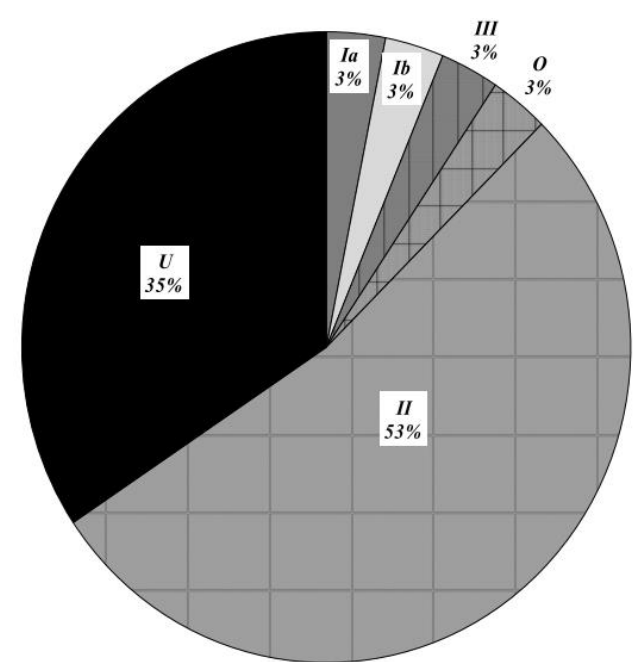

Figure 1-3-Toxicity classification of the pesticides applied within the L. Naivasha (Onyango et al. 2014)

\subsection{Objectives and research questions}

Awareness of micro-pollutants distribution which stems from pesticides and fertilizers and their fates can help understanding the hazards of chemical pollutions in soil, water and the plant cycle. During the application of pesticides from its source to agricultural area, some of it may be adsorbed into sediments, organic matter, soil particles, biota and crops. To understand the variation of pesticides in the environment, it is necessary to evaluate any relevant factors and variation of pesticides fates in the environment. In spite of the pollution potential of pesticides, it is still an important method, used for protecting agricultural and horticultural production against pests. However, the use of pesticides continues to cause anxiety about the effect of pesticides on the environment and on human health.

Although pesticide pollution around lake Naivasha has been explored in some studies, a comprehensive evaluation of environmental exposure to micro-contaminants resulting from pesticide application by using new techniques and models in the Naivasha river basin remains necessary. The scientific challenge of this study was to find the exposure risk of lake Naivasha to pesticides residues, identify the fate of pollutants by using a combined eco-partitioning, passive sampling and hydrological modelling approach. The main hypothesis of this study was that the pesticides pollution affects the ecosystem, human health and the quality of the streams in the basin and finally the lake. Therefore, this study focused on the assessment of pesticide pollution of tropical water bodies. 
To meet this challenge, the following research questions were raised:

1. Can a passive sampling approach, due to its advantage to capture and detect very low concentrations, give an improved insight to the pesticide residues distribution in the catchment? And what kind of pesticides (e.g., organochlorine pesticide residues) exists in the river network and lake Naivasha?

2. Can integrated catchment models (such as e.g., SWAT) be used to evaluate the connection and transport of pesticide residues from the upper basin to the lake through the river network?

3. Can an eco-partitioning modelling approach (e.g. Mackay model types) - focusing on the lake as receiving water body- help in identifying and quantifying the fate and exposure risk to pesticides residues in Naivasha?

\subsubsection{Specific objectives}

By considering the relevant factors which deal with pesticides in the study area, the following objectives were defined.

First objective: Application of passive sampling techniques for studying and measuring the pesticide residues in the aquatic environments of Naivasha basin.

Most aquatic study projects depend on gathering discrete grab, spot or bottle samples of water at specific times. Usually, where contaminants are present at just trace levels, large volumes of water need to be gathered. The laboratory investigation of the samples gives indication of toxin concentrations at the time of sampling. There are disadvantages to this methodology in situations where contaminant levels vary in time and episodic contamination occasions can be missed. One solution is to increase the frequency of inspection or to install programmed testing frameworks that can take various water tests over a given time period (Vrana et al. 2005). Passive sampling permits to collect chemicals over a distinct time period (e.g., one month) and also permits to diagnose very low concentrations.

Second objective: Modeling the transport of pesticide residues through rivers and the lake and evaluating the effect of different weather conditions and climate.

The main challenge of this objective was exploring the transport of pesticides from the upstream basin through the river network of the Naivasha basin to the lake by using a model approach. To meet this aim the data about the concentration of pesticides which were collected in the first objective as well as other necessary data (i.e. suspended 
sediment concentration and climate data) of the rivers for simulation by models were used.

Third objective: studying the pollution of pesticides residues in the water bodies of Naivasha basin and assessing the fate and the risk of exposure to them using an environmental compartment partitioning approach. For this part of the study, a partitioning modeling approach was used to find the fate of transported pesticides from the upper Malewa to lake Naivasha.

\subsection{Thesis outline}

This research was written into five chapters as follows: Chapter 1 consists of the introduction about the study, its objectives, the research questions, the main problem, motivation for the study, and a definition of the study domain. In Chapter 2 the distribution of organochlorine pesticides (OCPs) residues in the lake basin was explored using passive sampling approach. In this chapter the possibility and applying passive sampling for studying the content of pesticides in surface water resources with the focus on the rivers draining into Lake was described. Chapter 3 presents the modelling of discharge, suspended sediment and pesticides transport from the upper catchment downstream to the lake. In this chapter also the pollution caused by pesticide residues was simulated based on various environmental and hydrological criteria. Next, Chapter 4 presents the evaluation of pesticides fate in the different environmental compartments and an assessment of the exposure risk to pesticides pollution. Finally, the synthesis as well as the conclusions of this research are provided in Chapter 5. 


\section{Chapter 2: Evaluating Organochlorine Pesticide Residues in the Aquatic Environment of the Lake Naivasha River Basin Using Passive Sampling Techniques ${ }^{1}$}

\footnotetext{
1 This chapter is based on: Yasser Abbasi \& Chris M. Mannaerts, Evaluating organochlorine pesticide residues in the aquatic environment of the Lake Naivasha River basin using passive sampling techniques. Environ Monit. Assess (2018) 190: 349
} 
Evaluating Organochlorine Pesticide Residues in the Aquatic Environment of the Lake Naivasha River Basin Using Passive Sampling Techniques

\section{Abstract}

Passive sampling techniques can improve the discovery of low concentrations by continuous collecting the contaminants, which usually go undetected with classic and once-off time-point grab sampling. The aim of this study was to evaluate organochlorine pesticide (OCP) residues in the aquatic environment of the Lake Naivasha river basin (Kenya) using passive sampling techniques. Silicone rubber sheet and Speedisk samplers were used to detect residues of $\mathrm{a}-\mathrm{HCH}, \beta-\mathrm{HCH}, \gamma-\mathrm{HCH}, \delta-\mathrm{HCH}$, Heptachlor, Aldrin, Heptachlor Epoxide, pp-DDE, Endrin, Dieldrin, a-endosulfan, $\beta$ endosulfan, pp-DDD, Endrin aldehyde, pp-DDT, Endosulfan Sulfate and Methoxychlor in the Malewa river and Lake Naivasha. After solvent extraction from the sampling media, the residues were analyzed using gas chromatography electron capture detection (GC-ECD) for the OCPS and gas chromatography-double mass spectrometry (GC-MSMS) for the PCB reference compounds. Measuring the OCP residues using the Silicone rubber samplers revealed the highest concentration of residues ( $\Sigma$ OCPs of $81( \pm 18.9 S D) n g / L)$ to be at the lake site, being the ultimate accumulation environment for surficial hydrological, chemical and sediment transport through the river basin. The total OCP residue sums changed to $71.5( \pm 11.3 \mathrm{SD}) \mathrm{ng} / \mathrm{L}$ for the Middle Malewa and $59( \pm 12.5 S D) n g / L$ for the Upper Malewa river sampling sites. The concentration sums of OCPs detected using the Speedisk samplers at the Upper Malewa, Middle Malewa and the Lake Naivasha sites were 28.2( $\pm 4.2 \mathrm{SD}) \mathrm{ng} / \mathrm{L}, \quad 31.3( \pm 1.8 \mathrm{SD}) \mathrm{ng} / \mathrm{L}$ and $34.2( \pm 6.4 \mathrm{SD}) \mathrm{ng} / \mathrm{L}$, respectively. An evaluation of the different pesticide compound variations identified at the three sites revealed that Endosulfan Sulfate, $\mathrm{a}-\mathrm{HCH}$, Methoxychlor and Endrin aldehyde residues were still found at all sampling sites. However, the statistical analysis of one-way ANOVA for testing the differences of $\Sigma$ OCPs between the sampling sites for both the Silicone Rubber sheet and Speedisk samplers showed that there was not significant differences from the Upper Malewa to the Lake site $(P<0.05)$. Finally, the finding of this study indicated that continued monitoring of pesticides residues in the catchment remains highly recommended.

Keywords: Pesticide residues, passive sampling, Silicone Rubber sheet, Speedisk, Lake Naivasha 


\subsection{Introduction}

The first application of organochlorine pesticides such as DDT and Dieldrin dates back to 1956 and 1961, respectively, but due to the long half-life and their bio-accumulation in animals body, they were banned globally in 1976 (Keating 1983), except for regulated use of DDT for the control of malaria. After application of the chemicals, their residues can reach non-targets such as plants, soil, water, sediment, etc., by which these environmental compartments could be contaminated. Kaoga et al. (2013) explained that over 95 percent of applied insecticides and herbicides end up in non-target areas. This could potentially endanger the environment and also contribute to public health problems (Mutuku et al. 2014). Although most of the pesticides have a short half-life and are easily degradable, there are still persistent pesticides such as first-generation organochlorine pesticides (OCPs), which have long time half-life and are persistent in environment. Consequently, they can be washed off to waterbodies and cause considerable environmental risk (Gitahi et al. 2002). Lakes and reservoirs are typical accumulation sites for runoff, sediment and chemicals in catchments and, therefore, these aquatic environments are at risk of being contaminated. Bearing in mind that due to the threat of pesticides residue pose to aquatic life and ecosystems, careful evaluation is needed.

Aquatic monitoring programs are usually based on grab samples collected within a short time span. Grab sampling can only provide a snapshot of pollution levels (Hernando et al. 2007; Vrana et al. 2005) and also is associated with logistical and practical difficulties including transportation, filtration, extraction, and storage. Moreover, grab sampling as a way of monitoring pesticide pollution in aquatic environments cannot encompass all of the changes in pollutant concentrations (Ahrens et al. 2015). In other words, determining the dynamic status of pollution accurately during low and high flows is not entirely feasible with grab sampling. Consequently, the outcomes do not directly relate to the average load of pollutants (Jordan et al. 2013). In spite of these facts, grab sampling is useful for finding information quickly. However, extending measurements to cover fluctuations in flow and pollutant concentrations, requires increasing the sampling frequency and sample numbers, which is expensive and time consuming while the results remain uncertain (Rozemeijer et al. 2010).

Due to the challenges related to grab sampling, the passive sampling technique is considered as a promising alternative method for 
Evaluating Organochlorine Pesticide Residues in the Aquatic Environment of the Lake Naivasha River Basin Using Passive Sampling Techniques

measuring pollutants in aquatic environments. This method allows the accumulation of contaminants in the samplers, making it possible to determine very low concentrations of contaminants. Passive sampling provides means for continuous water quality monitoring from short term to long term (a week to some months) and allows determining time-weighted average (TWA) of contaminant concentrations (Ahrens et al. 2015). The chemical potential discrepancy between passive sampler media and the dissolved pollutants in the aquatic phase causes a partitioning of contaminants between water and the sampler (Allan et al. 2009). Moreover, in comparison with organisms, which undergo biotransformation and changing physiological conditions, the uptake of pollutants using passive samplers is more feasible (Smedes and Booij 2012). These features of passive sampling facilitate chemical examination of surface and other water bodies and provide an alternative approach to biomonitoring (Fox et al. 2010; Meyn et al. 2007; Munoz et al. 2010; Wille et al. 2011).

There are various kinds of non-polar passive samplers, which have been used for evaluating organic contaminants in aquatic environments (Brockmeyer et al. 2015). Passive samplers trap the pollutants in a kinetic or equilibrium diffusion, in which the whole process including selective analyte, isolation and pre-concentration occurs simultaneously (Vrana et al. 2005). The mass transfer of an analyte - an organic or inorganic compound - proceeds until the equilibrium phase occurs or the sampling is finished (Górecki and Namieśnik 2002). Silicone Rubber (SR) sheets and Speedisk samplers were selected in this study for the determination of organochlorine pesticides because Silicone Rubber samplers for more hydrophobic compounds and Speedisk samplers for more hydrophilic compounds are ideal samplers that have some advantages such as simple construction, robust for installing in the rivers or the lake, cheap and commonly available (Smedes et al. 2010).

The Lake Naivasha catchment is a major agricultural areas in Kenya and because of dense agricultural activity and population, there is a high demand for pesticides. Although there was a decline in organochlorine pesticide imports into the country, there is still risk of these pesticides application in agricultural areas. Therefore, a monitoring plan for pesticide residue pollution in aquatic environments is necessary to evaluate their potential risk on ecosystems and humans in general. The aim of this research was to gain understanding in the organochlorine pesticide residues pollution and their spatial variation in the Lake Naivasha catchment using passive sampling techniques.

\subsection{Materials and methods}




\subsubsection{Study area}

Lake Naivasha catchment is located in the eastern part of the Rift Valley region in Kenya with an area of about $3,400 \mathrm{~km}^{2}$. The eastern Rift has a tropical climate with two dry and two rainy seasons. The upper and middle parts of the catchment are mostly subjected to smallholder mixed farming for producing various crops. Moreover, there are various local dwellings in villages and towns all around the catchment that can influence the rivers and the Lake water quality located in the lower catchment. Input from upstream into the Lake includes water from the Malewa, Karati and Gilgil rivers plus surface runoff that drains from the catchment and reaches the Lake. But as the Malewa river accounts for approximately $80 \%$ of the inflow into Lake Naivasha, the samplers were installed in the Upper Malewa, Middle Malewa river and the Lake (Figure 2-1).

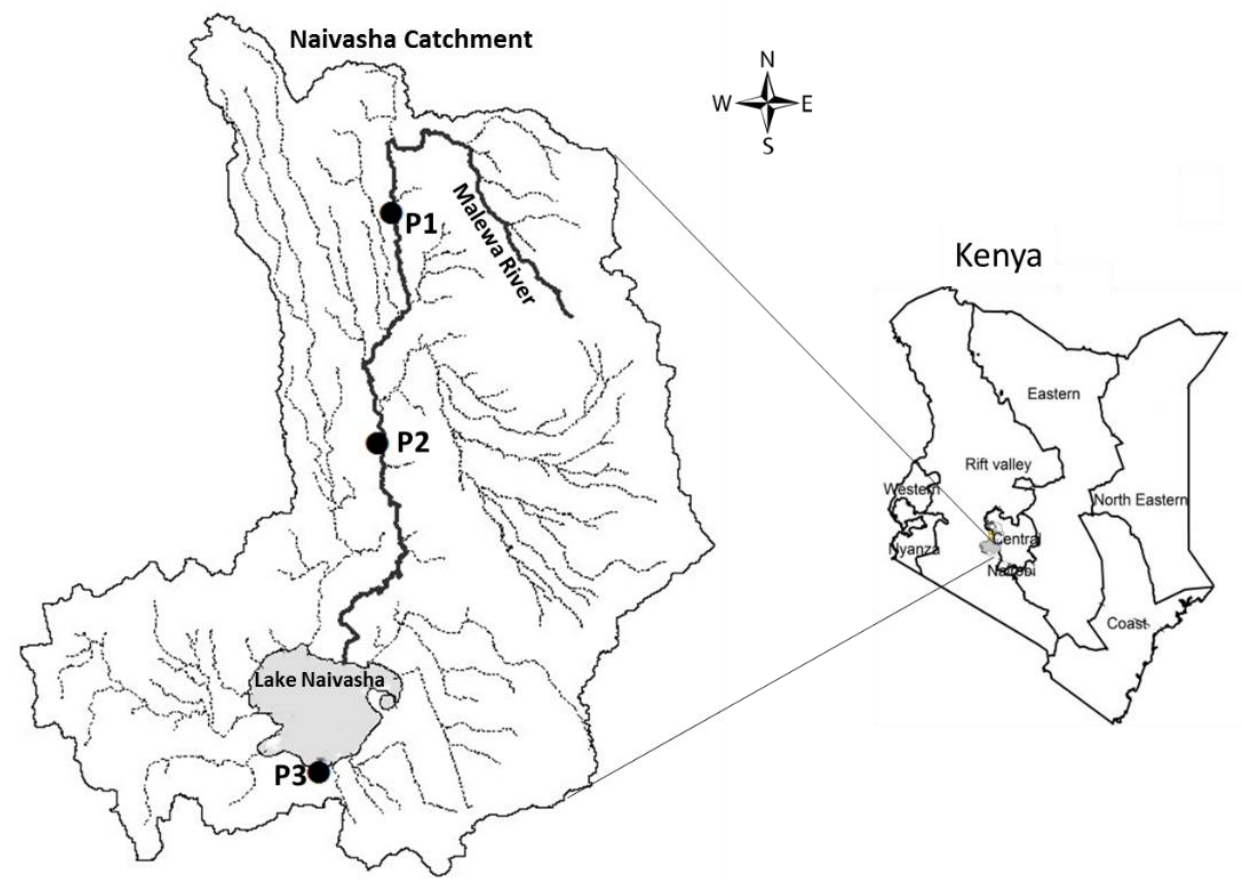

Figure 2-1-The study area and locations of passive samplers (P1, P2 and P3 are Upper Malewa, Middle Malewa and the Lake sites, respectively)

\subsubsection{Sampler preparation and installation}


Evaluating Organochlorine Pesticide Residues in the Aquatic Environment of the Lake Naivasha River Basin Using Passive Sampling Techniques

Large AlteSil silicone rubber (SR) sheets were cut into pieces with $55 \times 90 \times 0.5 \mathrm{~mm}$ dimensions and about $100 \mathrm{~cm} 2$-both sides- surface area. The SR samplers were pre-cleaned in soxhlet apparatus with ethyl acetate for at least $100 \mathrm{~h}$ to remove all chains of oligomers. Then they were air dried and spiked with Performance Reference Compounds (PRCs). Based on Smedes and Booij (2012) the SR samplers need to be spiked with at least six PRCs that have a sampler-water partition coefficient (logKpw) between 3.5-5.5 as well as a PRC that is rarely depleted $(\operatorname{logKpw}>6)$ and a completely depleted PRC $(\operatorname{logKpw}<3.3)$ for modeling water sampling rate and the concentration of the pollutants. Therefore, the applied PRCs in the SR samplers were BIP-D10, PCB001, PCB002, РCB003, РCB010, РCB014, РСB030, РCB050, РCB021, PCB104, PCB055, PCB078, PCB145, РCB204. Then, the prepared SR samplers were kept in air-tightened amber glass bottles in the freezer $\left(-20^{\circ} \mathrm{C}\right)$ until installation.

Speedisk extraction samplers, H2O-philic DVB Low capacity ( 0.6 gram) produced by Avantor, were also used for more hydrophilic substances. The Speedisks were conditioned by eluting them slowly with $15 \mathrm{~mL}$ dichloromethane (HPLC grade, 99.9\%), $10 \mathrm{~mL}$ acetone (HPLC grade, $99.5 \%$ ) and $20 \mathrm{~mL}$ distilled water, sequentially. They were then stored in a bottle of purified water and stored at $+4^{\circ} \mathrm{C}$ until deployment.

At the sampling sites, including two sites in the Malewa river and one site in the Lake Naivasha as represented in Figure (2-1), three sets of Silicone Rubber sheets and three sets of Speedisk passive samplers were installed for monitoring the concentration of $\mathrm{a}-\mathrm{HCH}, \beta-\mathrm{HCH}, \gamma-$ $\mathrm{HCH}, \delta-\mathrm{HCH}$, Heptachlor, Aldrin, Heptachlor Epoxide, a -endosulfan, $\mathrm{pp}-\mathrm{DDE}$, Endrin, Dieldrin, $\beta$-endosulfan, pp-DDD, Endrin aldehyde, ppDDT, Endosulfan Sulfate, and Methoxychlor in the Malewa river and the Lake Naivasha. Both the Speedisk and Silicone rubber sheet samplers were mounted on metal wire mesh (Figure 2-2) and immediately deployed in water. Additionally, one sampler was exposed to the air while installing the samplers, as reference sampler. Passive samplers were deployed in the water for one month from 20 June till 20 July, 2016, during the long rainy season when most of the agricultural activity and use of pesticides occur. After one month, the samples were collected from the sampling sites. As they were covered by some fouling or algae, they were cleaned using a pre-treated scourer (washed and rinsed with methanol and water) and the water of the same sampling site. Then the samplers were kept in a cool box (about $5^{\circ} \mathrm{C}$ ) during transfer and at $-20^{\circ} \mathrm{C}$ in the laboratory till treatment and analysis (Monteyne et al. 2013; Smedes and Booij 2012). 


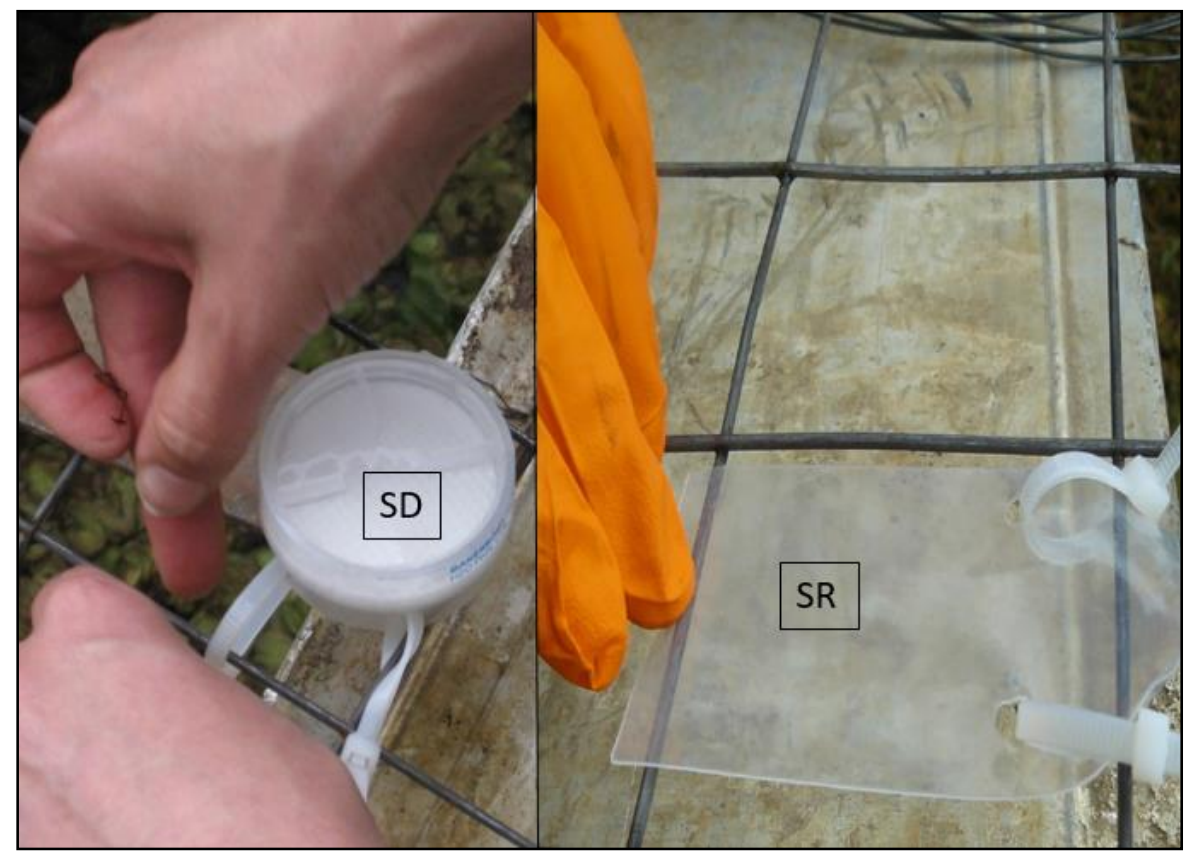

Figure 2-2-Mounting Speedisk(SD, left) and Silicone Rubber sheet (SR, right) passive samplers for deployment

\subsubsection{Extraction and analysis}

Various solvents such as acetonitrile, hexane, acetone, dichloromethane and methanol were used to extract the non-polar contaminants from the samplers. The solvents were all of HPLC grade ( $>99 \%$ purity) in order to extract the studied OCPs. All of the procedures for both the exposed passive samplers and the blanks (control samplers) such as samplers extraction by soxhlet apparatus, clean up, concentration and instrumental analysis were done according to the guidelines by Smedes and Booij (2012) and standard laboratory methods. After solvent extraction from the sampling media, the residues were determined using a gas chromatograph (Agilent 6890N) in combination with an electron capture detector (Agilent $\mu \mathrm{ECD}$ ) and an auto sampler (Agilent 7683 Series injector) for the OCPs (in Department of Chemistry at University of Nairobi, Kenya), and a gas chromatography (Agilent 7890A) coupled with a mass spectrometer (Agilent 7000 Series Triple Quadrupole MS detector) that had a possibility to measure with an MSMS method for the PRCs in Deltares (TNO laboratory, Netherlands). The temperature program of GC- $\mu \mathrm{ECD}$ was set as initially $90^{\circ} \mathrm{C}\left(3 \mathrm{~min}\right.$ ) then $90^{\circ} \mathrm{C}$ to $200^{\circ} \mathrm{C}$ (at $30^{\circ} \mathrm{C} / \mathrm{min}$ and hold time of $15 \mathrm{~min}$ ), $200^{\circ} \mathrm{C}$ to $275^{\circ} \mathrm{C}$ (at $30^{\circ} \mathrm{C} / \mathrm{min}$ and hold time 
Evaluating Organochlorine Pesticide Residues in the Aquatic Environment of the Lake Naivasha River Basin Using Passive Sampling Techniques

of $5 \mathrm{~min}$ ). The carrier gas was helium and nitrogen was used as makeup gas with a continuous stream of $2 \mathrm{ml} / \mathrm{min}$. The injection mode was pulsed-splitless with a volume of $1 \mu \mathrm{l}$. The column was a DB-5 (Agilent, USA) with length of $30 \mathrm{~m}$, internal diameter of $0.32 \mathrm{~mm}$ and film thickness of $0.25 \mu \mathrm{m}$. The calibration of the machine was done using the standards of organochlorine pesticides (purity of more than 99\%) in 10 concentration levels of $1,5,10,50,100,200,400,600,800$ and $1000 \mathrm{ng} / \mathrm{L}$. Finally, The quality control of the results was done by triplication for all the samples, and determination of recovery rates from blank treatments. The column of the GC-MSMS was also DB-5 (length: 30 meter; ID: $0.25 \mathrm{~mm}$; Film:0.25 $\mu \mathrm{m}$ ). The temperature program was set as initially $70^{\circ} \mathrm{C}$ for 1 min then Ramp 1 : increase $20^{\circ} \mathrm{C}$ $/ \mathrm{min}$ to $120 \mathrm{~min}$, hold time $0 \mathrm{~min}$, Ramp 2: increase $6^{\circ} \mathrm{C} / \mathrm{min}$ to $250^{\circ} \mathrm{C}$ hold time $0 \mathrm{~min}$ and Ramp 3: $17.5^{\circ} \mathrm{C} / \mathrm{min}$ to $300^{\circ} \mathrm{C}$, hold time 2.48 min. The low detection limit was also $1 \mathrm{ng} / \mathrm{L}$ for all the PRCs.

\subsubsection{Calculations:}

The amounts of PRCs fraction (fexp) indicates sampling rate and was estimated as:

$$
f_{\text {exp }}=\frac{N_{t}}{N_{0}}
$$

where Nt and NO are PRCs amounts (ng) in the exposed and the reference samplers, respectively. Booij and Smedes (2010) showed that $f$ is a continuous function of Kpw and the sampling rate (Rs):

$$
f_{\text {cal }}=e^{\frac{-R_{s} t}{K p_{w} m}}
$$

Where Kpw is the sampler-water partition coefficient $(\mathrm{L} / \mathrm{kg})$, Rs is the sampling rate (L/day), $\mathrm{m}$ is the sampler weight $(\mathrm{kg})$ and $\mathrm{t}$ is the exposure time (days). Rusina et al. (2010) demonstrated that sampling rate was a function of the hydrodynamic situation and the sampler surface area as well as the PRC molar mass (M). Therefore, their proposed equation (3) was used to demonstrate the relationship between these factors:

$$
R_{S}=\frac{F A}{M^{0.47}}
$$

The sampling rate was estimated by combining equations (2) and (3) and fitting the retained fraction and KpwM0.47 using a solver package. The non-linear least-squares (NLSs) method, which takes all of the PRCs into account, was applied for this aim (Booij and Smedes 2010). Booij et al. (2007) showed that the amount of a target compound in the sampler can be presented as:

$$
N_{t}=C_{w} \cdot K_{p w} m\left[1-\exp \left(\frac{-R_{s} t}{K_{p w} m}\right)\right]
$$

Therefore, by adjusting equations (3) and (4), the concentration of compounds was determined as: 


$$
C_{w}=\frac{N_{t}}{K_{p w} m\left[1-\exp \left(-\frac{F A t}{M^{0.47} K_{p w} m}\right)\right]}
$$

Finally, the standard deviations (SD) of the sampling rates as well as the pesticides concentration were calculated and included to the results. The statistical analysis of one-way ANOVA was also applied to explore the differences of total OCPs between the sampling sites at $95 \%$ confidence. This examination determined the spatial variation from the upper catchment to the Lake for the results of both kinds of passive samplers.

\subsection{Results and discussion}

Frequent measurements of different parameters at the sampling sites during sampler exposure time are presented in Table (2-1). It was found that the average acidity of water in the Malewa river and the Lake was between 7 to 7.8 and no remarkable difference was found. Moreover, the effect of water temperature on sampling rate has been studied by Booij et al. (2003) and they showed that sampling rate at $30^{\circ} \mathrm{C}$ was three times more than $20^{\circ} \mathrm{C}$. This issue demonstrates the relations between water temperature and up taking the contaminants. However, by calculating the sampling rates, the effect of different factors (e.g., Oxygen saturation, Salinity, Conductivity, Temperature, $\mathrm{pH}$, etc.) on the samplers performance is taken to account.

Table 2-1-Physicochemical properties of water at the sampling sites

\begin{tabular}{lllllll}
$\begin{array}{l}\text { Location } \\
\text { parameter }\end{array}$ & & $\mathrm{pH}$ & $\mathrm{T}(\mathrm{\circ} \mathrm{C})$ & $\begin{array}{l}\mathrm{EC} \\
(\mathrm{US} / \mathrm{cm})\end{array}$ & $\begin{array}{l}\text { Sal. } \\
(\% \mathrm{o})\end{array}$ & $\begin{array}{l}\text { Sat.O2 } \\
(\%)\end{array}$ \\
\hline \multirow{2}{*}{$\begin{array}{l}\text { The } \\
\text { Lake }\end{array}$} & Average & 7.8 & 20.1 & 352.2 & 0.11 & 87.1 \\
& Min & 6.8 & 18.6 & 309.0 & 0.10 & 53.7 \\
& Max & 8.6 & 21.0 & 366.0 & 0.12 & 104.8 \\
\hline \multirow{2}{*}{$\begin{array}{l}\text { Middle } \\
\text { Malewa }\end{array}$} & Average & 7.4 & 16.3 & 147.6 & 0.05 & 103.6 \\
& Min & 6.7 & 15.0 & 111.0 & 0.04 & 100.3 \\
& Max & 8.6 & 18.0 & 170.0 & 0.06 & 106.4 \\
Upper & Average & 7.7 & 16.3 & 150.4 & 0.05 & 103.2 \\
Malewa & Min & 7.0 & 15.6 & 120.0 & 0.04 & 101.7 \\
& Max & 8.9 & 17.2 & 174.2 & 0.06 & 105.0 \\
\hline
\end{tabular}

EC is Electrical Conductivity, Sal. is Salinity and Sat.O2 is Oxygen Saturation 
Evaluating Organochlorine Pesticide Residues in the Aquatic Environment of the Lake Naivasha River Basin Using Passive Sampling Techniques

The results of analysis showed that after 30 days of passive samplers deployment, the average of minimum remaining PRCs on the Silicone samplers was $4.7 \%( \pm 4.1 \mathrm{SD})$ for $\mathrm{BCP}-\mathrm{d} 10$ and the maximum average was $97 \%$ ( $\pm 7.4 S D$ ) for PCB204. The amounts of remaining PRCs with a logKpw of less than 4.2, such as PCB001 and BIP-D10, occurred on less than $20 \%$ of the samplers. The PRCs of PCB014 and PCB104 with a logkpw of more than 5.1 showed a variation of $73 \%( \pm 16.7 \mathrm{SD})$ to $102 \%( \pm 1.1 S D)$, which was in agreement with the results of the study by Monteyne et al. (2013). They indicated that the dissipation of more than $80 \%$ and less than $20 \%$ of the PRCs leads to difficulties in determining the initial and the final ratio of the PRCs on the samplers. Therefore, it could be concluded that the PRCs with a logKpw of 4.2 (PCB002) to 5.2 (PCB030) would be the most appropriate ones for calculating sampling rate. Moreover, as was concluded in other literature (Allan et al. 2009; Monteyne et al. 2013), the transition between linear and equilibrium phases occurred for the PRCs with logKpw between 4.2 and 5.2. Therefore, PCB010 and other compounds with this range of logKpw were still releasing and the sampling was continued.

The results of NLSs model showed that there was a good fit between the measured and calculated PRC fractions (Figure 2-3). Inclusion of a PRC with a low logKpw such as BIP-D10, which has a logKpw of 3.6, and PCB204, which has a high logKpw of 7.6, as well as other PRCs within this range led to a sigmoid trend among the retained fractions and $\log (K p w . M 0.47)$. With this approach, the results showed a minimum sampling rate occurring in the samplers that deployed in Lake Naivasha with $1.9( \pm 0.4 \mathrm{SD}) \mathrm{L} /$ day and a maximum rate at the Middle Malewa river site with 13.1( $\pm 1.7 \mathrm{SD}) \mathrm{L} /$ day. The average sampling rate at the Upper Malewa river site was $6.2( \pm 0.7 \mathrm{SD}) \mathrm{L} /$ day, an intermediate result compared to other sites. Silicone sheets have been used mostly for monitoring the PAHs and PCBs in marine aquatic environments. However, comparing the results of this study with other literature showed that these results were comparable with the study by Harman et al. (2009) who reported sampling rates between 4.1 and $14.8 \mathrm{~L} /$ day for a duration of 6 weeks. 


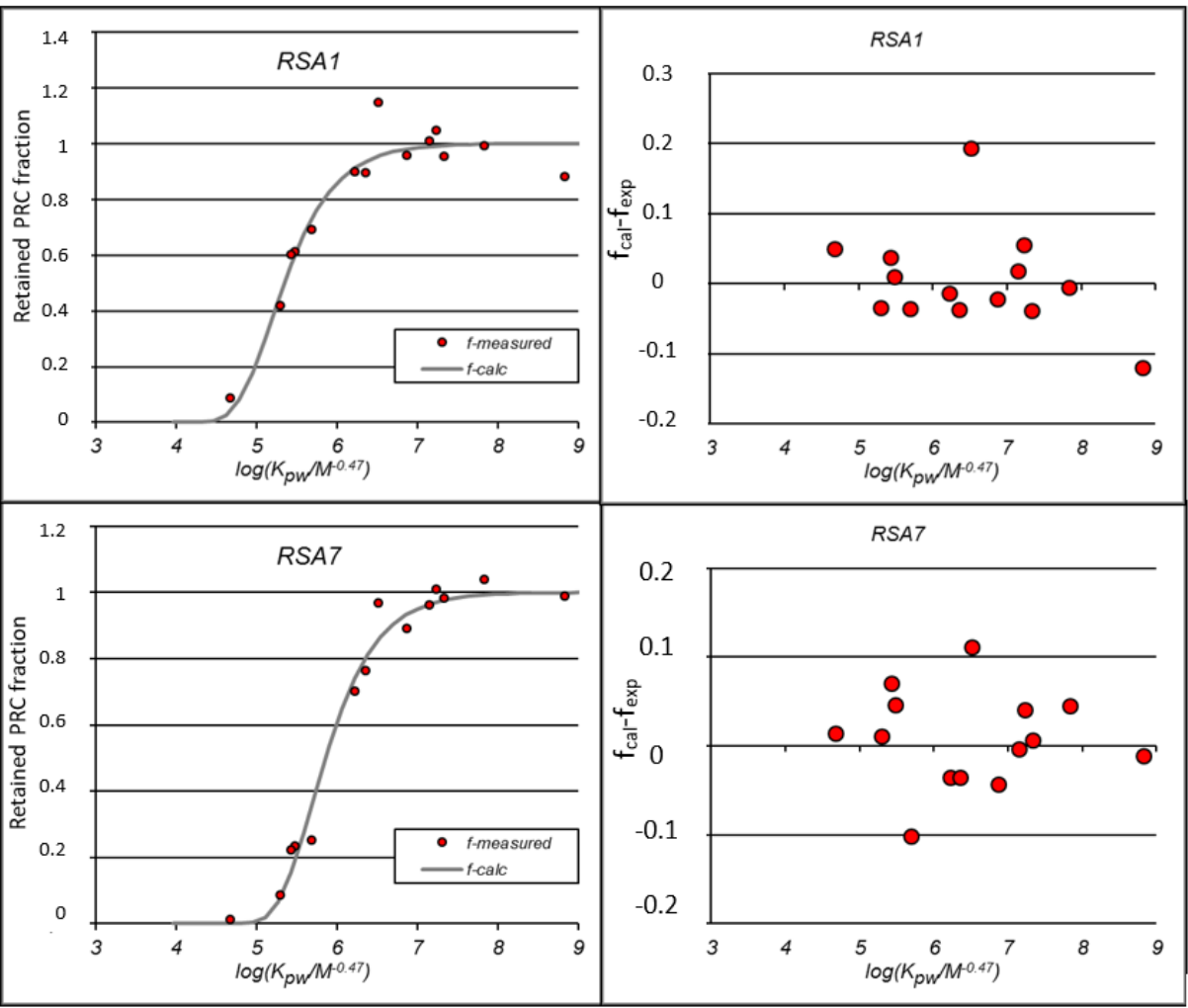

Figure 2-3-Example diagram of logKpw versus Retained PRC fractions (left) and difference of calculated and measured (calc.) (Right). The drawn line represents the best non-linear square for two example sites. (RSA1 and RSA7 are example samples in the Lake and in Malewa river, respectively).

The data of sampling rates were used to determine the pesticide concentrations in the water $(\mathrm{Cw})$. This approach allowed the use of passive sampling technique to monitor non-polar compounds. Calculating the concentration of OCPs with SR samplers showed that the total amount of a-HCH, $\beta-\mathrm{HCH}, \mathrm{Y}-\mathrm{HCH}, \delta-\mathrm{HCH}$, Heptachlor, Aldrin, Isodrin, Heptachlor Epoxide, a-endosulfan, pp-DDE, Endrin, Dieldrin, $\beta$-Endosulfan, pp-DDD, Endrin aldehyde, pp-DDT, Endosulfan Sulfate and Methoxychlor at the Lake site was the highest with a total amount of organochlorine pesticide residue ( $\Sigma$ OCPs) of $81( \pm 18.9 \mathrm{SD}) \mathrm{ng} / \mathrm{L}$. This total amount was 71.5( $\pm 11.3 \mathrm{SD}) \mathrm{ng} / \mathrm{L}$ and $59( \pm 12.6 \mathrm{SD}) \mathrm{ng} / \mathrm{L}$ for the Middle Malewa and the Upper Malewa river sites, respectively. The reason of reporting the results as a summation of OCPs is that the 
Evaluating Organochlorine Pesticide Residues in the Aquatic Environment of the Lake Naivasha River Basin Using Passive Sampling Techniques

individual concentrations of the OCPs were mostly low ranging between below detection limit to $56 \mathrm{ng} / \mathrm{L}$.

The variation in pesticides found at the three sampling sites using SR samplers was also investigated to evaluate possible differences in pesticide residue occurrence in different parts of the catchment (Figure 2- 4). Although there was an increasing trend from the Upper Malewa to the Lake, the results of one-way ANOVA for the means of the three sampling sites using SR samplers showed that there was not a significant spatial variations $(P>0.05)$. Apart from application of pesticides in the down part of the catchment, as the hydrological stream flow and suspended sediment transport processes is the main reason for agrochemical movement from the upper part of the catchment to the down part, the increasing concentration gradient to the Lake could be due to the effect of downstream transport and accumulation of pesticides. The results showed that a-HCH, Endosulfan Sulfate and Methoxychlor formed the most prevalent pesticide's residues. They were detected in almost all of the samplers and their concentrations generally increased from the Upper Malewa to the Lake site. Based on the results of SR samplers, Endosulfan Sulfate formed the largest component of pesticide residue in the study area with concentrations of $56( \pm 18 S D) \mathrm{ng} / \mathrm{L}, \quad 39.3( \pm 29.3 \mathrm{SD}) \mathrm{ng} / \mathrm{L}$ and $34.2( \pm 11.8 S D) n g / L$ in the Lake Naivasha, Middle Malewa river and Upper Malewa river sites, respectively, that accounted, respectively, for $69 \%, 55 \%$ and $58 \%$ of $\Sigma$ OCPs in these sites. The second major pesticide residue found on the SR samplers at all of the sites was a$\mathrm{HCH}$. The concentration of this pollutant varied from 19.3( $\pm 6.7 \mathrm{SD}) \mathrm{ng} / \mathrm{L}$ at the Middle Malewa river site ( $27 \%$ of the $\Sigma$ OCPs) to the amount of $11.3( \pm 4.8 \mathrm{SD}) \mathrm{ng} / \mathrm{L}$ at the Lake site. $\mathrm{a}-\mathrm{HCH}$ is an isomer of Hexachlorocyclohexane $(\mathrm{HCH})$ that has different isomers and the main ones are $\mathrm{a}-\mathrm{HCH}, \beta-\mathrm{HCH}, \mathrm{Y}-\mathrm{HCH}$, and $\delta-\mathrm{HCH}$. All of these isomers are insecticides that are mostly used on fruit, vegetables and animals. a$\mathrm{HCH}$ is byproduct of Lindane but due to the persistence in environment and bioaccumulation, it has been classified as persistent organic pollutant (POP) by Stockholm Convention on Persistent Organic Pollutants in 2009 (ATSDR 2005). Methoxychlor was also found in the SR samplers at all sampling sites. It is an insecticide that has a wide range of application for controlling the insects on crops, livestock and homes. It dissolves in the water or evaporate into air very rarely and once reaches the ground, sticks to the soil particles that can be transported to water bodies by runoff. The process of degradation in the environment is slow and may takes several months (ATSDR 2002a). The ratio of other pesticides occurred in very low percentages. DDT, for instance, accounts for a very low percentage $(1 \%-2 \%)$ of residue and this finding is in agreement with previous studies, indicating that the use of this pesticide has significantly decreased 
(Gitahi et al. 2002). Although in very low concentration, Endrin aldehyde was another pesticide that was found in the SR samplers at all of the sites. Comparing the results from the SR samplers at different sites showed that the Middle Malewa river site had most different kinds of applied pesticides. In addition to the mentioned pesticides that were found at the Lake and Upper Malewa river sites, $\beta-\mathrm{HCH}$, Endrin, $\beta$ endosulfan, $\mathrm{pp}$-DDD and pp-DDE were found at the Middle Malewa river site. $p p-D D D$ and $p p-D D E$, occurring with a concentration of less than $1 \mathrm{ng} / \mathrm{L}$ (almost $1 \%$ ratio of $\Sigma O C P s$ ) at the Middle Malewa river site, are the metabolite of DDT, which may originate from pesticide application in the past still present in the environment. It is noticeable that $\mathrm{DDT} /(\mathrm{DDD}+\mathrm{DDE})$ ratio is an indication of DDT application history that the amount of less than one means there might not be current input of the parent DDT into the study area and vice versa (Gbeddy et al. 2012). The results showed that this ratio was less than one for the sampling sites.

Considering the sampling rates of Speedisk samplers and the total of pesticides taken up by these samplers, the maximum amount of pesticides was $\Sigma O C P s=34.2( \pm 6.5 \mathrm{SD}) \mathrm{ng} / \mathrm{L}$ that found at the Lake Naivasha site. The amounts of $\Sigma$ OCPs from the Speedisk samplers at Middle Malewa and Upper Malewa sites were 31.3( $\pm 1.8 \mathrm{SD}) \mathrm{ng} / \mathrm{L}$ and $28.2( \pm 4.2 S D) n g / L$, respectively. Based on the one-way ANOVA results of Speedisks for exploring the spatial variations of the OCPs at the sampling sites, these amounts were not significantly different $(P>0.05)$.

Evaluating pesticide variation in the studied area by Speedisk samplers also demonstrated that a-HCH occurred at all of the sampling sites (Fig.4). The Lake site, with a concentration of $16.1( \pm 5.1 \mathrm{SD}) \mathrm{ng} / \mathrm{L}$, which is equivalent to $47 \%$ of $\Sigma O C P s$, revealed the highest measured amount. The concentration of this pesticide's residue was $13( \pm 1.9 S D) n g / L$ in the Upper Malewa river and decreased to the $5.9( \pm 1.8 \mathrm{SD}) \mathrm{ng} / \mathrm{L}$ in the Middle Malewa river(19\% of $\Sigma$ OCPs). Although the Middle Malewa and Upper Malewa river sites were situated in the same river, the sites were placed far apart to discover the effect of the surrounding agricultural areas of the sampling sites on the pollution situation of the Malewa river. The selected site location in the Lake Naivasha was also at the opposite side of the Lake to the Malewa river estuary, in order to minimize the effect of Malewa river on the Lake Naivasha sampling site. Therefore, the results of each of the sites can be said to be mostly related to the pollution in adjacent areas. Moreover, although the interview with the farmers about the pesticides use for controlling any kind of diseases in their products (e.g. cabbage, tomato, potato, maize, etc.) did not show any OCPs application, the results of samplers analysis demonstrated the OCPs residues in the sampling sites. Nearly all of the explored $\mathrm{HCH}$ isomers were found in 
Evaluating Organochlorine Pesticide Residues in the Aquatic Environment of the Lake Naivasha River Basin Using Passive Sampling Techniques

the Middle and Upper Malewa river. It is noticeable that some of the OCPs such as a-HCH, $\beta-\mathrm{HCH}, \mathrm{Y}-\mathrm{HCH}, \delta-\mathrm{HCH}$ and pp-DDT, pp-DDE and pp-DDD that are metabolites of $\mathrm{HCH}$ and DDT can remain in the environment for an extremely long time by accumulating in different environmental compartments. For instance, when DDT is broken down by microorganisms or under environmental condition, DDE and DDD are produced which are similar to their parents. The residue of these chemicals that are not dissolved easily in water, can stick to soil particles and remain in environment up to 15 years (ATSDR 2002b).

Passive samplers accumulate pesticide residues from the water during deployment, therefore they may be more useful than grab sampling for finding OCPs. Moreover, as the behaviour of the passive samplers for accumulating the contaminants mimics the bioaccumulation by organisms (e.g., uptake of pesticides by aquatic biota like fish), the outcomes of passive sampling studies are more comparable with biomonitoring ones (Smedes and Booij 2012). Therefore, the results of this study can be compared with the study by Gitahi et al. (2002) that explored pesticides contamination in water resources of Naivasha using fish samples. Their study about organochlorine pesticides pollution in various species of fish, water and sediment samples in Lake Naivasha demonstrated different levels of lindane, dieldrin, $\beta$-endosulfan and Aldrin in the fat of fish. Their results showed a technical use of these pesticides in the studied area, which would agree with the findings of this study.

Based on the report of the Pest Control Products Board of Kenya PCPB (2008), import and use of many of the studied pesticides has been discontinued. However, different studies (Gitahi et al. 2002; Onyango et al. 2014) indicated application of these pesticides in the Lake basin. Lindane was a commonly used pesticide in Kenya. It was used as insecticide and for seed dressing. $\mathrm{HCH}$ and its isomers are the main pesticide residues found in the Speedisk samplers. These results seem to indicate the use of $\mathrm{HCH}$ and its isomers in the Lake Naivasha catchment. Endosulfan Sulfate is an oxidation product of Endosulfan, which has a high acute toxicity and can be potentially bio accumulated. Because of the threats of Endosulfan and its isomers (a-endosulfan, $\beta$ endosulfan and Endosulfan Sulfate) to human health and the environment, there was a global ban on its application under the Stockholm Convention. Based on Camacho-Morales and Sánchez (2015), the estimated half -life time of these chemicals (endosulfan and endosulfan Sulfate) can vary from nine months to six years. However, Endosulfan Sulfate was found in the SR samplers at all of the sampling sites. 


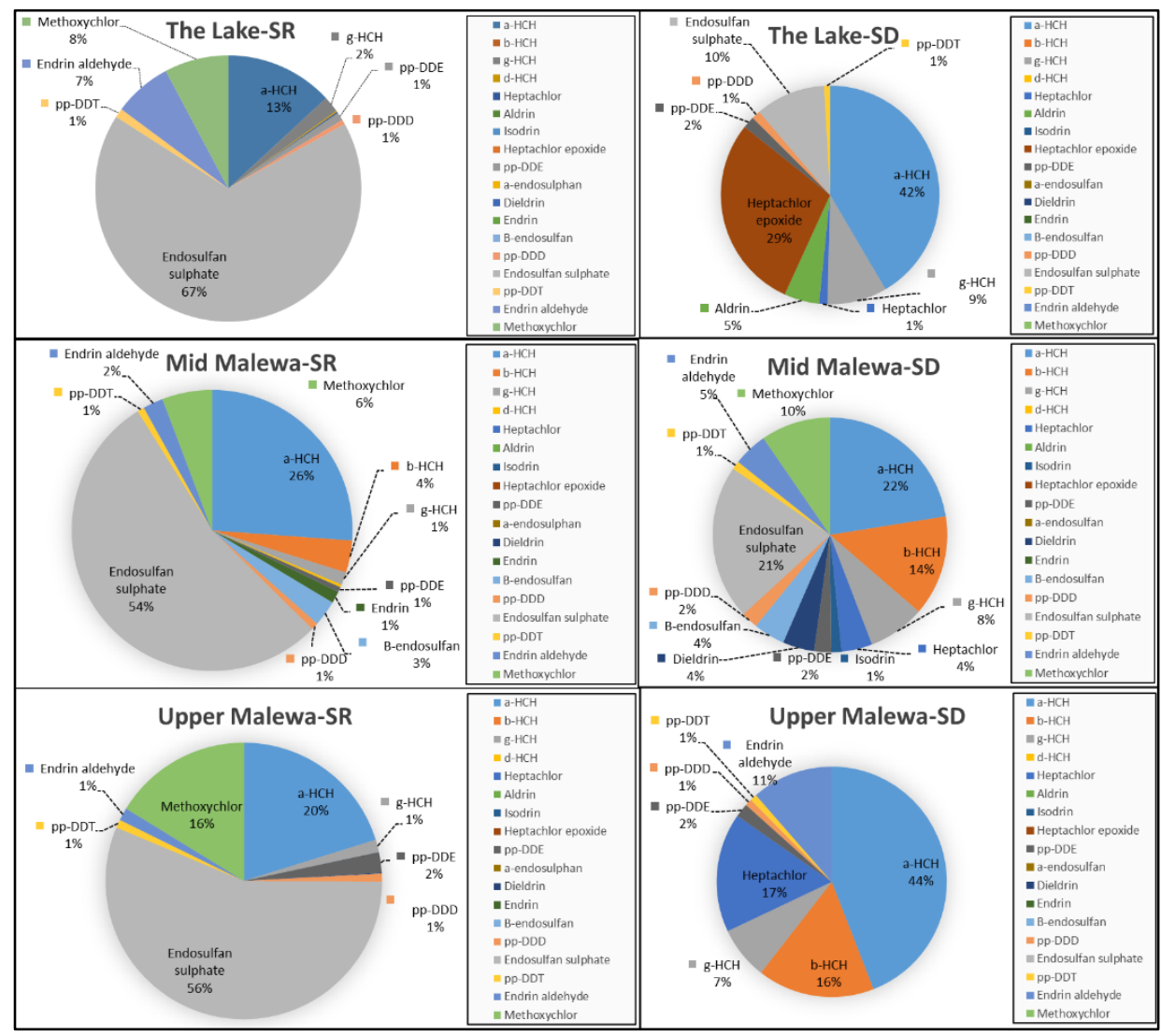

Figure 2-4-Distribution of organochlorine pesticide residues on the Silicone Rubber (SR) and Speedisk (SD) Passive sampling media at the 3 sampling sites (based on June-July 2016 sampling campaign data)

Comparing the pollution levels of pesticides in the water for different sampling sites with the drinking water standards criteria (WHO 2011) showed that the concentrations of all the studied pesticides were below the WHO drinking water standard and limits (Figure 2-5). Results of this study are in agreement with another recent pesticide residue study in the lake basin by Onyango et al. (2015). They reported on 4,4-DDT, 2,4-DDE, 4,4-DDD, $\mathrm{Y}-\mathrm{HCH}, \mathrm{a}-\mathrm{HCH}$ and Aldrin contamination in the aquatic environment of the Lake Naivasha catchment and concluded there was no potential effect of these pesticides on human health in drinking water. However, because of bio-accumulation of pesticides in aquatic organisms and the risk of entering the higher food web and chain, the concentration of pesticide residues, even in low concentrations, needs to be monitored continuously. 
Evaluating Organochlorine Pesticide Residues in the Aquatic Environment of the Lake Naivasha River Basin Using Passive Sampling Techniques

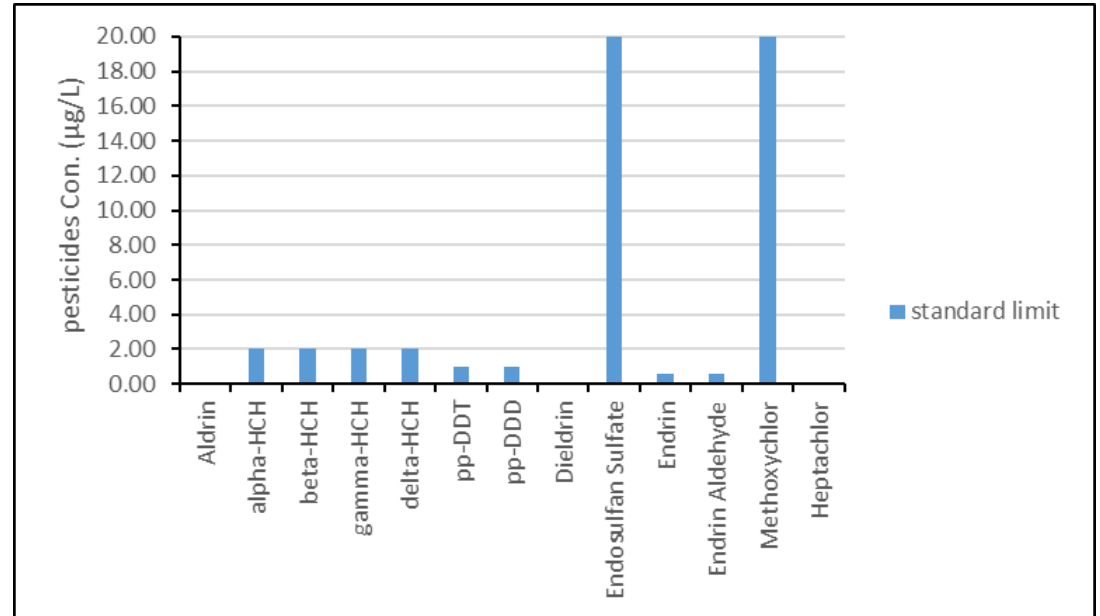

Figure 2-5- WHO drinking water standards and limits

\subsection{Conclusions}

This study investigated organochlorine pesticide residues in surface water resources on Naivasha, Kenya using passive sampling techniques. Analysis of OCP concentrations showed that the total amounts at the Lake site was highest. This could be due to the fact that the Lake was the final accumulation site for runoff and suspended sediments from the basin. The $\Sigma O C P s$ for the Middle Malewa and the Upper Malewa river sites represented the second and third level, respectively. The results showed that Endosulfan Sulfate was the main pesticide residue found at all of the sampling locations. The results from the SR samplers showed that there was also contamination by a$\mathrm{HCH}$, Endrin aldehyde and Methoxychlor at all of the sites. Finally, it was concluded that continuous monitoring of OCPs and other pesticides using passive sampling was a very useful technique that could contribute to environmental monitoring and pollution assessment of water resources in the studied area.

\section{Acknowledgments}

This study commenced within the framework of the Integrated Water Resources Assessment Project - Naivasha or IWRAP project - and was completed in cooperation with the "Waterschap Noorderzijlvest" (the Netherlands) with support from the WWF (World Wildlife Fund for nature, Nairobi office) and the Water Resources Management Authority (WRMA) of Naivasha (Kenya). Passive samplers were prepared and dedicated by Deltares (the Netherlands) and chemical pesticide residue analysis was carried out in Department of Chemistry at University of 
Nairobi and in Deltares (TNO) laboratories (Utrecht, Netherlands). Authors would like to express thanks to Dr. Jasperien de Weert (Deltares company, Utrecht, Netherlands), Prof. Onyari John Mmari, Dr. Madadi Vincent Odongo and Mr. Enock Osoro (University of Nairobi) and the people in the WWF and WRMA, who all facilitated this study. 
Evaluating Organochlorine Pesticide Residues in the Aquatic Environment of the Lake Naivasha River Basin Using Passive Sampling Techniques 


\section{Chapter 3 : Modeling Pesticide and Sediment Transport in the Malewa River Basin (Kenya) using SWAT ${ }^{1}$}

\footnotetext{
1 This chapter is based on: Abbasi, Yasser, Mannaerts, Chris $M$ Makau, William. Modeling Pesticide and Sediment Transport in the Malewa River Basin (Kenya) Using SWAT. Water 2019, 11, 87; doi: $10.3390 /$ w11010087
} 


\begin{abstract}
Understanding the dynamics of pesticide transport in the Malewa river and lake Naivasha, a major fresh water resource, is critical to safeguard water quality in the basin. In this study, the Soil and Water Assessment Tool (SWAT) model was used to simulate the discharge of sediment and pesticides (notably the organochlorine residues of a-HCH, Methoxychlor and endosulfan-sulfate) into the Malewa river basin. Model sensitivity analysis, calibration and validation were performed for both daily and monthly time steps using the Sequential Uncertainty Fitting version 2 (SUFI-2) algorithm of the SWAT-CUP tool. Water level gauge data as well as a DTS-12 digital turbidity sensor for suspended sediment transport were used for the SWAT calibration. Pesticide residues were measured at Upper and Down Malewa locations using a passive sampling technique and their quantity was determined using laboratory Gas Chromatography. The sensitivity analysis results showed that curve number (CN2), USLE soil erodibility factor (USLE-K) and pesticide application efficiency (AP_EF) formed the most sensitive parameters for discharge, sediment and pesticide simulations, respectively. In addition, SWAT model calibration and validation showed better results for monthly discharge simulations than for daily discharge simulations. Similarly, the results obtained for the monthly sediment calibration demonstrated more match between measured and simulated data as compared to the simulation at daily steps. Comparison between the simulated and measured pesticide concentrations at upper Malewa and down Malewa locations demonstrated that although the model mostly overestimated pesticide loadings, there was a positive association between the pesticide measurements and the simulations. Higher concentrations of pesticides were found between May and mid-July. The similarity between measured and simulated pesticides shows the potential of the SWAT model as initial evaluation modelling tool for upstream to downstream suspended sediment and pesticide transport in catchments.
\end{abstract}

Keywords: SWAT, hydrologic simulation, pesticide residues, passive sampling, sediment, Malewa river 


\subsection{Introduction}

Lake Naivasha (in Kenya) serves as a source of fresh water for most of the farms in the area. It also provides fresh water for domestic consumption and supports a variety of wildlife around the Lake. The long-term use of agrochemicals and the continuous upstream to downstream transport of suspended sediment into the lake could endanger the ecosystem as well as the livelihood of the local people. Intensive and extensive agricultural activities have been identified as the main contributors to sediment generation in the lake Naivasha catchment (Harper et al. 2011). Furthermore, pollution by agrochemicals causes the death of the aquatic life that provides a livelihood for many fishermen in the area.

Generally, the transport of agrochemicals and sediment that are mainly associated with runoff, raise concern about the management of water quality and quantity in watersheds. Sediments and adsorbed pesticides cause the deterioration of the quality of fresh water bodies in various regions in the world (Warren et al. 2003). Turbidity, light penetration and dissolved oxygen are all to a large extent affected by sediments. Moreover, sediments can transport adsorbed pollutants into water bodies (Vigiak et al. 2017). The estimation of runoff, sediment and pesticide loading into a water resource can be helpful in many applications, such as protection of aquatic life habitats. Understanding the movement of pesticides in catchment is very important to determine their concentration in receiving water bodies. This is vital as pollution by pesticides could be associated with human health risk (Panuwet et al. 2012). For studying environmental pollution, measuring all soil erosion resources and sediment transport plus the chemical processes is not feasible through the traditional ways (Odongo et al. 2013). Combining all of the hydrological parameters and the variations of the pollutants during the transport, increases the complexity of estimating the transported sediment and pesticides by runoff. Therefore, simulation models can be of assistance and form an appropriate way to provide spatiotemporal information on sediment and chemical transport.

In hydrological studies, the application of models has increased in support of environmental planning and decision-making. Models can be a cost and time effective way for evaluating and quantifying pollutants (Chen et al. 2017). There are various hydrological models in use for simulating hydrological behavior and estimating different variables such as runoff, sediment, and agrochemicals under varying climatic and land conditions (Ben Salah and Abida 2016). Borah and Bera (Borah and Bera 2004) reviewed and provided a summary of models that could be used to simulate transport of pesticides. Their results indicated that AnnAGNPS (Annualized Agricultural Nonpoint Source Model), HSPF (Hydrology Simulation Program-FORTRAN) and SWAT 
(Soil and Water Assessment Tool) were most appropriate for pesticide modeling. SWAT is a basin simulation model developed for simulation of the effects of practices carried out on land in vast and heterogeneous watersheds. It is a physically based semi-distributed model implemented in ArcGIS that aims to predict the impact of land practices on water and of sediment and agrochemical production in watersheds for diverse soil types and varying land use and management conditions (Scopel). This model has been used in different studies for simulating discharge, sediment yield and agrochemicals transport (Abbaspour et al. 2007; Bannwarth et al. 2014; Chen et al. 2017; Dutta and Sen 2017; Ligaray et al. 2017; Luo et al. 2008; Mahzari et al. 2016; Folle 2010; Parker et al. 2007; Winchell et al. 2018) and in most of them the capability of this model has been confirmed.

For estimating the variables and parameters used by the hydrological models, it is necessary to calibrate the model based on field measured parameters. It should be noted that direct measurement of all the variables used by SWAT model, which contains a huge number of variables, would be a practically impossible approach (Abbaspour et al. 2007). Calibration of the model, which has to be achieved by adjusting the hydrological parameters in the model in a reasonable range, will need to focus on the most sensitive parameters (Arnold et al. 2012). In such circumstances, inverse modeling (e.g., using SWAT-CUP) may be a promising method for calibration (Wang et al. 2003), as it is based on assigning uncertainties to the variables in order to match the outputs with the measured data using an objective function (Abbaspour et al. 2007).

This study focuses on hydrological modeling of runoff, sediment and pesticides residues in the Malewa river basin located in the Lake Naivasha catchment, Kenya. The study aims to quantify the pesticides that are washed out from the sub-basins and their possible connection to Lake Naivasha. This may provide information for management to adopt in order to curb the pollution risk and thus to safeguard the natural aquatic ecosystem of the Lake.

\subsection{Materials and methods}

\subsubsection{Study area}

Lake Naivasha is a fresh water lake located in the Eastern Rift valley of Kenya at $00^{\circ} 46^{\prime}$ to $00^{\circ} 52^{\prime}$ Latitude and $36^{\circ} 15^{\prime}$ to $36^{\circ} 25^{\prime}$ Longitudes in zone $37 \mathrm{~S}$ UTM (Figure 3-1). The lake forms a closed basin without identifiable outlet (Xu 1999). The eastern side of the catchment (Aberdare Ranges) has the highest elevation at $3990 \mathrm{~m}$ above sea level, while the lowest elevation is about $1980 \mathrm{~m}$ (Odongo et al. 2013). 
The catchment climate is semi-arid with mean monthly temperatures of around $16^{\circ} \mathrm{C}$ and maximum and minimum mean temperatures of $26^{\circ} \mathrm{C}$ and $7{ }^{\circ} \mathrm{C}$, occurring in January and August, respectively. Rains occur from March to June (the long season) and short rains are experienced from October to early December. The average yearly rainfall in the lake area is about $600 \mathrm{~mm}$ with the high-altitude areas receiving about 1200 to $1500 \mathrm{~mm}$ (Odongo et al. 2013). The rainy seasons are preceded by dry months that span from December to February and from July to September. However, these periods are not constant and may change over the years.

The major rivers in the lake Naivasha catchment are the Malewa, Gilgil and Karati rivers. The Malewa river is the dominant river that provides up to $80 \%$ of the total inflow into the Lake (Becht, Odada, and Higgins 2010) and forms a sub-basin of approximately $1600 \mathrm{~km}^{2}$ in the Naivasha catchment. The study focuses on this sub-basin (Figure 1). There is also a small diversion dam near the Turasha stream outflow to the main Malewa river. This diversion draws and transfers about $1800 \mathrm{~m}^{3} /$ day of water to the lake Nakuru basin (and city) outside the study area. A large portion of the sub-basin land is used for agriculture (both irrigated and rain-fed). Natural vegetation (shrubs, grasses and forests) also cover a large area of the catchment. The main agricultural activities in the basin consist of small-scale crop growing of, for example, pyrethrum, wheat, maize, onions and potatoes. A considerable portion of the study area has been put under pasture and livestock rearing which is practiced both intensively and extensively. 


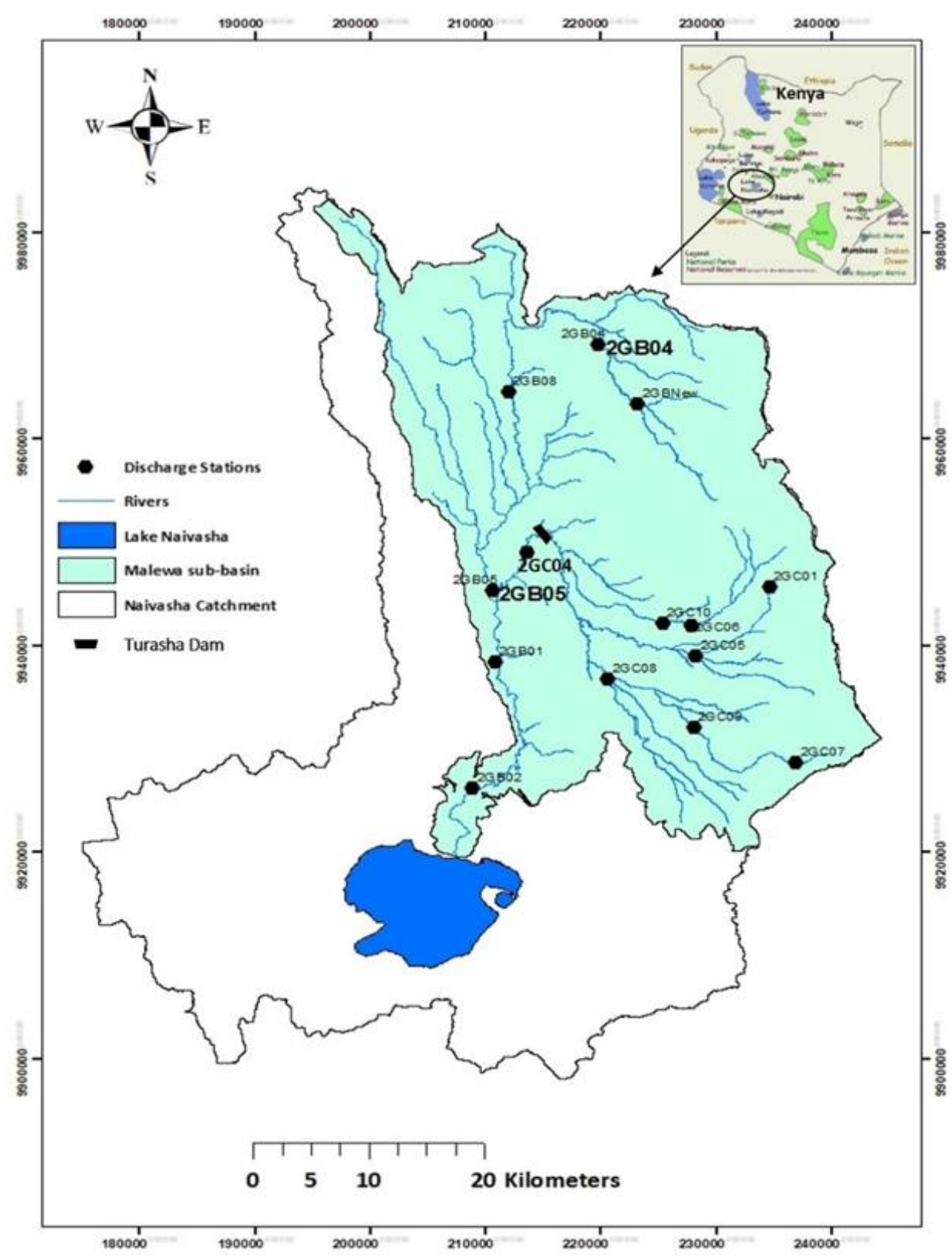

Figure 3-1-Study area map showing the location of Malewa river basin and hydrological stations 


\subsubsection{Data procurement}

A Digital elevation model (DEM) forms the essential input for the provision of topographic information in the basin. An ASTER satellite sensor-based DEM with a resolution of $20 \mathrm{~m}$ and WGS_1984 datum for the Lake Naivasha catchment was used. Land use-Land cover (LULC) is a major input component of the SWAT model as it is used in analysis of hydrological response units (HRUs). The characteristics of the various vegetation and land cover types dictate the hydrological response in the area. Based on land cover and land use, SWAT is thus able to compute the canopy storage and the runoff by which soil is eroded into the streams (M. Meins 2013). Therefore, a LULC map with $30 \mathrm{~m}$ resolution that was derived from Landsat 7 ETM for the study area (Odongo et al. 2014) was used. The map has 12 general classes and closer visual inspection proved that there was a fair match between the map and the ground LULC. The soil map adopted for use in SWAT was derived from Kenya Soil Survey maps and data. The parameters that were missing in the soil map were identified by field measurement and/or laboratory determination. The hydraulic conductivity, bulk density and the percentages of sand, silt, clay and rock in the soil were derived from soil samples identified during the field expeditions and further determined in the laboratory. Daily precipitation data from 11 rainfall stations plus the minimum and maximum daily temperature data from three stations within or close to the catchment were acquired. It is noticeable that the catchment has a tropical climate with relatively small spatial temperature variations in which there occur no very low (e.g. freezing temperatures) as well as no extremely high temperature (due to the moderate highland altitude $1800-2500 \mathrm{~m}$ on the equator). Therefore it is assumed that the temperature data could represent the studied area properly. Additionally, the long term meteorological data such as average solar radiation, relative humidity and wind speed were also provided for the model's weather data definition. It is notable that relative humidity and wind speed datasets are not needed to provide for the model when the Hargreaves method is selected for determining the potential evapotranspiration.

The River Malewa basin has several gauge stations (Figure 1) installed for the daily measurement of discharge. These are manned and managed by the Water Resources Management Authority (WRMA) in Naivasha. Not all gauge stations were in operation, but the ones that had enough data to be used in the modeling were the 2GB04, 2GB05, 2GB08, 2GC04, and 2GC05 stations. The daily discharge data for the years 2004-2017 was obtained from the database of the WRMA. There were no pesticide application data available regarding organochlorine 
pesticides (OCPs) in the studied area covering this study period. These kinds of pesticides have been banned from import and use in Kenya for many years. However, there is still a risk of finding their residues in the catchment (Gitahi et al. 2002). Therefore, a field survey was conducted to gather information on farm operation management such as cultivation practices, cultivated crops, harvesting methods, pesticides applied, as well as times and amounts of application of these pesticides. The 2016-17 surveys did not reveal any data on OCPs. Then, a field campaign was carried out in June-July 2016 to measure pesticide content using passive sampling technique (silicon rubber sheets) at 2GB04 and 2GB05 stations (Figure 3-1), located in the main river as Upper Malewa and Down Malewa (Abbasi and Mannaerts 2018). Passive sampling method allows the measurement of low concentrations by collecting the pollutants over a long time period (e.g., some months). Therefore, the samplers were deployed at the sampling stations during June-July according to the relevant passive sampling instructions (Abbasi and Mannaerts 2018). After the exposure time, the samplers were collected from the sampling stations and after the initial preparations in the lab, the organochlorines residues were analyzed using a gas chromatograph in combination with an electron capture detector (GC- $\mu \mathrm{ECD}$ ) (Abbasi and Mannaerts 2018).

Based on the results of these measurements, the residues of Methoxychlor, a-HCH and endosulfan-sulfate were found in the Malewa river basin. It is noticeable that endosulfan-sulfate is the oxidation product of endosulfan as the parent insecticide that was evaluated. However, the possible time and amount of application and physiochemical properties of these pesticides' parameters, such as soil adsorption coefficient ( $\mathrm{S}_{K o c}$ ), wash-off fraction (WOF), half-life in soil and foliage (HLIFE_S and HLIFE_F) as well as solubility in water (WSOL), were acquired as input to SWAT. Additionally, daily suspended sediment monitoring data were also obtained by installing a Digital Turbidity Sensor (DTS-12, Forest Technology Systems, Canada) in the river at 2GB04 station from April to December 2017. The DTS sensor measurements were taken at 15 minutes intervals to capture the variations at high temporal resolution. The DTS data were also calibrated against sediment concentration, during suspended sediment sampling campaigns (April-June and September-October, 2017) using a US DH-48 hand-held depth-integrating sampler.

\subsubsection{Model setup}

The ArcSWAT interface version 2012 was used for modeling discharge, sediment and pesticide transport in Malewa river basin. The model 
delineates the watershed into sub-basins and Hydrological response units (HRUs). The HRU is defined as a unit of uniform hydrological response and land properties in terms of land cover and use, soil and topography. A sub-basin is defined as an area that is composed of several hydrological response units (Neitsch et al. 2011). Based on the combination of the data fed into the model (e.g., topography, land cover and use, soil properties and weather data), the model uses the HRUs and the sub-basins during its simulation to predict the discharge inflows and outflows as well as the sediment and chemical transport from every sub-basin.

After overlaying the land use, soil and slope maps, $147 \mathrm{HRUs}$ with 22 sub-basins were created. The HRU thresholds were set to $10 \%, 5 \%$ and $10 \%$ for land use, soil and slope respectively (Ben Salah and Abida 2016). The weather data in the model consist of precipitation, temperature, relative humidity, solar radiation and wind speed. These input tables can be either introduced to the model or simulated using a weather generator option in the model. However, as rain data are governing input data that directly influence the results (Dutta and Sen 2017), it is important to provide the model with the measured rain data. The model calculates the hydrological parameters for the HRUs, which are linked to the sub-basin's level and finally routed to the outlet points of the basin (Dutta and Sen 2017). Calibration and validation of the model for discharge data was, respectively, performed from 2007 to 2012 (with a 3 year warm-up period from 2004 to 2006) and 2013 to 2017. As sediment and pesticides data time series was short, the model was (only) validated with discharge measurements. The daily sediment data were collected during nine months (April-December, 2017) and pesticides were collected during 2 months (June-July, 2016) of taking measurements.

Discharge is a key factor in sediment transport, and calibration of the sediment was done on the discharge-calibrated and validated model. The model was calibrated for both daily and monthly data to determine which approach would provide a better output. The Soil Conservation Service (SCS) was used to estimate the surface runoff (Chen et al. 2017), which is governed by Curve Number (CN) values. This method is a function of soil infiltration, land use and soil moisture (Dutta and Sen 2017) with a larger CN representing higher potential runoff yield, and vice versa. The hydrological process is based on the water balance, which is a function of precipitation, evapotranspiration, quick runoff, irrigation, infiltration rates and lateral flow (Neitsch et al. 2011). The hydrological component of the model at each HRU simulates the hydrological balance using following equation: 


$$
S W t=S W o+\sum_{t=1}^{t}(R d a y-Q \operatorname{surf}-E a-W s e e p-Q g w)
$$

where SWt is final soil moisture content $(\mathrm{mm}), S W o$ is initial water content $(\mathrm{mm}), \mathrm{t}$ is time in days, Rday is precipitation $(\mathrm{mm}), Q$ surf is surface runoff $(\mathrm{mm}), E a$ is Evapotranspiration $(\mathrm{mm})$, Wseep is amount of water seeping into the soil profile $(\mathrm{mm})$ and $Q g w$ is amount of return flow $(\mathrm{mm})$.

As pesticides move through runoff and sediment, either dissolved in water or attached to soil and sediment particles, monthly and daily sediment calibration was also performed with this calibrated model being used to simulate pesticide movement. The Modified Universal Soil Loss Equation (MUSLE) is applied in the SWAT model for the calculation of sediment yield. This equation is a function of surface runoff and is defined as:

$$
\text { Sed }=11.8 \times\left(Q_{\text {surf }} \times q_{\text {peak }} \times \underset{\text { area }}{\text { hrru }}\right)^{0.56} \times K_{U S L E} \times C_{U S L E} \times P_{U S L E} \times L S_{U S L E} \times
$$

where Sed is the sediment yield (metric tons) of a HRU, $Q_{\text {surf }}$ is the volume of surface runoff $(\mathrm{mm} / 104 . \mathrm{m} 2), q_{\text {peak }}$ is peak runoff rate $(\mathrm{m} 3 / \mathrm{s})$, area $_{h r u}$ is area of the HRU (104.m2), $K_{U S L E}$ is Universal Soil Loss Equation (USLE) soil erodibility factor, $C_{U S L E}$ is USLE cover and management factor, $P_{U S L E}$ is USLE support practice factor, $L S_{U S L E}$ is USLE topographic factor and $C F R G$ is coarse fragment factor.

Surface runoff transports adsorbed pesticides in sediment and into the main channels. The adsorbed pesticide loads can be calculated by the following equation:

$$
\text { Pst }_{\text {sed }}=0.001 \frac{C_{\text {solidphase }}^{* \text { sed }}}{\text { Area }_{\text {hru }}^{*} \varepsilon_{\text {pstsed }}}
$$

where $P s t_{\text {sed }}$ is Sediment with adsorbed pesticide in the main channel ( $\mathrm{kg}$ pesticide/104.m2), $C_{\text {solidphase }}$ is Concentration of sediment on the top soil layer in ton soil, sed is daily sediment yield (metric tonnes), Area $_{h r u}$ is the area of the HRU (104 .m2), $\varepsilon_{\text {pstsed }}$ is enrichment ratio of the sediment. The total amount of pesticides is calculated by summing up the adsorbed and the dissolved amounts. 


\subsubsection{Model sensitivity analysis, calibration and validation}

Usually, initial modeling with SWAT using default parameters does not produce promising outputs in relation to model inputs (Dutta and Sen 2017). This calls for the model to be calibrated, which involves adjustment of parameters until the simulation results match with the observed data for a specific time period. The identification of the best adjusted parameters for better simulation is achieved with a sensitivity analysis, with the aim to minimize the amount of time consumed trying to calibrate the model. Based on different studies (Chen et al. 2017; Dutta and Sen 2017; Mahzari et al. 2016; Zettam et al. 2017) there were various parameters related to discharge, sediment and pesticides transport to be calibrated. The surface runoff lag coefficient (SURLAG) was responsible for the control of the fraction of the total amount of water that entered the outlet in a day (Table 3-1). The groundwater delay time that controls the amount of time it takes for water to move from the vadose region to the deeper shallow aquifer was affected by the GW_DELAY parameter, while the ALPHA_BF factor governed the discharge recession curve intended to correctly depict the base flow drainage tendencies of the watershed. The parameters related to the channels, such as $\mathrm{CH} \_\mathrm{N} 2$ and $\mathrm{CH} \_\mathrm{K} 2$ were also used to adjust the discharge. The flow of water through the soil was regulated by the hydraulic coefficient parameter (SOL_K) and GWQMN was needed for return flow to occur. The model parameters that were used for sediment and pesticides calibration are presented in Tables (3-3 and 3-4).

The Calibration and Uncertainty Procedures (SWAT-CUP) tool was used to find the most sensitive parameters in the modeling. In this model, the SUFI-2 algorithm was selected to describe the uncertainty of the parameters based on a uniform distribution assumption. This algorithm is able to perform the approximation at a 95 percent prediction uncertainty level called 95PPU (Chen et al. 2017). SUFI-2 initially assumes large uncertainty in the parameters covering all the observed data at 95PPU level. This uncertainty is reduced in subsequent rounds until the difference between the upper and the lower parts of 95PPU $97.5 \%$ and $2.5 \%$ levels - is minimized and 95PPU includes $80-100 \%$ of the observations (Abbaspour et al. 2007). The SUFI-2 algorithm uses a Latin Hypercube (MCkay, Beckma, and Conover 2000) sampling approach where $\mathrm{n}$ parameters are combined in a satisfying simulation number (500-1000 runs), with the simulations thereafter being assessed using an objective function (Abbaspour et al. 2007). There are several objective functions in SWAT-CUP dealing with model 
calibration (Abbaspour 2015). In this study, the Nash-Sutcliffe coefficient, R squared and percent bias (PBIAS) (Eq. 4 to 6 ) were used as model performance measures for the assessment of discharge and sediment simulations (Moriasi et al. 2015) that permit an appropriate parameter and model performance evaluation.

$$
\begin{aligned}
& \text { NSE }=1-\frac{\sum_{i=1}^{n}\left(y_{i}^{\text {obs }}-y_{i}^{\text {sim }}\right) 2}{\sum_{i=1}^{n}\left(y_{i}^{\text {obs }}-y_{\text {mean }}\right)^{2}} \\
& R^{2}=\left(\frac{\sum_{i=1}^{n}\left(y_{i}^{\text {obs }}-y_{\text {mean }}^{\text {obs }}\right)\left(y_{i}^{\text {sim }}-y_{\text {mean }}^{\text {sim }}\right)}{\sqrt{\sum_{i=1}^{n}\left(y_{i}^{\text {obs }}-y_{\text {mean }}^{\text {obs }}\right)^{2}} \times \sqrt{\sum_{i=1}^{n}\left(y_{i}^{\text {sim }}-y_{\text {mean }}^{\text {sim }}\right)^{2}}}\right)^{2} \\
& \text { PBIAS }=\frac{\sum_{i=1}^{n}\left(y_{i}^{\text {obs }}-y_{i}^{\text {sim }}\right)}{\sum_{i=1}^{n}\left(y_{i}^{\text {obs }}\right)} \times 100
\end{aligned}
$$

where $Y_{i}^{\text {obs }}$ is the $\mathrm{i}^{\text {th }}$ value of observed data, $Y_{i}^{\text {sim }}$ is the $\mathrm{i}^{\text {th }}$ value of simulated data, $Y_{\text {mean }}^{\text {obs }}$ is mean value of the observed data and $Y_{\text {mean }}^{\text {Sim }}$ is mean value of the simulated data. The NSE ranges from - $\infty$ to 1 . Values for the NSE from 0 to 1 indicate a tolerable level of performance, while values below zero are not acceptable. PBIAS represents the average affinity of the simulated values to be more or less than measured data (Moriasi et al. 2015). The model was calibrated based on the most sensitive parameters (Table 3-1) for surface discharge data from the sampling stations that had a complete dataset for the period 2004-2012. The model was then validated against the measured data for the period 2013-2017 without further adjustment of the parameters. The results were evaluated for correctness using the suitable model performance statistical measures of PBIAS, NSE and R squared. The model was also calibrated for the sediment simulation by keeping the discharge related parameters fixed and adjusting the sediment related parameters (Table 3-3) (Malone et al. 2015). Finally, as there was a pesticide data shortage, the average monthly data over two months were used to gain insight in the pesticide simulation based on operational management in the basin. Without changing other parameters in the model, the parameters governing pesticide movement were adjusted manually to achieve the best possible match between the model results and the measured pesticides at 2GB04 and 2GB05 station (e.g., Upper and Down Malewa, respectively). The possible times of pesticide applications and cultivation practices were assumed to be in the rainy seasons, when agricultural activities occur. It should be noted that per simulation, only one pesticide can be traced 
(Arnold et al. 2013), therefore, the model calibration for pesticides was separately performed for Methoxychlor, a-HCH, and endosulfan-sulfate (Table 3-4).

\subsection{Results}

\subsubsection{Discharge simulation}

The sensitivity analysis of the model using SWAT-CUP indicated 16 sensitive parameters related to discharge (Table $3-1$ ) that could be adjusted to calibrate the model. The results showed that the discharge peaks during the simulations were most sensitive to Curve Number (CN2) values and the SOL_K parameter, which both vary spatially in the basin, and other parameters were in lower level of sensitivity.

The results of the statistical evaluation of discharge simulations are presented in Table (3-2). The results of calibration for daily simulation in the gauge stations showed an R2 between 0.61 and 0.05 , NSE between -1.20 and 0.47 and $|P B I A S|$ up to $50 \%$ that based on Moriasi et al. (Moriasi et al. 2015) were unsatisfactory. While the monthly simulations with an R2 of 0.70 to 0.86 , NSE of 0.51 to 0.64 and $|P B I A S|$ within $15 \%$ showed satisfactory to very good outputs (Moriasi et al. 2015) (Figure 3-2 and 3-3). As in some of the stations the time period for daily and monthly calibration was not the same, the PBIAS values were different for daily and monthly simulations. During the validation period also, the results of the daily discharge simulation at the stations varied between 0.28 and 0.60 for $\mathrm{R}^{2}$, between 0.02 and 0.47 for NSE and up to $66 \%$ for $|P B I A S|$. Comparing the simulated and measured data for the monthly validation period also showed satisfactory to good results (Moriasi et al. 2015). Generally, the results showed that the output of the model was appropriate. Moreover, the results of the uncertainty analysis showed more than 70 percent of the discharge variations to be bracketed by the 95PPU during both calibration and validation of the monthly simulation, confirming a promising model output (Abbaspour 2015; Chen et al. 2017). Abbaspour et al. (Abbaspour et al. 2004) introduced a P-factor and an R-factor to quantify the match between simulated and measured data. The percentage of the enclosed observed data is represented by the Pfactor while the R-factor shows the thickness of the 95PPU. They also suggested that the P-factor of more than 70 percent and the R-factor of about 1 denote a good result. The results of the monthly simulation revealed a P-factor of more than $80 \%$ and an R-factor of 1.1, confirming a satisfying monthly discharge simulation. 
Table 3-1-Parameters sensitivity of discharge simulations in SWAT

\begin{tabular}{|c|c|c|c|c|c|}
\hline Parameter(unit) & $\begin{array}{l}\text { SWAT } \\
\text { code }\end{array}$ & $\begin{array}{l}\text { Min } \\
\text { value }\end{array}$ & $\begin{array}{l}\text { Max } \\
\text { value }\end{array}$ & $\begin{array}{l}\text { Fitted } \\
\text { Value }\end{array}$ & Rank \\
\hline SCS runoff curve (-) & CN2 & 35 & 95 & {$[79-93]^{*}$} & 1 \\
\hline $\begin{array}{l}\text { Base flow alpha factor } \\
\text { (day) }\end{array}$ & ALPHA_BF & 0.15 & 0.50 & {$[0.15-0.38]$} & 4 \\
\hline Groundwater delay (day) & GW_DELAY & 0 & 500 & 10.90 & 11 \\
\hline $\begin{array}{l}\text { Threshold depth outflow } \\
\text { from shallow aquifer } \\
(\mathrm{mm})\end{array}$ & GWQMMN & 1 & 500 & 35.43 & 10 \\
\hline $\begin{array}{l}\text { Threshold depth of water } \\
\text { in the shallow aquifer } \\
(\mathrm{mm})\end{array}$ & REVAPMN & 0 & 1000 & 599 & 6 \\
\hline $\begin{array}{l}\text { Soil available water } \\
\text { storage capacity (mm } \\
\text { H2O/mm soil) }\end{array}$ & SOL_AWC & 0 & 1 & {$[0.1-0.3]$} & 7 \\
\hline Soil conductivity (mm/h) & SOL K & 0 & 200 & {$[4-41]$} & 2 \\
\hline $\begin{array}{l}\text { Soil evaporation } \\
\text { compensation coefficient } \\
(-)\end{array}$ & ESCŌ & 0 & 1 & 0.46 & 9 \\
\hline $\begin{array}{l}\text { Manning's value for } \\
\text { overland flow (-) }\end{array}$ & OV_N & 0.01 & 30 & {$[0.01-3.79]$} & 15 \\
\hline $\begin{array}{l}\text { Manning's value for the } \\
\text { main channel }\end{array}$ & $\mathrm{CH} \_\mathrm{N} 2$ & 0.1 & 0.5 & 0.21 & 14 \\
\hline $\begin{array}{l}\text { Main channel hydraulic } \\
\text { conductivity }(\mathrm{mm} / \mathrm{h})\end{array}$ & $\mathrm{CH} \_\mathrm{K} 2$ & 0.01 & 173 & [1-122.92] & 13 \\
\hline $\begin{array}{l}\text { Deep aquifer percolation } \\
\text { fraction }(-)\end{array}$ & RCHRG_DP & 0 & 1 & 0.15 & 5 \\
\hline $\begin{array}{l}\text { Transmission losses } \\
\text { from channel to deep } \\
\text { aquifer fraction }\end{array}$ & TRNSRCH & 0 & 1 & 0.18 & 3 \\
\hline $\begin{array}{l}\text { Soil depth of layers } \\
(\mathrm{mm})\end{array}$ & SOL_Z & 0 & 2000 & [380-1153] & 16 \\
\hline $\begin{array}{l}\text { Groundwater "revap" } \\
\text { coefficient }\end{array}$ & GW_REVAP & 0.02 & 0.40 & 0.2 & 8 \\
\hline $\begin{array}{l}\text { Surface runoff lag } \\
\text { coefficient }\end{array}$ & SURLAG & 0 & 4 & {$[0.3-2]$} & 12 \\
\hline
\end{tabular}

*values in brackets show variable ranges based on HRUs or soil types 

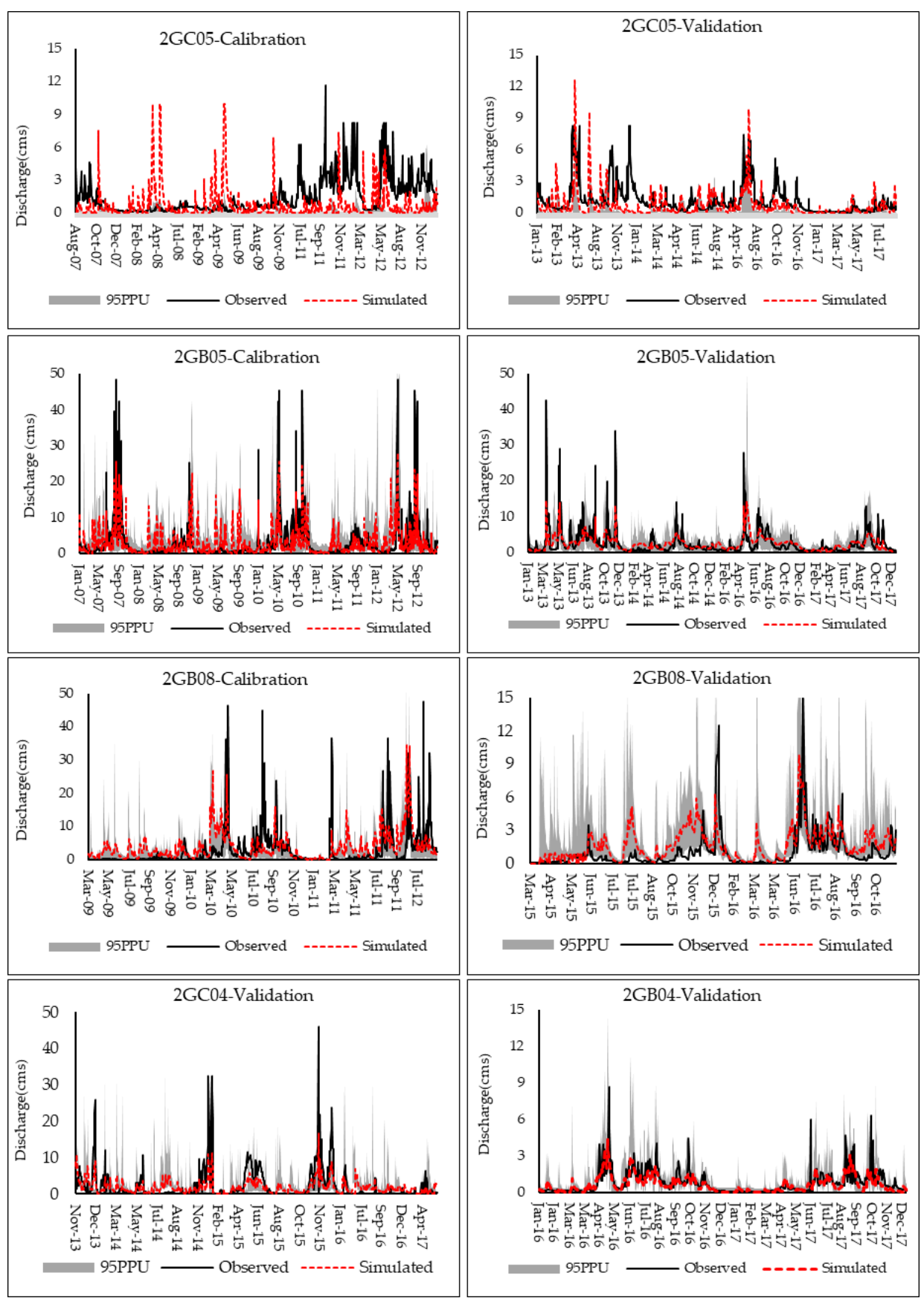

Figure 3-2-Daily discharge Calibration and Validation for different gauge stations ${ }^{2}$

2 As there were no data values or no events in some periods, the $\mathrm{x}$-axis might have gaps in some periods 


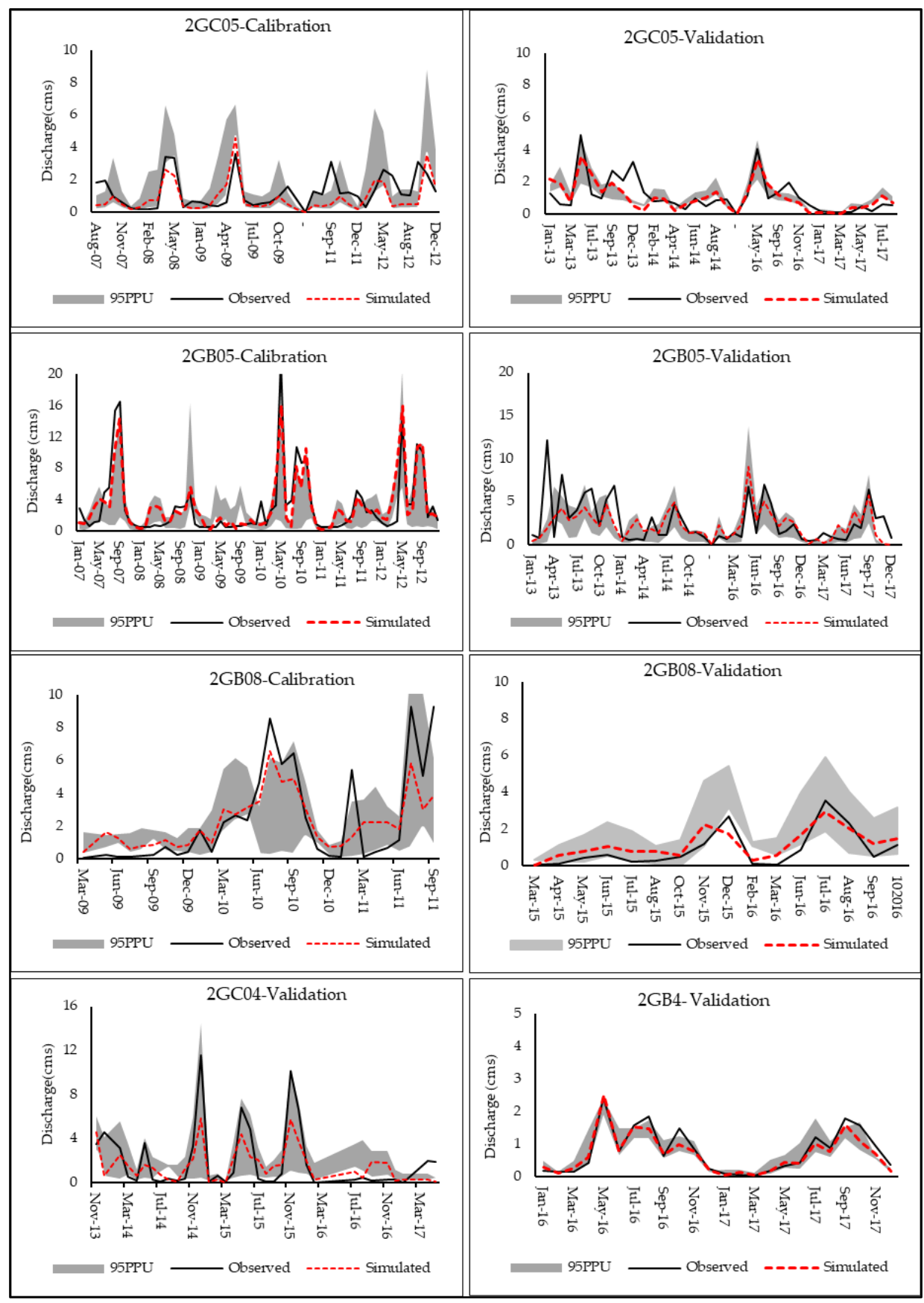

Figure 3-3-Monthly discharge Calibration and Validation for different gauge stations 


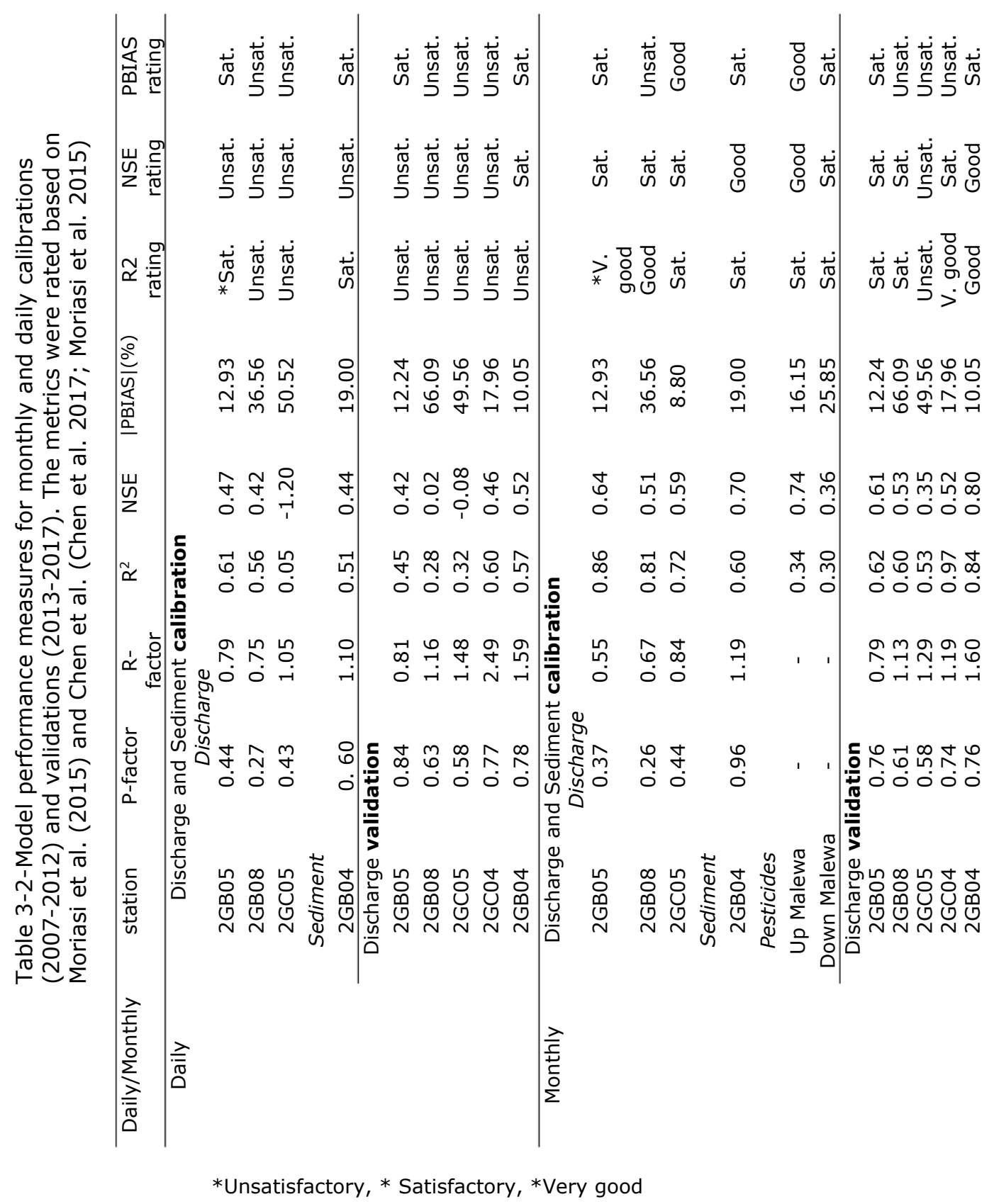




\subsubsection{Suspended sediment transport simulation}

The parameters that were specifically related to sediment loadings from the HRUs and sub-basins that were most sensitive in the model calibration are found as Table (3-3). The results of sensitivity analysis showed that among these parameters, the most sensitive one was the USLE soil erodibility factor (USLE-K). The soil conservation support practice factor in the USLE equation (USLE_P) was in the second rank and depends on land use - land cover of the area. This parameter represents the human interventions with the soil, and the crop management processes that take place in the basin. The parameters of $\mathrm{CH}$ _COV and $\mathrm{CH}$ _EROD also showed high sensitivity and could influence the amount of simulated sediment production due to sediment loss from the channels (Dutta and Sen 2017). The comparison of daily and monthly results showed that simulated and measured sediment matched well (Figure 3-4), with the monthly simulation exhibiting better results than the daily steps. The statistical results of model performance also showed the $\mathrm{R}^{2}=0.51, \mathrm{NSE}=0.44$ and $\mid$ PBIAS $\mid=19 \%$ for the daily and $\mathrm{R}^{2}=0.60, \mathrm{NSE}=0.70$ and $|\mathrm{PBIAS}|=19 \%$ for the monthly simulations that both are in range of satisfactory to good (Chen et al. 2017; Moriasi et al. 2015).

Table 3-3-Parameters sensitivity in sediment calibration

\begin{tabular}{|c|c|c|c|c|c|}
\hline Parameter(unit) & $\begin{array}{l}\text { SWAT } \\
\text { code }\end{array}$ & $\begin{array}{l}\text { Min } \\
\text { value }\end{array}$ & $\begin{array}{l}\text { Max } \\
\text { value }\end{array}$ & $\begin{array}{l}\text { Fitted } \\
\text { Value }\end{array}$ & Rank \\
\hline $\begin{array}{l}\text { USLE soil erodibility } \\
\text { factor }\end{array}$ & USLE-K & 0 & 0.7 & 0.025 & 1 \\
\hline $\begin{array}{l}\text { USLE equation support } \\
\text { practice factor }\end{array}$ & USLE_P & 0 & 1 & $\begin{array}{l}{[0.036-} \\
0.9]^{* *}\end{array}$ & 2 \\
\hline $\begin{array}{l}\text { Sediment calculation } \\
\text { Linear parameter* }\end{array}$ & SPCON & 0 & 1 & 0.025 & 3 \\
\hline $\begin{array}{l}\text { Sediment calculation } \\
\text { Exponent parameter* }\end{array}$ & SPEXP & 0.1 & 2 & 0.25 & 6 \\
\hline Channel cover & CH_COV & 0 & 1 & 0.5 & 4 \\
\hline Channel erodibility & $\mathrm{CH} \_\mathrm{EROD}$ & 0.05 & 0.9 & 0.5 & 5 \\
\hline
\end{tabular}

*This is for calculating sediment re-entrained in channel sediment routing, **This factor varied for different land properties 


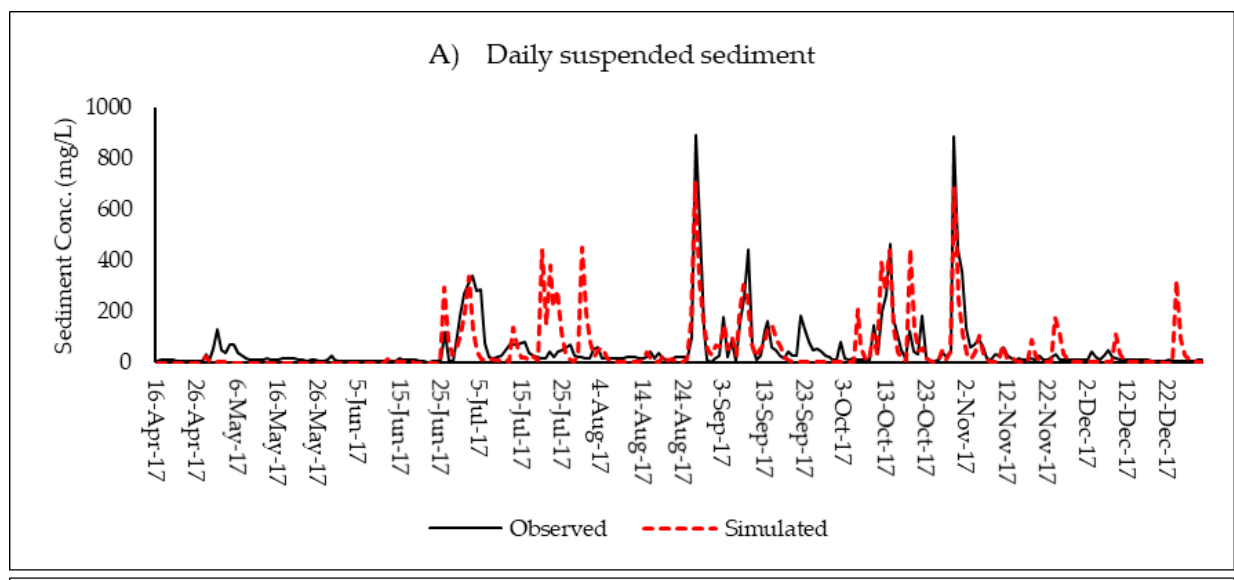

B) Monthly suspended sediment

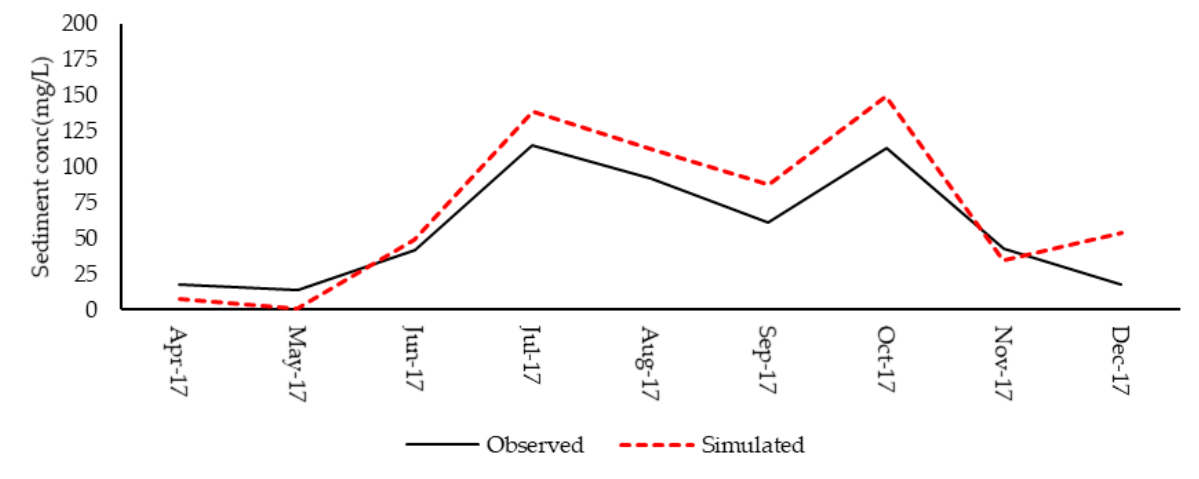

Figure 3-4-Observed and simulated daily (A) and monthly (B) suspended sediment in 2GB04 station (Upper Malewa basin)

\subsubsection{Pesticides transport simulation}

Although data on organochlorine pesticides loading in the rivers of the Lake Naivasha catchment were limited for a full model calibration and validation (Gitahi et al. 2002), the attempt at simulating the fate of the pesticide residues of Methoxychlor, $\mathrm{a}-\mathrm{HCH}$ and endosulfan-sulfate using in-situ measured concentrations could help gain insight into pesticide application and mobility in the study area. The sensitive parameters in the model calibration of pesticide residues are presented in Table (3-4). The results of this calibration demonstrate that application efficiency (AP_EF) forms the most sensitive parameter when simulating the pesticides. HLIFE_S and HLIFE_F that show half- 
life duration (days) of the pesticides in the soil and on the foliage, respectively, also proved highly sensitive in the calibration.

Correlation between the simulated and measured pesticide residue concentrations at the Upper Malewa and Down Malewa sites is represented in Table (3-2) and Figure (3-5). The results of pesticide transport modeling are based on data converted from masstransported amounts to pesticide concentrations. It was found that most applications and consequently the highest concentrations of the studied pesticide residues occurred from May to mid-July during the simulation period. The simulation results showed the month May to have the highest pesticide loading into the rivers for all studied pesticides. According to the results of simulations that are supported by measured data, endosulfan-sulfate had the highest concentration on average, i.e. from 22 to $28 \mathrm{ng} / \mathrm{L}$. During June and July the model mostly overestimated pesticide residue concentrations. However, the model simulated a valid and observed trend in pesticide variation based on the measured data, confirming the capability of the SWAT model to evaluate the rainfall-runoff based transport of pesticide residues. 


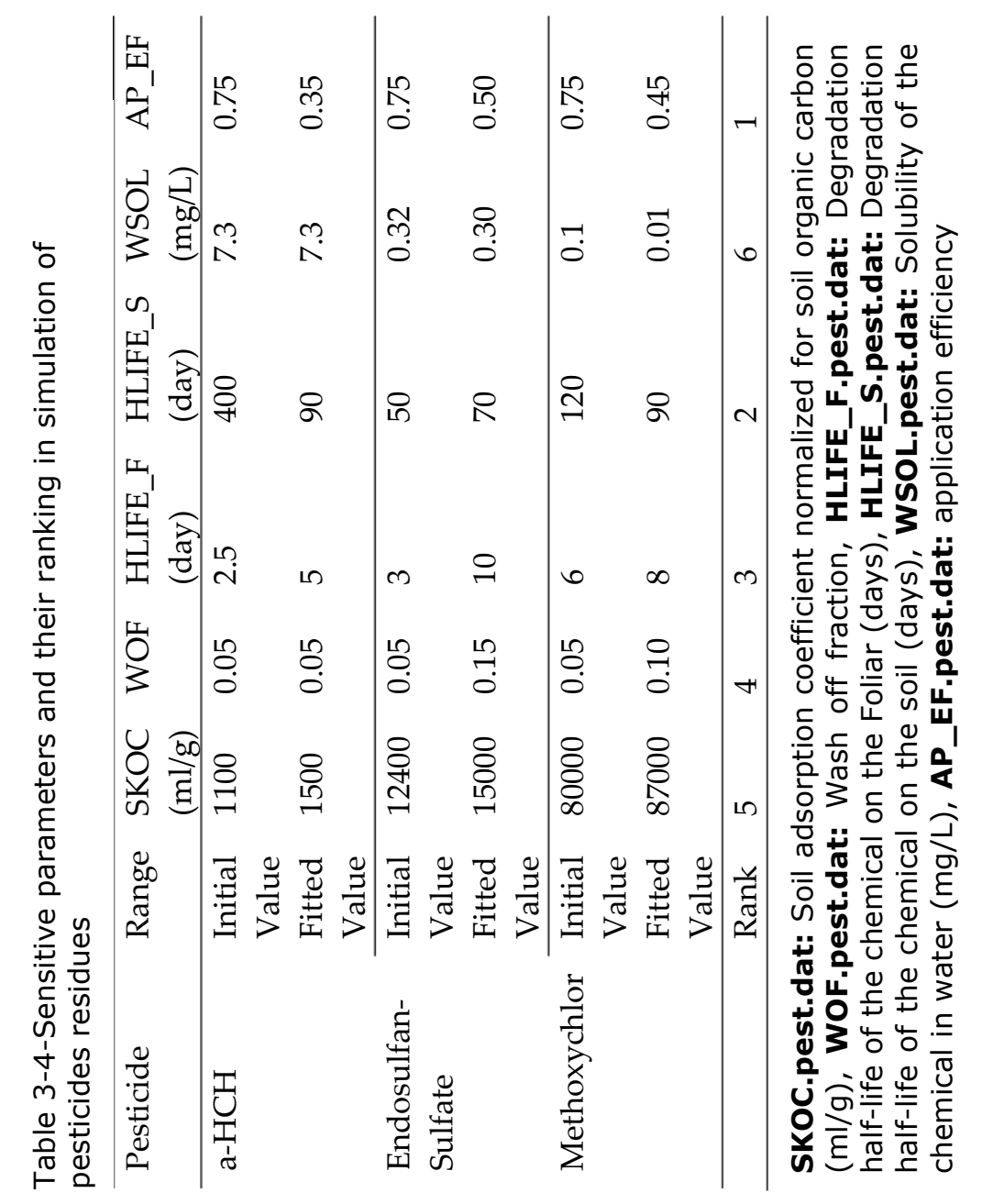




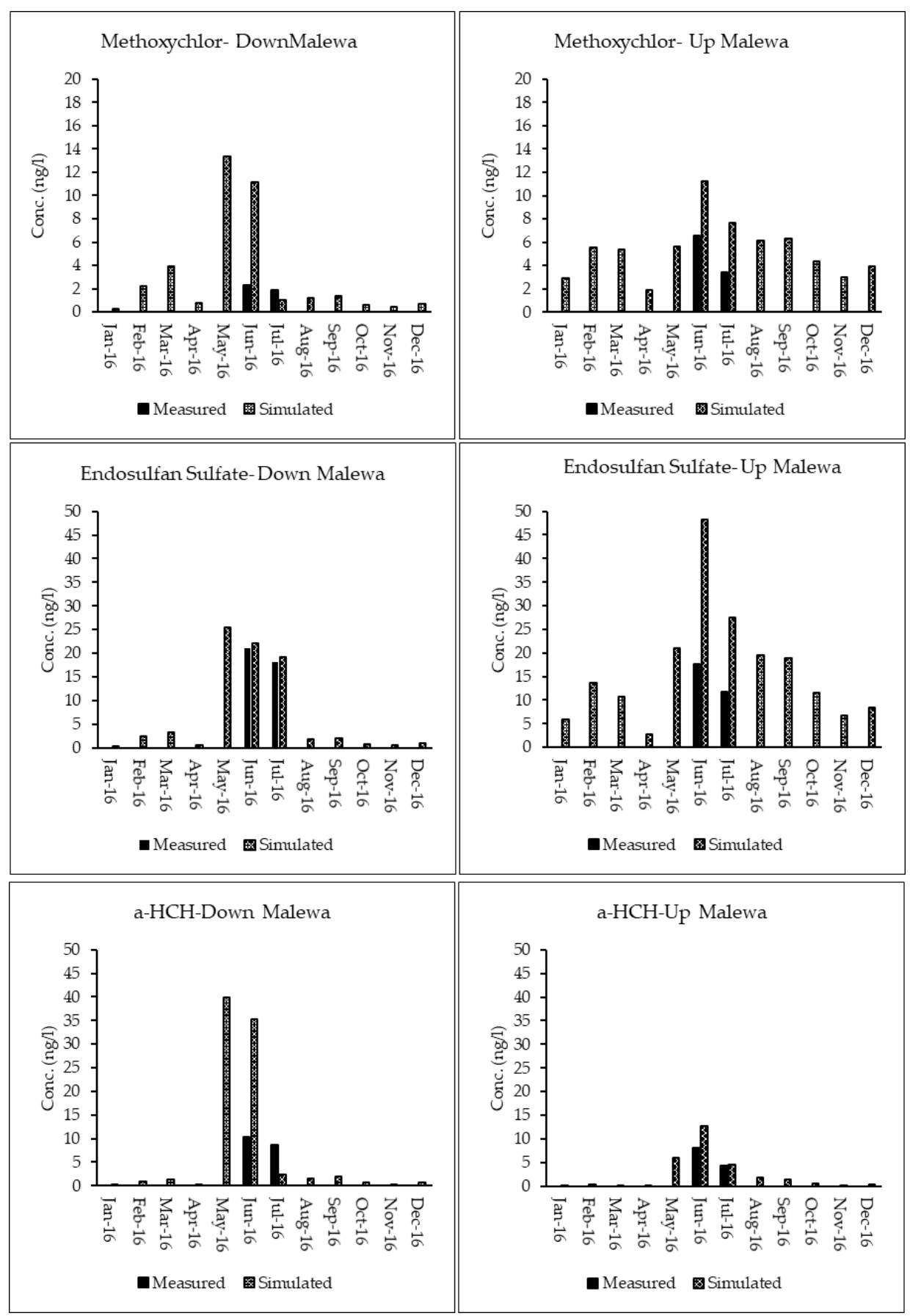

Figure 3-5- Comparing Observed and simulated monthly pesticides residues in the upstream and downstream Malewa river 


\subsection{Discussion}

Rainfall-runoff and river discharge are the main driving force behind the movement of sediment and pesticides through the basin. Therefore, an appropriate calibration of the SWAT model, which is a physically based model, can play an important role in final outcomes. By applying SWAT-CUP as a tool for calibrating the model, the values of the observed and the model simulated monthly discharge for the calibration period (2007-2012) were found to display a satisfactory statistical agreement. The daily simulation results were not as good as the monthly ones. In fact, the SWAT model generally displays better results over longer steps than short (e.g., daily or hourly) steps. The studies by Liu et al. (Liu et al. 2015) and Spruill et al. (Spruill, Workman, and Taraba 2000) also demonstrated that the model had a better performance in monthly and yearly simulations than the daily steps that can support the results of this study. This may be attributed to the fact that daily rainfall-runoff processes display higher variability rather than aggregated data on monthly basis in which the average of accumulated data is taken and the local and any short term variations are smoothed while the general trend is still followed. The studied basin has very diverse land properties (e.g., slope, land cover and use, soil), which may influence the response to rain events in hydrological units on a daily scale. Different sub-basins have varying features and the sensitive parameters for discharge simulation may differ from one to another. However, the results of several studies (Dasa, Nga, and Perera 2013; Dutta and Sen 2017; Mahzari et al. 2016; Zettam et al. 2017) demonstrate that the SCS curve number for soil moisture condition (CN2.mgt) is the most or, at least, one of the most sensitive parameters in model calibration for discharge simulation, which is supported by the findings of this study. This landscape parameter can affect the peak flow (Chen et al. 2017) and varies across hydrological units, based on their land use and soil properties, which can affect their potential for runoff from rainfall events. Soil hydraulic conductivity (SOL_K) follows as next most sensitive parameter in discharge simulation, showing the potential for soil infiltration by either transforming the rain into surface discharge or conveying the water down into the soil layers. It should be noted that the Lake Naivasha catchment has diverse soil properties, with high spatial variability in the soil parameters (e.g., SOL_K of between 4 and $41 \mathrm{~mm} / \mathrm{h}$ ). Moreover, although this is a simplified explanation of the relation between surface and groundwater, GW_DELAY, GWQMN, GW_REVAP, 
and $\mathrm{CH}$ _K2 were used to simulate their interaction in the modeling (Chen et al. 2017; Traum et al. 2014).

The diagram of the calibration (2007-2012) and validation (2013 2017) periods shown in Figure (3-6) demonstrates agreement between discharge and precipitation with slight underestimation by the model in the wet seasons and overestimation in the dry seasons. The statistical evaluation measurements of the model's monthly simulations are also acceptable $\left(R^{2}>0.46\right.$ and NSE $\left.>0.44\right)$, which means that the selected range of model parameters matches the basin condition. The reason that the dry seasons are slightly overestimated by the model may be caused by the curve number method not being able to generate runoff accurately during prolonged dry periods despite independent rainfall events occurring during that time (Qiu, Zheng, and Yin 2012).

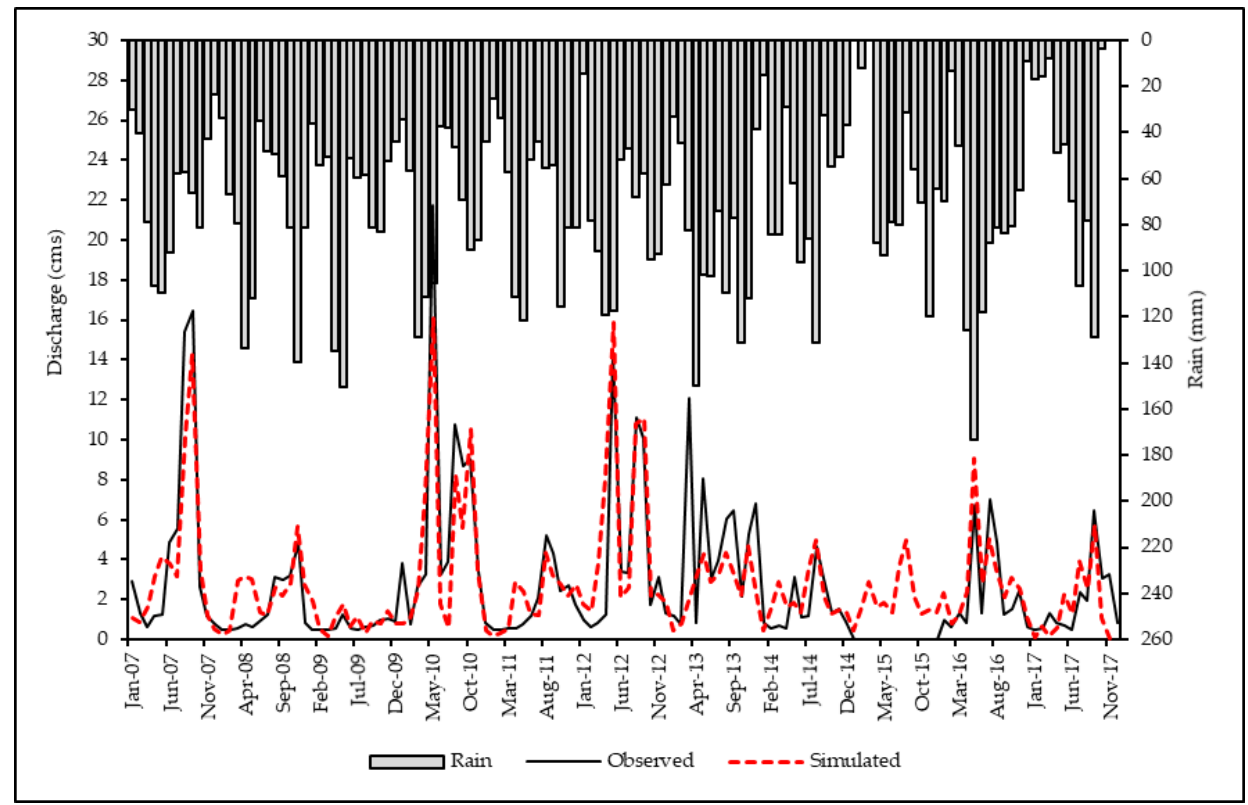

Figure 3-6-Simulated and observed monthly discharge for calibration (20072012) and validation (2013-2017) periods against rainfall. No observed discharge data were available for the 2015 period.

The simulation of sediment production and transport showed that most of the sediment is produced during events of high rainfall and discharge. The discharge is a proxy for soil erosion. As more soil is eroded the sediment amounts in the stream channels will increase. This is in agreement with findings by Asres and Awulachew (Asres and Awulachew 2010), who explored sediment yield in the Gumera 
watershed of Ethiopia. The calibration of the model for sediments over nine months captured both the wet and dry season in the area. Normally, the main rainy period is during April-June, but because of a short drought in the catchment, the rainy season was delayed to JulyOctober. Comparing simulation results against the observed sediment loads confirmed that there was more sediment production in this period, receding from October onwards (Figure 4). Exploring the daily results of the sediment estimation showed that although the $R^{2}$ of simulation was almost promising $\left(R^{2}=0.51\right)$, the results were not as good as the monthly simulations. The conclusion is that the model does not satisfactorily detect discharge and sediments produced by single storms in a day. It is more accurate in predicting sediment yield by a series of continuous rainfall events.

However, statistical comparison between the monthly simulated sediment loads and the observed loads demonstrated that the performance of the model was reasonable. Soil erosion in SWAT is based on the Modified Universal Soil Loss Equation (MUSLE) (Shen et al. 2009). Sensitivity analysis and calibration of this equation in the Malewa basin was explored by Odongo et al. (Odongo et al. 2013) and the results showed that the model could reasonably be applied for sediment simulation. Moreover, comparing the daily results of this study with their results based on some events that occurred during September to October showed that the range of sediment yields were comparable. Two of the most sensitive variables that were used in the model calibration for estimation of sediment transport were USLE-K and USLE_P. The first factor shows the inherent susceptibility of soil to erosion by water and can be calculated as the eroded soil mass per unit rainfall erosivity and area (Renschler, Mannaerts, and Diekkruger 1999). This parameter can be estimated from soil properties such as soil texture, organic matter and structure (Renschler, Mannaerts, and Diekkruger 1999). USLE_P is related to soil conservation conditions such as land contouring, tillage and terracing and demonstrates the effect of surface management on erosion processes during runoff events. But as it is difficult to determine the real value for this factor, a calibrated or default value is applied, which is not to be recommended (Renschler, Mannaerts, and Diekkruger 1999). Changing these two factors to a calibration factor in the SWAT model allows matching between measured and simulated data, while these parameters in fact need to be derived from soil or land surface properties. Therefore, as these factors are not single parameters that can be changed by calibration, it is understood that the SWAT model simplifies the estimation of soil erosion and sediment yield. 
It should be noted that calibration of the model on a large scale is associated with many uncertainties (Ficklin, Luo, and Zhang 2013), with the main uncertainty possibly being caused by agricultural management activities, which can influence the sediment loading (Chen et al. 2017). Nonetheless, calibrating the model using a highquality dataset that was recorded automatically and compiled with rainfall events should aid the achieving of a proper sediment estimation. The simulation of the sediment load depends on several factors in the watershed. These factors could be physiographical, the contribution of the watersheds to the stream flow that moves to the outlet, the quantity of the highest rate of runoff, the intensity of precipitation and concentration of the sediment (Dutta and Sen 2017). The SWAT Model produces the sediment results per sub-basin, making analysis at sub-basin level possible. The possible causes leading to various sediment production fluxes in the catchment were investigated to ascertain the different factors other than the precipitation amounts and geographical factors that could influence the sediment production rate in each sub-basin. The SWAT model uses the Thiessen polygon method to allocate the nearest rainfall station to a sub-basin. The variations in rainfall around the basin could lead to different amounts of sediments being produced in the catchment. Moreover, sub-basins with more agricultural activity as well as high slopes could have higher rate of sediment yield than other parts. This finding confirms that agricultural activity on the higher slopes of a sub-basin encourages soil erosion and hence sediment production.

Integrating the results of discharge and sediment simulations for the daily and monthly steps confirmed that the monthly simulations were more reliable than daily simulations which was overall unsatisfactory. By selecting the monthly time step for estimating the pesticide load, it became possible to evaluate pesticide transport. There are several studies that have applied the SWAT model successfully to simulate pesticides transport in catchments (Bannwarth et al. 2014; Chen et al. 2017; Folle 2010; Kannan et al. 2006). This proves the capability of this model for exploring chemical transport by water. In this study, because of limited data, the model validation of the pesticides was not done which can cause uncertainty of the results. However, as other studies in this catchment about organochlorine pesticides used only grab samples analysis (spot measurements) (Gitahi et al. 2002), the modeling in this study can be considered as a pilot application which improves our insights into the pesticides transport in the catchment. Moreover, use of passive sampling that allows measuring low 
concentrations of pesticide residues, helped the improvement of the data for more reliable modelling and assessment.

From the sensitive parameters in pesticide simulations (Table 3-4) can be seen that increasing the application efficiency (Ap_EF) caused an increase in the quantity of pesticide that entered the system, consequently increasing the pesticide load as well. Comparing the effect that this parameter had on the pesticides simulation with the study by Chen et al. (Chen et al. 2017) supported this finding. The pesticide percolation coefficient (PERCOP) was also seen as an important parameter to be defined and has been reported in different studies (Bannwarth et al. 2014), however 0.50 was found to be the best match with the simulation. The next parameter that had most effect on the results was HLIFE_S, which controls the pesticides degradation process. Obviously, by increasing this parameter, more pesticide residue has a chance to be washed out and reach the streams during the runoff events (Chen et al. 2017). Normally organochlorine pesticides have a long half-life and depending on the conditions can remain in the environment from some months to some years (ATSDR 2002). Lindane (for instance), has various isomers (e.g., $\mathrm{a}-\mathrm{HCH}, \beta-$ $\mathrm{HCH}, \gamma-\mathrm{HCH}, \delta-\mathrm{HCH}$ ) that are used as insecticide for protecting fruits, vegetables and animals. These isomers are very stable in environment (half-life of years) and are categorized as the persistent organic pollutants (POPs) by Stockholm Convention on Persistent Organic Pollutants ('STOCKHOLM CONVENTION ON PERSISTENT ORGANIC POLLUTANTS (POPs), Text and Annexes' 2009). The environmental fate and distribution of a-HCH, like that of other organic chemicals, is related to environmental conditions and its interactions with other environmental compartments as well as the physical chemical properties of the isomers (ATSDR 2005). Methoxychlor also binds strongly to soil particles and might be transported by wind and rain in eroded polluted soils or can be washed to water bodies by runoff. Depending upon the existence of photosensitizers, Methoxychlor can have a half-life of 4.5 months to half-life of less than 5 hours (ATSDR 2002). Half-life of Methoxychlor in sediments in anaerobic is more than 28 days and aerobic is more than 100 days (ATSDR 2002). Endosulfan has some isomers such as a-endosulfan, $\beta$-endosulfan and endosulfan sulfate that have high acute toxicity and could remain in environment. The main metabolite of endosulfan degradation in soil is endosulfan sulfate that is the oxidation product of endosulfan (Weber et al. 2010). The fate of endosulfan is strongly governed by environmental conditions. When it is released to air, the vapor-phase endosulfan can be degraded in the atmosphere with half-life of about 2 days ('National 
Center for Biotechnology Information. PubChem Compound Database; $\mathrm{CID}=3224, \quad$ https://pubchem.ncbi.nlm.nih.gov/compound/3224 (accessed Dec 8, 2018).'). When released to soil, based on its Koc values, it can have an average to only low mobility and is not expected to volatize from the soil. In this condition, half-lives of 32 and 150 days for aerobic and anaerobic soils have been reported ('National Center for Biotechnology Information. PubChem Compound Database; CID=3224, https://pubchem.ncbi.nlm.nih.gov/compound/3224 (accessed Dec 8, 2018).'). If released to water, the suspended solids could adsorb the endosulfan and under aerobic and anaerobic conditions the half-life varies between 2 and 8 days, respectively ('National Center for Biotechnology Information. PubChem Compound Database;CID=3224, https://pubchem.ncbi.nlm.nih.gov/compound/3 224 (accessed Dec 8, 2018).'). Therefore, with regard to these various physico chemical features and behaviors of the studied pesticides, the difference in observed and simulated results can be understood.

Moreover, organochlorine pesticides also have a low tendency for solubility in water, making this feature to be found in small values of WSOL parameter. The sensitivity of Skoc differed among the pesticides depending on the kind of pesticide. Therefore, $\mathrm{a}-\mathrm{HCH}$ was more sensitive to changing $S_{k o c}$ than Methoxychlor and endosulfan-sulfate. It is noticeable when $S_{k o c}$ is increased in a specific kind of pesticide, the expected amount of washed pesticide will decrease (Kannan et al. 2006). This issue can also affect the WOF parameter. Therefore, selecting a proper amount of $S_{к о с}$ can influence the coherence between simulated and measured pesticide values.

Generally, there was a better match between estimated and measured concentrations in the Upper Malewa (2GB04) than in the Down Malewa station (2BG05). One of the reasons that may explain this result is that at the upper site it takes less time for runoff and pesticides to reach the outlet of the subbasin and consequently there is a quicker response to changes. In moving from Upper Malewa to Down Malewa, the hydrological contribution increases, as does the complexity of accurately predicting the concentrations of pesticides. This issue is added to the increasing time for an amount of the pesticides to reach the basin outlet, affecting the mechanism of pesticide conveyance and the breakdown of pesticides into soluble and sorbed phases (Kannan et al. 2006). This may also be true for the application time. Changing the time of application of pesticides impacts on the arrival of the pesticides at the basin outlet (Bannwarth et al. 2014) and consequently changes the amount of pesticide that leaches from the soil surface particles. Therefore the best time to achieve good results in this study 
was from the mid-May, which coincided with the rainy season and the time of agricultural activity and pesticide application. It should be noted that defining a fixed application operation in such a vast basin is practically impossible (Bannwarth et al. 2014; Doppler et al. 2012). The timing may vary depending on the farmers willingness, weather conditions, plant properties and existing pests that may change spatially and temporally (Chen et al. 2017). This will influence the fluctuation in pesticides in the streams and, accordingly, the uncertainties of the simulations.

Additionally, the accuracy of pesticide simulations strongly depends on the hydrology calibration of the model (Luo et al. 2008). In fact, because of the challenges that are associated with the large numbers of input data, their variability and consequently the uncertainties that arise, satisfactory modeling is always wrought with difficulties (Schuol et al. 2008). Simulating pesticides in this study after hydrological calibration and validation showed that the main pesticide loadings occurred at the time of peaks in runoff and sediment loads. The main governing factor in runoff and sediment producing is the major rainfall occurring during May-June-July. Amoung the studied pesticides, a- $\mathrm{HCH}$ is least likely to adhere to soil and sediment particles. This leads to the conclusion that a-HCH will be mostly translocated by runoff. In contrast, methoxychlor and endosulfan-sulfate have a large Skoc, meaning that they have a high tendency to cling to be absorbed by soil and sediment particles and consequently the main force of transport will be via erosion and sediment loading. This means that the better hydrological processes are modelled, the more reliable the pesticide results could be.

\subsection{Conclusion}

In this study, a modeling approach using SWAT was conducted to simulate the discharge, sediment loading and pesticides residues transport regarding a-HCH, methoxychlor and endosulfan-sulfate in the river Malewa basin. The SWAT-CUP tool was used to calibrate the model for discharge and suspended sediment simulations. It was found that 16 parameters affected calibration, of which the CN parameter proved most sensitive to spatial changes. The statistical analysis showed that both the calibration and validation periods of discharge were promising. Moreover, calibration of the model for monthly sediment simulation showed that, despite slightly overestimating the results of the simulation, the overall performance of the model could be rated acceptable. The average monthly sediment production and the differences in sediment amounts in the sub-basins could be 
explained by precipitation, slope variation and land use properties in the basin. Moreover, the use of a digital turbidity sensor (DTS-12) is recommended for calibration of the sediment yield sub-model in SWAT. Finally, simulating pesticides could provide a good insight into historical pesticide application in the basin. Some of the parameters, namely SKOC, WOF, HLIFE_F, HLIFE_S, WSOL and AP_EF, were sensitive to calibration of the pesticide sub-model. AP_EF showed the highest sensitivity towards all the pesticides. The results revealed that the amounts of pesticide generally increased from the Upper Malewa to the Down Malewa. Passive sampling was judged to be an essential method in detecting low concentrations of pesticide residues in runoff of the Malewa river. In this study we used a limited but considered high quality (passive sampling with low detection limit) data set of pesticide measurements in the basin. Further investigation of the fate and transport of pesticides using longer series of data and use of more advanced physicochemical models is recommended to overcome the uncertainty that arises from limited in-situ measurements combined with simplifying model formulations.

Acknowledgments: The authors thank the Water Resources Management Authority (WRMA) and WWF in Naivasha that provided the discharge data and contributed in the passive sampling campaign. The Laurel flower farm (Naivasha) for helping us with instruments maintenance.

Author Contributions: Yasser Abbasi designed and conducted the fieldwork and data collection, model calibration-validation and writing the paper. Chris Mannaerts (C.M.) and Yasser Abbasi developed the research objectives and conducting of methods. Chris Mannaerts also verified the model simulation results and contributed to editing of the paper. William Makau was involved in the field data collection and the model simulations.

Funding: This research received no external funding.

Conflicts of Interest: The authors declare no conflict of interest. 


\section{Chapter 4 : Exploring the Environmental Exposure of the Lake Naivasha (Kenya) to Pesticides Residues Using a Multimedia Fate Modelling Approach ${ }^{1}$}

\footnotetext{
1 This chapter is based on: Yasser Abbasi and Chris M. Mannaerts, Exploring the Environmental Exposure to Methoxychlor, a-HCH and Endosulfan-sulfate Residues in Lake Naivasha (Kenya) Using a Multimedia Fate Modeling Approach. Int. J. Environ. Res. Public Health 2020, 17(8), 2727; https://doi.org/10.3390/ijerph17082727
} 
Exploring the environmental exposure of the Lake Naivasha (Kenya) to pesticides residues using Multimedia fate modeling approach

\begin{abstract}
Distribution of pesticide residues in the environment and their transport to surface water bodies is one of the most important environmental challenges. Fate of pesticides in the complex environments, especially in aquatic phases such as lakes and rivers, is governed by the main properties of the contaminants and the environmental properties. In this study, a multimedia mass modeling approach using the Quantitative Water Air Sediment Interaction (QWASI) model was applied to explore the fate of organochlorine pesticide residues of Methoxychlor, a-HCH and endosulfan-sulfate in the lake Naivasha (Kenya). The required physicochemical data of the pesticides such as molar mass, vapour pressure, air-water partitioning coefficient (KAw), solubility, and the Henry's law constant were provided as the inputs of the model. The environment data also were collected using field measurements and taken from the literature. The sensitivity analysis of the model was applied using One At a Time (OAT) approach and calibrated using measured pesticide residues by passive sampling method. Finally, the calibrated model was used to estimate the fate and distribution of the pesticide residues in different media of the lake. The result of sensitivity analysis showed that the five most sensitive parameters were Koc, logKow, half-life of the pollutants in water, half-life of the pollutants in sediment, and $\mathrm{K}_{\mathrm{AW}}$. The variations of outputs for the three studied pesticide residues against inputs were noticeably different. For example, the range of changes in the concentration of a-HCH residue was between $96 \%$ to $102 \%$, while for Methoxychlor and endosulfan-sulfate was between $65 \%$ to $125 \%$. The results of calibration demonstrated that the model was calibrated reasonably with the $\mathrm{R}^{2}$ of 0.65 and RMSE of 16.4 . It was found that Methoxychlor had a mass fraction of almost $70 \%$ in water column and almost $30 \%$ of mass fraction in the sediment. In contrast, endosulfansulfate had highest most fraction in the water column (>99\%) and just a negligible percentage in the sediment compartment. a-HCH also had the same situation like endosulfan-sulfate (e.g., $99 \%$ and $1 \%$ in water and sediment, respectively). Finally, it was concluded that the application of QWASI in combination with passive sampling technique allowed an insight to the fate process of the studied OCPs and helped actual concentration predictions. Therefore, the results of this study can also be used to perform risk assessment and investigate the environmental exposure of pesticide residues.
\end{abstract}

Keywords: organochlorine pesticides; fate modeling; QWASI model; multimedia; passive sampling 


\subsection{Introduction}

The contamination of water bodies by pesticides residues that can originate from agricultural application is considered as one of the most important environmental issues (Herrero-Hernández et al. 2013; Kapsi et al. 2019). The residues of the applied pesticides can be transported using surface runoff and pollute the water resources. This issue could be influenced by several factors such as physico-chemical properties of the pesticides, topography, soil properties and weather conditions (Konstantinou, Hela, and Albanis 2006). Among different environmental compartments, surface water resources are considered as an important ecosystems that offer a useful environmental service for human and the nature. But it is a fact that these sources are very sensitive as they are under presser by the human activities that cause the pollution by chemicals emissions (Bao et al. 2012; Kong et al. 2018; Kwadijk, Korytar, and Koelmans 2010).

When the chemicals are emitted to environment, their fate and distribution in the multimedia environments (e.g., aquatic phases such as lakes) is governed by the main properties of the contaminates such as basic features (e.g., melting point, vapor pressure, partitioning coefficients between soil, sediment and water) (Gramatica and Di Guardo 2002). The natural processes also can changes the interaction of the chemicals among environmental compartments and causes the complexity of predicting their pathways by which the chemicals could enter. Consequently, it is more difficult to study the environmental exposure to the pollutants which depends on their fate in environment (Mohamed and Paleologos 2018). The pollutants properties which control the tendency of the pollutants to be transported among different phases are important in assessment of the pollutants behavior in environment. This information is the initial inputs for the models to describe the fate and variations of the chemicals.

By using the mathematical equations it is possible to explain the partitioning, variations of the chemicals and their movements. For this aim, the chemicals properties of the pollutants variations such as their movements to different media and the tendency of partitioning, the mechanisms of chemicals loss, the leaning of the chemicals for exchange with other media and their persistency have to be considered. The importance of any one of these parameters and their influence on the chemicals fate can be also evaluated using the sensitivity analysis(Mackay et al. 1996). There is a series of models in different level of complexity that are categorized as Level I, II, and III which help to fully understand how the properties of the pollutants as well as the environmental features can affect the fate and conveyance of the chemicals. The main features of these models have been described by(Mackay 2001). The Level I explains the equilibrium dispersion of a specific amount of the pollutant among various 
Exploring the environmental exposure of the Lake Naivasha (Kenya) to pesticides residues using Multimedia fate modeling approach

environmental phases. Level II model applies the effect of half-life of the pollutant in different environmental compartments to explain their fate. The Level III model which is the most complex level consists of all the procedures which affect the transport and fate of the pollutants in an actual environment. In summary, these fugacity based models are easy to understand and apply for assessment of the fate of longterm variation of chemicals(Seth and Mackay 2001).

With regard to the difficulty of studying the chemicals variations in environment (e.g., air, water, soil, sediment and biota) using multimedia models is necessary to estimate the fate and transfer of the pesticides(Xu et al. 2013). The chemicals that are nonreactive and persistent against degradation can remain in the environment for long time and make drastic disasters by entering and accumulating in environment. For such pollutants, it is proposed to use the models with multimedia mass balance approach(Seth and Mackay 2001). The fugacity models(Mackay 2001) that are used for this aim can help by simplifying the calculations. Among different multimedia models, the fugacity model by(Mackay 1979) has been used successfully in many case studies to evaluate the fate of chemicals (Xu et al. 2013; Lang et al. 2008; Wang et al. 2011). Many of the studies quantify the fate and exchange of the chemicals in the nature by considering the steady or unsteady conditions (Huang et al. 2019; Jung et al. 2014; Kim and Lee 2017). The Quantitative Water Air Sediment Interaction (QWASI) fugacity model(Mackay, Paterson, and Joy 1983) is one of the models that have been used to explore the chemicals (e.g., pesticides and heavy metals) by many researchers (Xu et al. 2013).

The QWASI model was established based on the fugacity perception that has been widely used (freely available) in the fate modeling of the chemicals in environment (Mackay et al. 2014). The QWASI model assumes a well-mixed aquatic environment as well as mass balance procedure. In this model, the mass balance equations have been applied to establish a steady state condition for the both sediment and water media. Moreover, this concept is applied for chemicals content using fugacity model. It is notable that the model can be also modified to one and two order differential equations for the dynamic situations then be calculated numerically or analytically. The models then are easily understood and interpreted because the procedures are presented using the fugacity concept that allows understanding the pollutants diffusion, reaction and advection conveyance (Mackay et al. 2014).

In this study, the multimedia mass modeling approach was applied to explore the fate of organochlorine pesticides residues in the lake Naivasha (Kenya). Naivasha lake is one of the most important fresh water resources in the region. It provides irrigation water for most of 
the riparian farms in the area as well as the fresh water for domestic drinking and supports a variety of wildlife around the lake wetland ecosystem (Gitahi, Harper et al. 2002). However, the previous studies showed the residues of some organochlorine pesticides (OCPs) in the water resources of Naivasha (Gitahi, Harper et al. 2002, Abbasi and Mannaerts 2018). Based on the Secretariat of the Stockholm Convention on Persistent Organic Pollutants, these pesticides are categorized as the persistent chemicals (UNEP 2009) that their residues can remain in the environment for a long time. In addition to the studies mentioned earlier, several recent researches have applied QWASI or other kinds of modelling approaches (Fang, Zhang et al. 2016, Hu, Liu et al. 2017, Wu, Davie-Martin et al. 2017, Bonnell, Zidek et al. 2018, Guo, Zhou et al. 2019, Wang, Khan et al. 2020). In most of these studies, fugacity models have been applied to explore the fate of chemical residues in different media. In this study also the multimedia modeling approach in combination with measured low concentrations of pesticide residues using the passive sampling method combined with laboratory gas chromatography of the lake Naivasha water was applied, which is the novelty of this study, with respect to other studies for predicting the distribution and fate of pesticide residues. Finally, due to the high concentration of Lindane residue (e.g., a-HCH), Endosulfan-Sulfate and Methoxychlor (Abbasi and Mannaerts 2018), it was decided to explore the fate of these residues in the aquatic environment of Naivasha.

\subsection{Materials and methods}

\subsubsection{Data acquisition}

In this study, the fugacity multimedia model of QWASI (Mackay, Paterson, and Joy 1983) was used to evaluate the environmental exposure to a-HCH, Endosulfan-sulfate and Methoxychlor pesticides residues. This model is a steady state non-equilibrium (Level III) multimedia fate and transport model which was designed specifically to represent processes operating in lakes(Whelan 2013). Chemical behaviour is represented in the model using fugacity concepts(Mackay 2001). The processes considered by the model and the studied area are shown schematically in Figure (4-1). 
Exploring the environmental exposure of the Lake Naivasha (Kenya) to pesticides residues using Multimedia fate modeling approach

The model needs the physico-chemical data of the pollutants as well as the environmental properties data as inputs information to calculate the level of pollution in every environmental compartment. The physico-chemical properties of a-HCH, Methoxychlor and Endosulfansulfate are presented in Table (4-1). After providing information of molar mass, vapor pressure, solubility of the chemicals and the intended temperature, the model is able to calculate the Henry's law constant as well as the Air-Water partitioning coefficient (KAW). Based on different studies(Mackay et al. 2014; Xu and Kropscott 2012) the measured $K_{A W}$ amounts that reported in the literatures are significantly different than each other among which the analytical technique established by Xu and Kropscott (Xu and Kropscott 2012) is the most suitable method (Mackay et al. 2014). The Henry's law constant and the Air-Water partitioning coefficient (KaW) were calculated as follow:

$$
\mathrm{H}: \mathrm{P} / \mathrm{S} \times \mathrm{M}
$$

Where $\mathrm{H}$ is Henry's law constant, $\mathrm{P}$ is vapour pressure $(\mathrm{Pa}), \mathrm{S}$ is the chemical solubility in water $(\mathrm{mg} / \mathrm{L})$ and $M$ is the molar mass $(\mathrm{g} / \mathrm{mol})$. Consequently, the Kaw coefficient was calculated by considering the Henry's constant and the temperature as follows:

$$
\mathrm{K}_{\mathrm{AW}}=\mathrm{H} / \mathrm{RT}
$$

Where $\mathrm{H}$ is Henry's law constant, $\mathrm{R}$ is the gas constant (8.314 $\mathrm{J} \cdot \mathrm{K}^{-1} \cdot \mathrm{mol}^{-1}$ ) and $\mathrm{T}$ is the temperature at the Kelvin scale (K). Mackay et al. (Mackay et al. 2014) used the next equation also to calculate $K_{A W}$ at a specific temperature:

$$
K_{A W}(T)=K_{A W}\left(T_{r}\right) \cdot \exp \left(\frac{\Delta U_{A W}}{R}\left(\frac{1}{T_{r}}-\frac{1}{T}\right)\right)
$$

with $\Delta U_{\mathrm{AW}}=92.7 \mathrm{~kJ} / \mathrm{mol}$.

The next coefficient which is used by the model is the Organic carbonwater partition coefficient (Koc). Karickhoff (Karickhoff 1981) found that this factor could almost totally govern the sorption capability of sediment. Consequently, the partitioning tendency between water and sediment which is represented as Koc coefficient can be connected to Octanol-Water partitioning coefficient (Kow). He developed the relationship between these two coefficients using experiments with different soil organic matter percentage and pollutants that had different Kow (Mackay et al. 2006). Then the Koc factor is calculated from Kow as follow:

$$
\mathrm{Koc}=0.41 \mathrm{Kow}
$$

Additionally, the model takes the half-lives of chemicals into account both in the aquatic and sediment environments to evaluate their fate. The half- life of every individual chemical depends on both the physicochemical properties of the pollutant and the environmental properties. The model estimates the reaction half-life at different temperatures using the activation energy $(\mathrm{J} / \mathrm{mol})$ in a desired temperature $\left({ }^{\circ} \mathrm{C}\right)$ as below: 


$$
\tau_{T}=\tau_{298.15} \exp \left[\frac{E_{A}}{R}\left(\frac{1}{T}-\frac{1}{298.15}\right)\right]
$$

Where $E_{A}$ is the activation energy $(\mathrm{J} / \mathrm{mol})$ and $T$ is the temperature (converted from ${ }^{\circ} \mathrm{C}$ to $\mathrm{K}$ ) and $\mathrm{R}$ is gas constant $\left(8.314 \mathrm{~J} \cdot \mathrm{K}^{-1} \cdot \mathrm{mol}^{-1}\right.$ ).

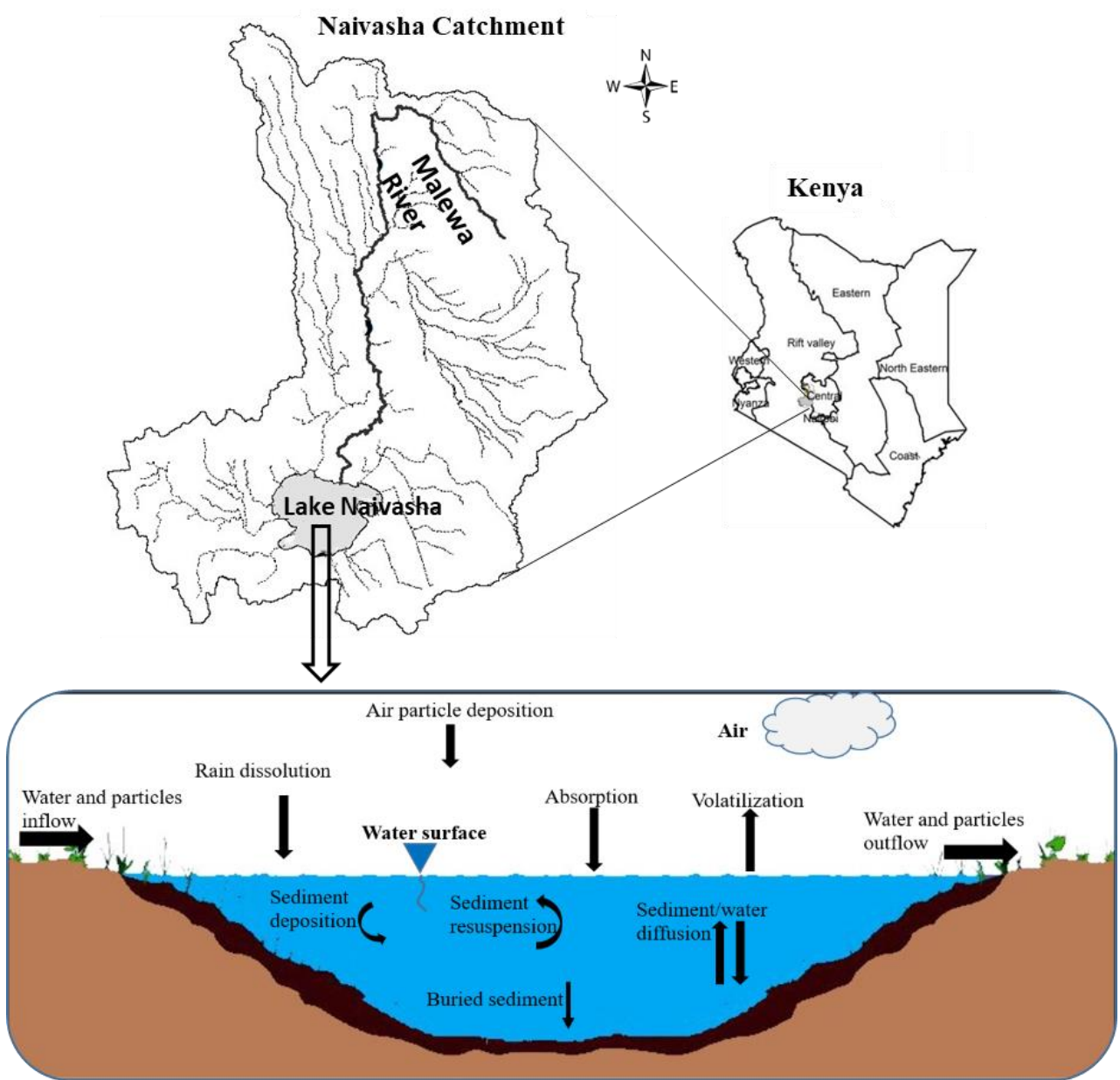

Figure 4-1-Schematic profile of the lake Naivasha and representation of the QWASI model (reproduced partly from Whelan 2013) for different environmental compartments

In addition to the chemicals data, the QWASI model needs the environment data to predict the fate of pollutants. The details of the environmental input data (Table 4-2) are explained in the following section. 


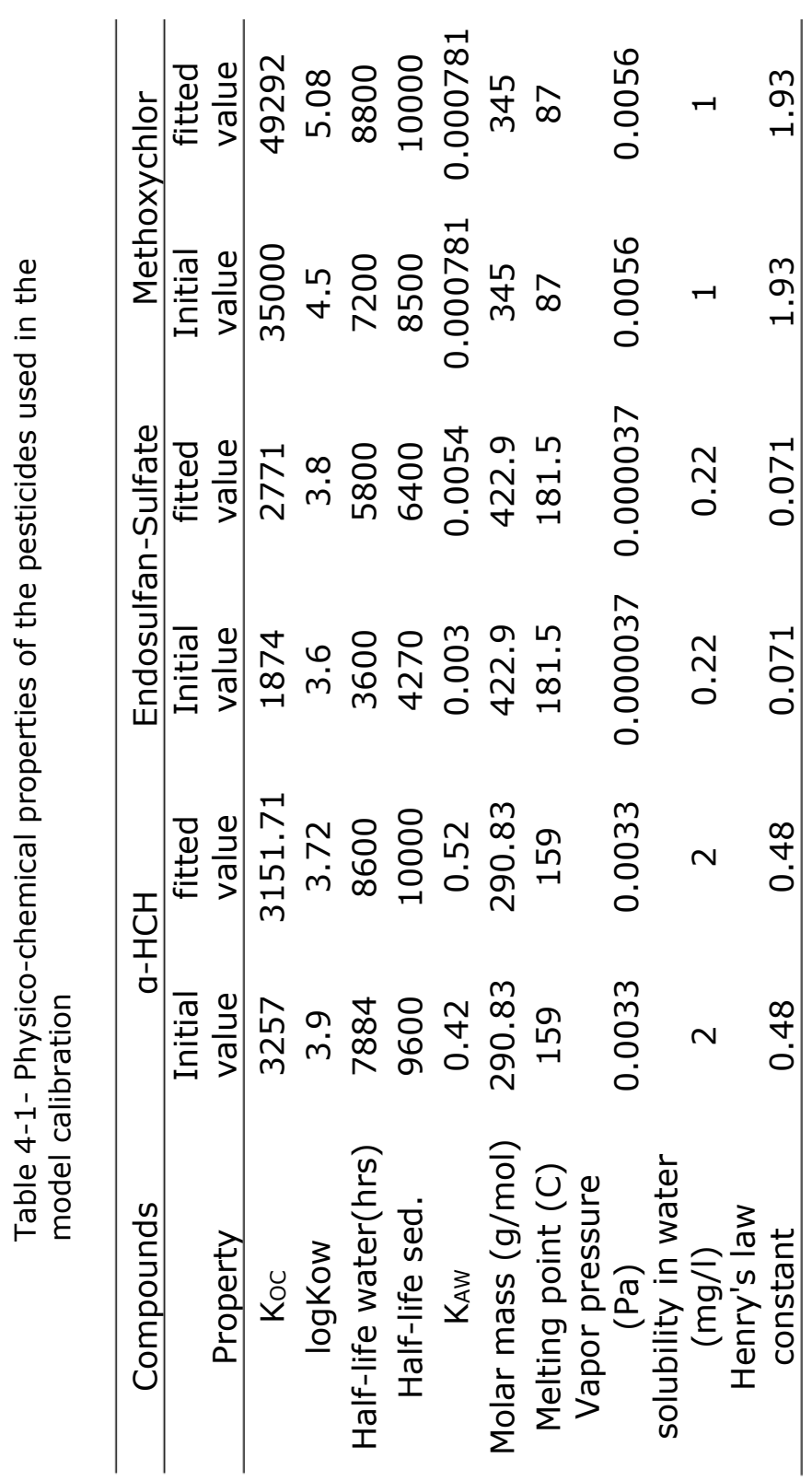




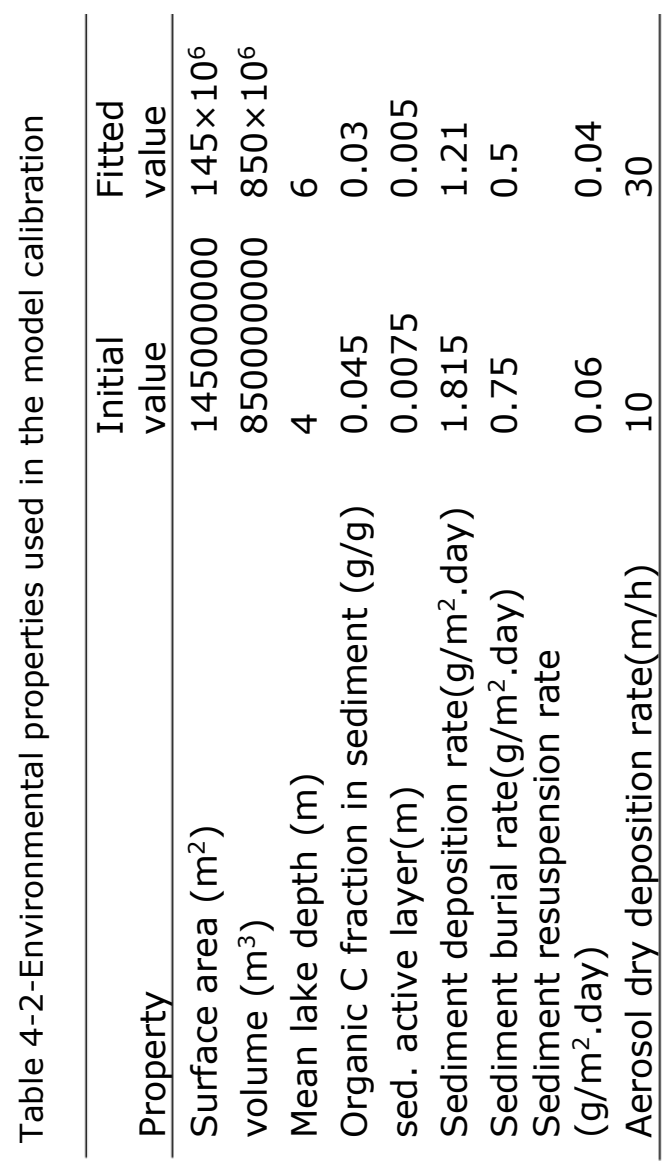

\subsubsection{Environment characteristics}

Lake Naivasha is one of the fresh water resources which is in the Eastern Rift valley of Kenya with the Latitude of $00^{\circ} 46^{\prime}$ to $00^{\circ} 52^{\prime}$ and Longitudes $36^{\circ} 15^{\prime}$ to $36^{\circ} 25^{\prime}$ in zone $37 \mathrm{~S}$ UTM (Figure 1 ). The most important streams in the Lake Naivasha basin are Malewa, Gilgil and Karati rivers. The main inflow to the lake is Malewa river which provides up to $80 \%$ of the total inflow into the Lake(Becht, Odada, and Higgins $2010 \mathrm{~b})$ but there is not any identifiable outlet from the lake. Another input to the lake comes from the rainfall which occurs from March to June as the long wet season and from October to early December as short wet season. The dry months also start from December to 
Exploring the environmental exposure of the Lake Naivasha (Kenya) to pesticides residues using Multimedia fate modeling approach

February and from July to September but these durations may change over the years. Agriculture is one of the major part of the basin which can cause a high potential of the pollution in the water resources of the region by using the agrochemicals.

The main environmental parameters of the lake Naivasha as inputs of QWASI model are presented in Table (4-2). Some of these parameters such as the lake dimensions, inflow, suspended sediments and organic carbon content were measured in the field for this study, but there are several studies also that have already reported environmental parameters of the lake Naivasha (Ayenew, Becht et al. 2007, Becht, Odada et al. 2010, Stoof-Leichsenring, Junginger et al. 2011). The volume of the lake was determined using remote sensing data for the lake surface area, bathymetric data and geographic information system (e.g. GIS tools). It is obvious that the depth of the lake changes during the dry and wet seasons. However, in this study we used the average depth of the lake during the sampling in June-July 2016.The thickness of active sediment layer is also a required parameter as an environmental input for the model. This parameter can be changed both temporally and spatially and is difficult to directly measurer. Therefore, the initial amount of this input data was selected as the default value in the model and finally was fitted in the calibration process. The concentration of the solids was measured during the field data collection using $0.45 \mu \mathrm{m}$ filter paper. For the remaining parameters such as aerosol deposition, volatilization, sedimentation and sediment resuspension, the initial amounts in the model were used then they were modified during the calibration process.

\subsubsection{Pesticides properties}

In this study the fate of three kinds of pesticides residues were explored. Lindane was used in the past for protecting fruits, vegetables and animals against the insects. The isomers of Lindane (e.g., a-HCH, $\beta-\mathrm{HCH}, \gamma-\mathrm{HCH}, \delta-\mathrm{HCH}$ ) can remain in environment for long time and are considered as the persistent organic pollutants (POPs) by Stockholm Convention on Persistent Organic Pollutants (Abbasi, Mannaerts, and Makau 2019). The environmental properties and the interchanges between this pesticide and the environment can influence its fate. The environmental fate of $\mathrm{a}-\mathrm{HCH}$ is governed by environmental effects and its interactions with environment as well as the inherent properties (e.g., physical and chemical)(ATSDR 2005). Based on the environmental conditions, Methoxychlor also can have a half-life of less than five hours to several months(ATSDR 2002). For instance, in the sediment has a half-life of 28days and more than 100 days in anaerobic and aerobic conditions, respectively(ATSDR 2002). These properties allow the Methoxychlor to remain in environment for a long time and 
enter the water bodies via different ways such as wind and runoff. Endosulfan-sulfate also has a high acute toxicity as another POP that by its degradation endosulfan sulfate is produced (Medicine 2019). However, the fate of endosulfan sulfate also, like other chemicals, is up to the environmental conditions. When it is entered the water resources, the residues of this pesticides residue can be adsorbed by the suspended particles while in the soil its fate is governed by the Koc value of the soil which has a slow movement(Medicine 2019).

In this study, the physicochemical properties of the mentioned pesticides were taken in to account for modeling their fate. It is noticeable that as these parameters are variable and direct measuring in the field is almost impossible, therefore the initial values in the literatures were used, then based on the measured concentrations of the pesticides residues were revised. Moreover, the concentration of the pesticide residues in the lake and the rivers that inflow to the lake also was measured using the passive sampling method followed by laboratory gas chromatography (GC-ECD and GC-MSMS) (Abbasi and Mannaerts 2018). In addition to the concentrations in water, some reference samplers were used to measure the pesticides concentration in the air that showed the pesticides content in the air was below detection limit. Therefore, in this study we assumed that the concentrations of the pesticides in the air were zero as the model input.

\subsubsection{Sensitivity analysis and calibration}

Usually the input data for the modeling process are subjected to uncertainties. Therefore the effect of the uncertainty of the data was explored using sensitivity analysis (Buser, MacLeod et al. 2012) for which the most influencing parameters were selected carefully. For this aim, the sensitivity analysis using one at a time (OAT) approach was conducted for evaluating the chemical and environmental parameters (Macleod, Fraser et al. 2002, Whelan 2013). In this method, the values of desired parameters were changed gradually and their effect on the results were explored. The magnitude of the yield parameters as $Y$ and the input parameters as $X$ were considered that resulted a $S$-matrix as below (Mackay, Hughes et al. 2014):

$$
S=\frac{\delta \ln (y)}{\delta \ln (x)}=\frac{\left(\frac{d y}{y}\right)}{\left(\frac{d x}{x}\right)} \sim \frac{\left(\frac{\Delta y}{y}\right)}{\left(\frac{\Delta x}{x}\right)}
$$

Where $\Delta x / x$ is the partial changes in the input data and $\Delta y / y$ represents the fractional change in the result. It is noticeable that the results can be positive or negative that explain if changing the inputs can increase or decrease the outputs. 
Exploring the environmental exposure of the Lake Naivasha (Kenya) to pesticides residues using Multimedia fate modeling approach

Moreover, as the initial values of the input data are mostly different from the actual values to match the model with the measured data, the results can contain error that requires a suitable calibration to decrease the uncertainty of the outputs. Therefore, the model was calibrated based on the most sensitive parameters. The values of the parameters were adjusted until the best fit between measured and simulated results was observed (Table 4-1 and 4-2). The average of calibrated model's estimates was compared to the measured concentrations graphically (Figure 4-5). In addition to this, the results of the calibrations were evaluated using the objective functions Rsquared $\left(R^{2}\right)$ and root mean square error (RMSE). These two functions show how well the model is calibrated as the more $R^{2}$ is close to 1 and RMSE is smaller, the better the model has been calibrated.

\subsection{Results and discussion}

The results of sensitivity analysis of the parameters in the model are demonstrated in Figures (4-2 - 4-3) and consequently the fitted values for the calibrated model are represented in Tables (4-1 and 4-2). The results showed the most five sensitive parameters were Koc, logKow, Half-life of the pollutants in water, Half-life of the pollutants in sediment and $\mathrm{K}_{\mathrm{AW}}$. It is notable that some of these parameters such as the half-lives were included uncertainty as they have been reported in different studies for different conditions. Therefore defining a constant value was not reasonable; thus the calibration procedure allowed estimating a suitable amount in the reported ranges(ATSDR 2002, 2005). The sensitivity analysis showed that the percentage of the variations of the outputs (e.g., the concentration of the pollutants in either sediment or water) against the change of the inputs parameters was different (Figures 4-2 - 4-4). Moreover, the behavior of the three studied pesticides residues were obviously different than each other. For example, the range of changes in the concentration of a-HCH residue was between $96 \%$ to $102 \%$, while for Methoxychlor and Endosulfan sulfate it was almost between $65 \%$ to $125 \%$. This means that selecting a correct amount of the parameters for modeling the Methoxychlor has a higher effect on the results than the modeling of $\mathrm{a}-\mathrm{HCH}$. It is notable that mass balance models simplify the complex processes of the chemicals fate. However, the results of such a model should be able to reflect the fate and the movement procedure of the pollutants (Mackay et al. 2014). Moreover, it is important to explain the scale of the uncertainties which could be involved in the modeling results(Mackay et al. 2014; Macleod, Fraser, and Mackay 2002; Saltelli et al. 2006). 
With regard to analyzing the sensitivity of different pesticides responses to the parameters changes, we assumed that the environmental dimensions were certain enough. Then all of the environmental features analysis were limited to some parameters such as sediment active layer, sedimentation and similar factors or chemical interaction factors in different media that can govern the fate and transformation of the chemicals(Whelan 2013). The parameter of KOC was found to be the key factor in the sensitivity analysis of a-HCH concentrations, both in the water and sediment, in which by increasing the amount of this parameter, the variations of the concentration was also increased. However, this parameter was in lower importance in changing the concentration of endosulfan-sulfate and Methoxychlor residues in water and sediment. It was found that the half-lives of the chemicals also had an important role in governing the fate of all three studied pesticides which could confirm that the interaction of the pollutants with the environment as well as their physicochemical properties had significant effect on their existence in different environmental media. Moreover, from the variations of the pollutants concentrations against the physical parameters, it could be understood that some parameters such as sedimentation or sediment resuspension could influence the amount of the pesticides residues in the sediment media than the aquatic phase. Therefore, it is concluded that for determining the fate of the pesticides in any one of the phases (e.g., water or sediment), estimating precise environmental parameters input was required. 
Exploring the environmental exposure of the Lake Naivasha (Kenya) to pesticides residues using Multimedia fate modeling approach

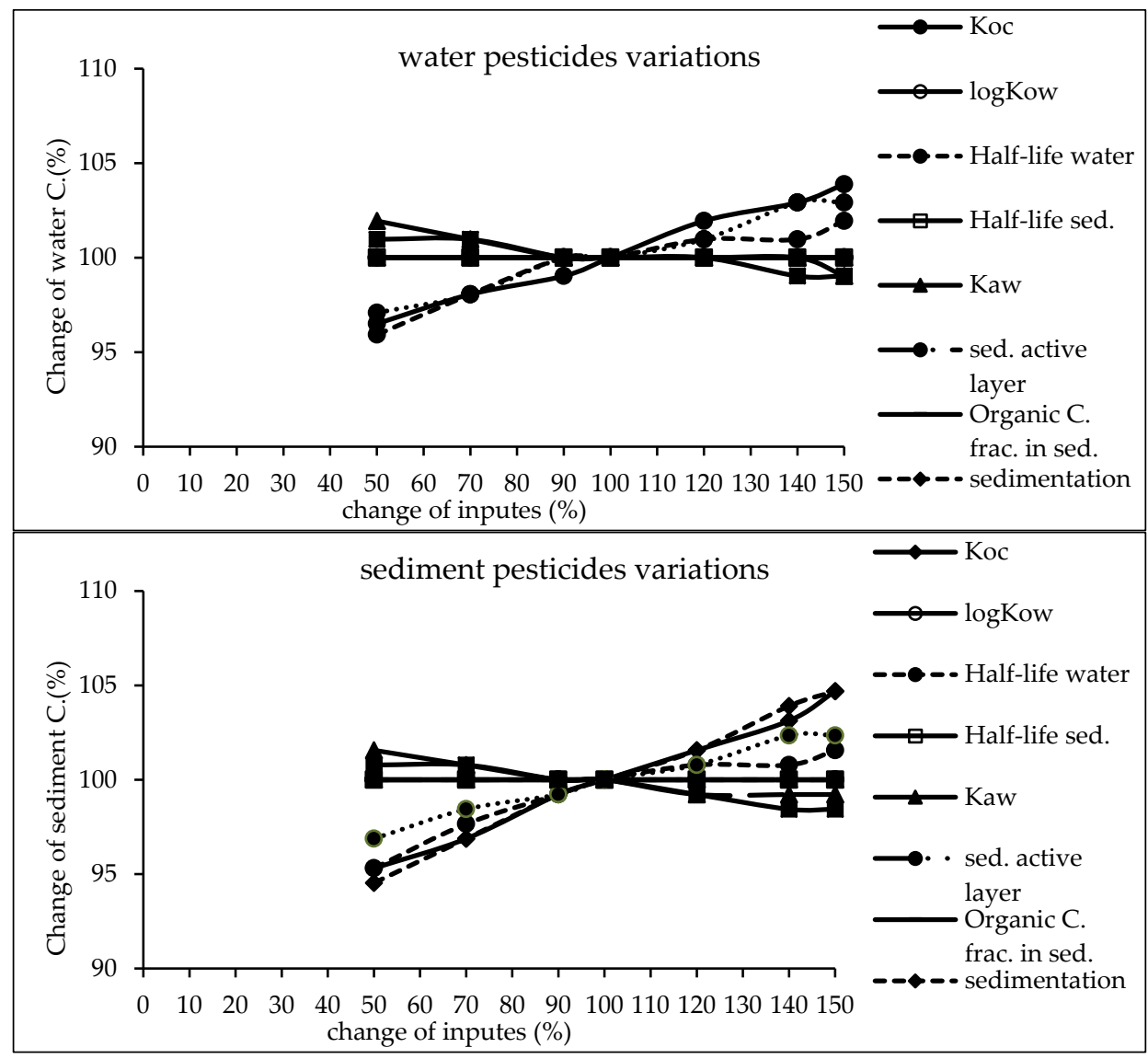

Figure 4-2-Results of the sensitivity analysis for a-HCH in Lake Naivasha 


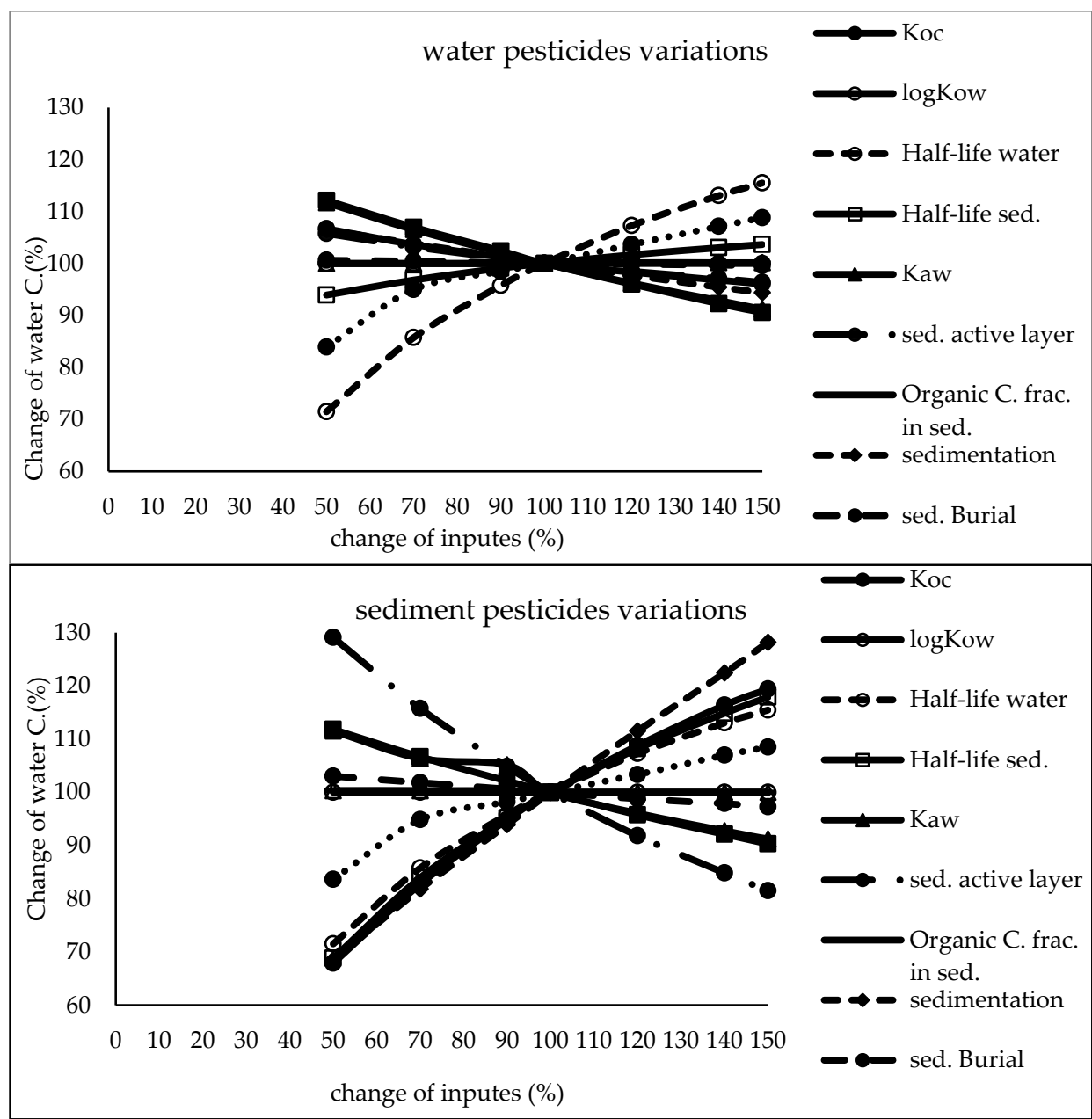

Figure 4-3-Results of the sensitivity analysis for Methoxychlor in Lake Naivasha 
Exploring the environmental exposure of the Lake Naivasha (Kenya) to pesticides residues using Multimedia fate modeling approach

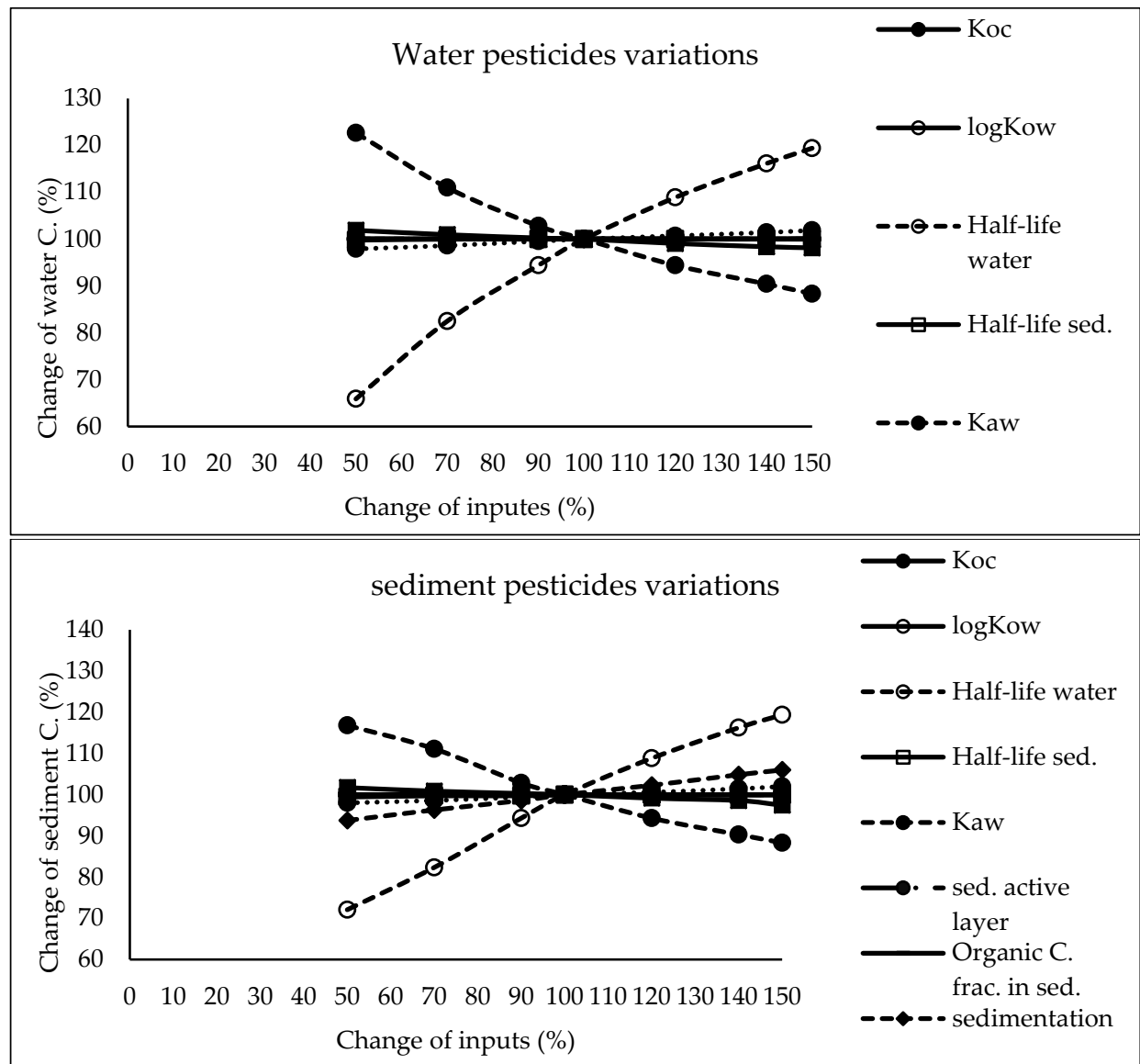

Figure 4-4-Results of the sensitivity analysis for Endosulfan-sulfate in Lake Naivasha

Moreover, as the initial amounts of the input data are mostly different than the actual amounts to match the model with the measured data, the results can contain error that needs a suitable calibration to decrease the uncertainty of the model outputs. With regard to the outcome of the sensitivity analysis, the model was calibrated based on the sensitive parameters. Comparing the average of measured concentrations to the results of the calibrated model (Figure 4-5) demonstrated that the model was calibrated reasonably. The statistical evaluation of the model calibration also showed the R-square of 0.65 and RMSE of 16.4, respectively. Therefore it can be concluded that the model predicts the concentration of the pollutants properly. Based on the study by Moriasi et al. (Moriasi, Gitau et al. 2015), the model results with R-square between 0.30 to 0.65 is considered as satisfactory. In addition to this, using passive sampling method helped 
calibrating the model with high quality database and consequently more reliable results.

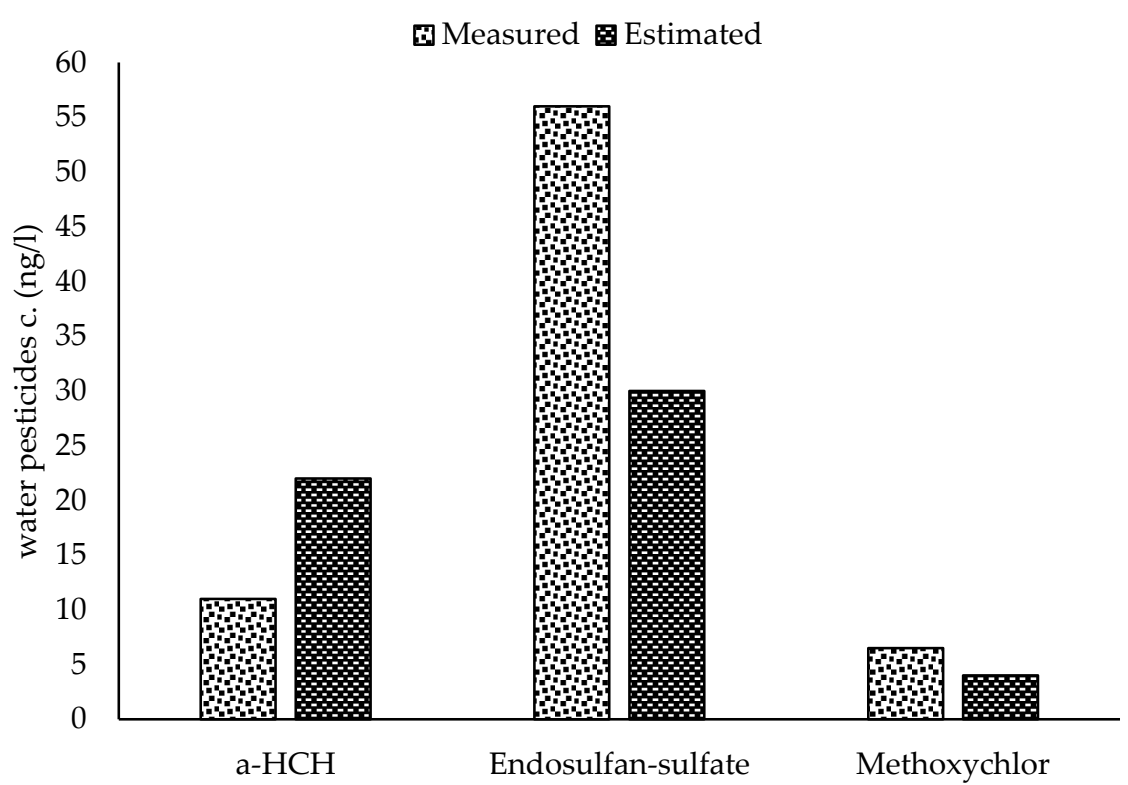

Figure 4-5-Comparison of the average measured and estimated concentrations of pesticides residues in the aquatic phase of Lake Naivasha

In comparison to other studied lakes using QWASI (e.g., study by Mackay et al. (Mackay et al. 2014)) lake Naivasha is a low volume and short retention time lake. Therefore the modeling was based on well mixed water assumption and there was not spatial differences in the lake chemical concentrations. While for the large lakes, the average concentration of the chemical has to be used and a multi compartment model that considers the seasonal variations be applied(Kaur et al. 2012; Mackay et al. 2014). The $D$ values (mol. $\mathrm{Pa}^{-1} \mathrm{~h}^{-1}$ ) are presented in Figure (4-6). These values are parameters which are based on the fugacity amounts and show the process rate $(\mathrm{mol} / \mathrm{h})$ or the transformation of the chemicals(Webster et al. 2006). In another word, the rate of the pollutants process in environment is the product of these $D$ values as well as the fugacity. However, with regard to the process that can affect the fate of pollutants, the results of mass balance modeling of the pesticides residues in the lake are presented in Figures (4-7 - 4-9). It was found that there was significant differences (specially Methoxychlor than another two kinds) between their fate in the lake. These difference could be explained using different half-lives 
Exploring the environmental exposure of the Lake Naivasha (Kenya) to pesticides residues using Multimedia fate modeling approach

and different partitioning coefficients (e.g., $\mathrm{K}_{\mathrm{AW}}$ ) that influenced the tendency of the pollutant for different levels of sedimentation, volatilization or suspension(Hughes et al. 2012). For example, the amount of volatilization of Methoxychlor is the least in which the KAw is also significantly less than a-HCH and Endosulfan-sulfate (Table 4-1). The factor of $\mathrm{Koc}$ is linked to the suspended compounds in the aquatic environment. It was found that Methoxychlor had higher amount of the sedimentation in which the KOC value was more than 18 times bigger than that of a-HCH and Endosulfan-sulfate. The Figures (4.8-4.10) shows the distribution of the chemicals among different media in which the amount of partitioning of $\mathrm{a}-\mathrm{HCH}$ and Endosulfan-sulfate to the sediment is similar (e.g., less than $1 \%$ ) while it is significantly higher (e.g., almost 30\%) for Methoxychlor. This result can confirm the effect of KOC parameter on the fate and trend of the chemicals in environment. The overall residence times of the chemicals were 48, 25 and 302 days for Endosulfan-sulfate, a-HCH and Methoxychlor, respectively, and their depositions were 29,5 and $4 \mathrm{~kg} /$ year. The most important point of these residence times is that, although the residence time is influenced by the half-life of the chemicals, they don't have a linear relation. Because, the residence time and consequently the deposition rates are, in addition to the half-life, governed by the parameters that influence the mass fractions and the loss processes(Mackay et al. 2014).

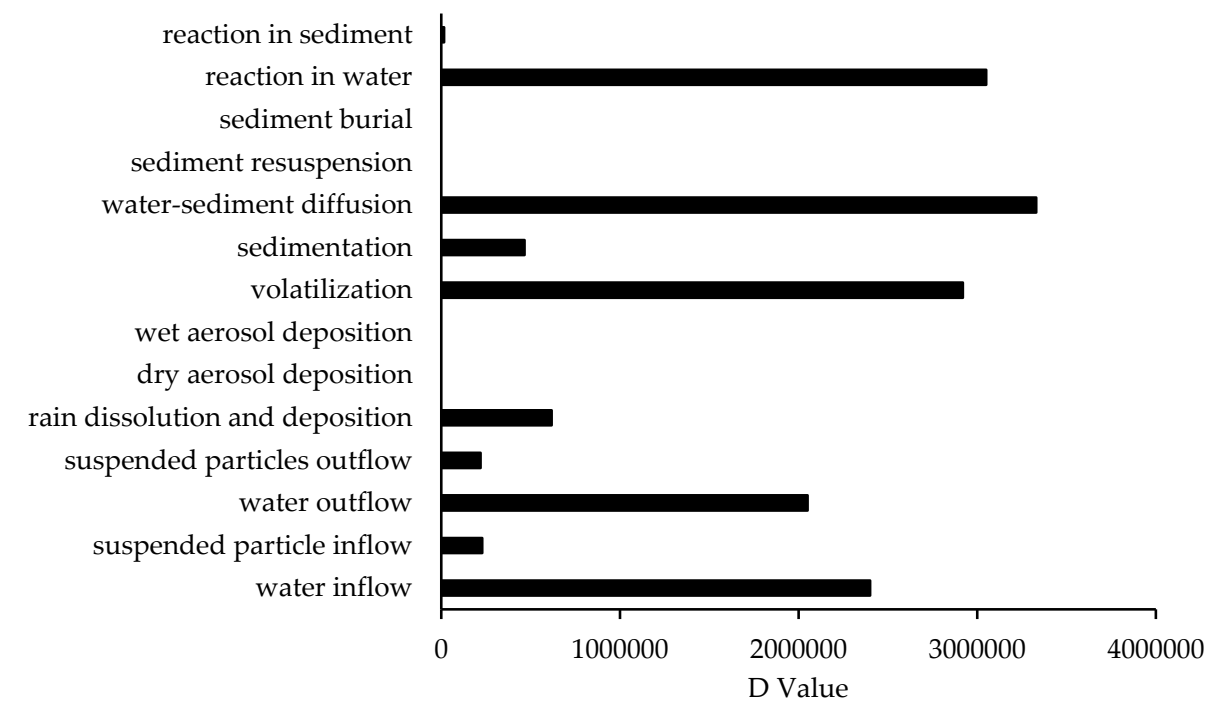

Figure 4-6-The $D$ values of different process that affect the fate of contaminates 
Comparing the predicted amounts of pesticides residues concentrations in the water column and sediment compartment showed that the OCPs residues had different levels of pollutions. It is noticeable that these amount are the outcome of the combination of different factors such as physicochemical properties of the compounds, the emission rates and the environmental criteria. However, based on the available input data for the model, the results showed that Methoxychlor had the mass fraction of almost $70 \%$ in water column and almost $30 \%$ of mass fraction in sediment. In contrast, Endosulfan-sulfate consisted the most fraction in the water column (>97\%) and just 2.2 percent in sediment compartment. $\mathrm{a}-\mathrm{HCH}$ had also the same situation of Endosulfan-sulfate (e.g., $99 \%$ and less than $1 \%$ in water and sediment, respectively), and the absolute magnitude of this compound concentration falls between Endosulfan-sulfate and Methoxychlor. Generally, it can be concluded that in comparison to two other pesticides, Methoxychlor had a higher affinity to sediments that can be mostly related to its high $\mathrm{K}_{\mathrm{OC}}$ and low $\mathrm{K}_{\mathrm{Aw}}$ values which highlights the role of these coefficients in the fate of pesticides residues. In aspect of emission rate also, there was a higher concentration of Endosulfansulfate in the inflow which comes from the lake catchment that resulted more pollution in the lake.

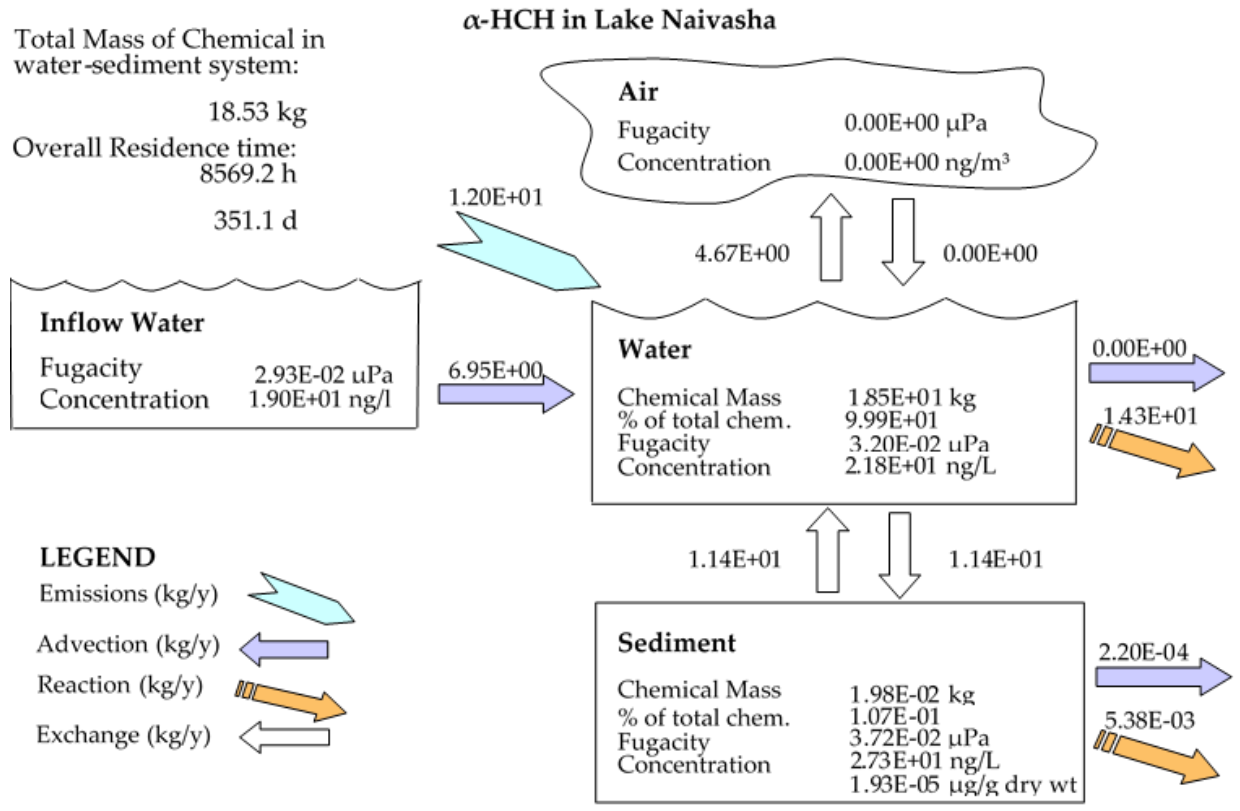

Figure 4-7-Mass balance diagram of a-HCH residues in the lake Naivasha 
Exploring the environmental exposure of the Lake Naivasha (Kenya) to pesticides residues using Multimedia fate modeling approach

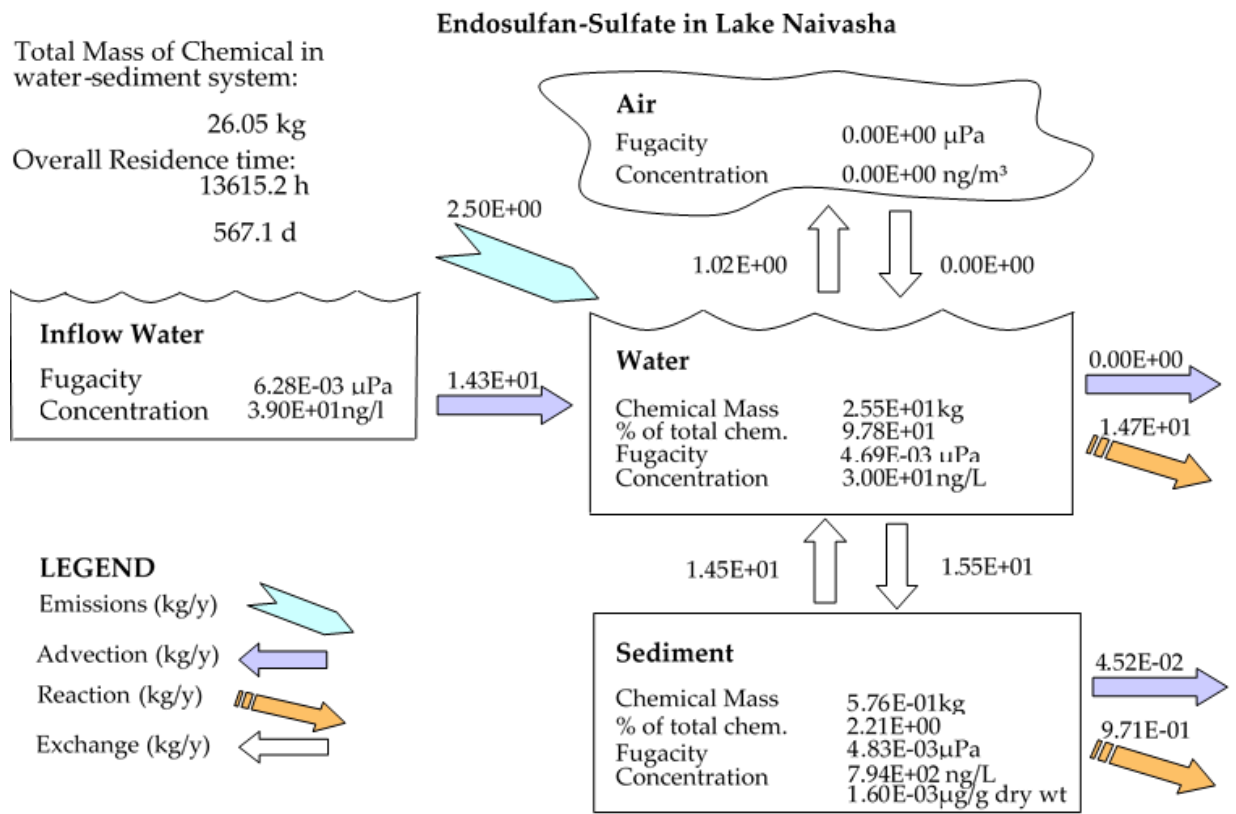

Figure 4-8-Mass balance diagram of Endosulfan-Sulfate residues in the lake Naivasha 


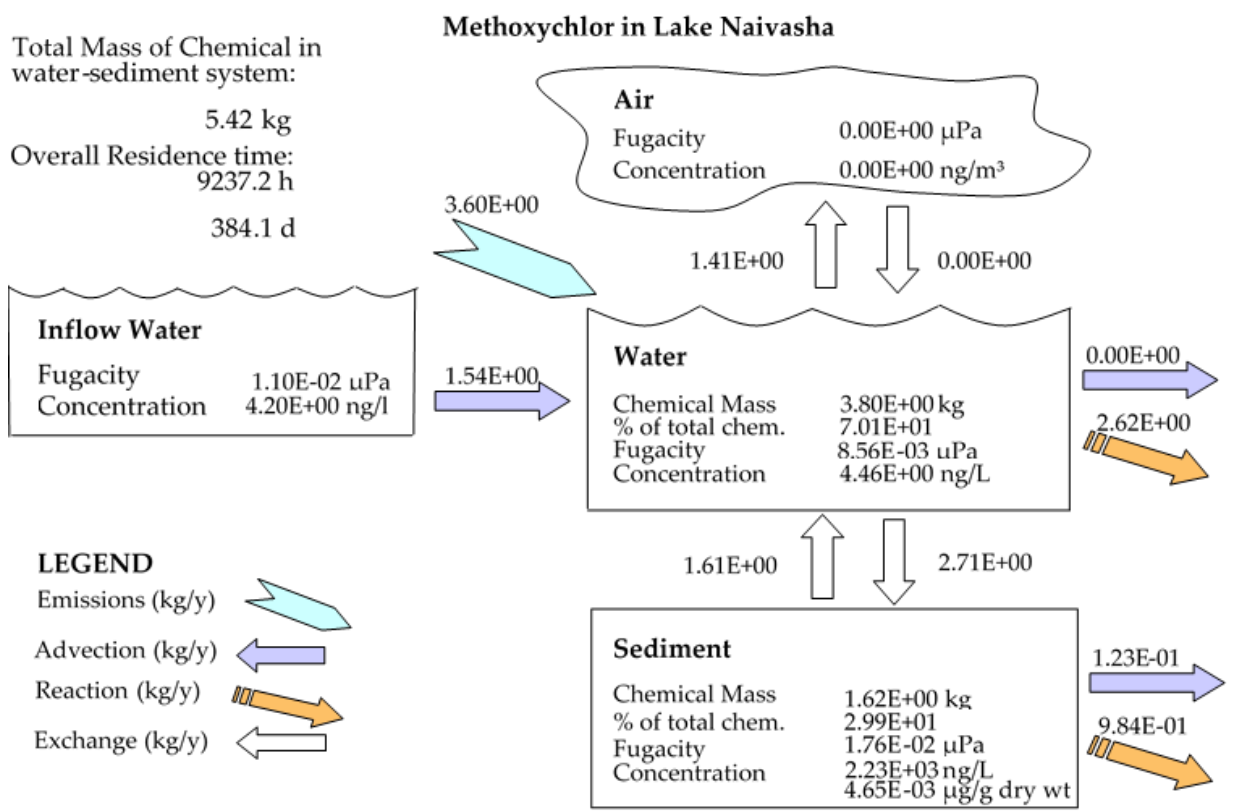

Figure 4-9-Mass balance diagram of Methoxychlor residues in the lake Naivasha

With regard to the pollution sources of the Lake Naivasha, it is notable that this lake is under the effect of the anthropogenic activities in Naivasha catchment which is located in the upstream of the lake. In addition to this, the lake is also located beside Naivasha town. Then it can receive both hydrological and urban surface runoff and can be polluted by a number of point (e.g., sewage from the residential houses) or nonpoint (e.g., agricultural area) sources. Although importing and using OCPs in Kenya have been stopped, there is still a potential of OCPs residues that can remain from last or current usage (Abbasi and Mannaerts 2018). There are some studies about OCPs pollution in the lake(Gitahi, Harper, Muchiri, Tole, and Ng'ang'a 2002; Onyango, Kreuzinger, and Kitaka 2015) that can confirm this statement. This study, which was based on the database of the passive sampling campaign(Abbasi and Mannaerts 2018), could highlight the existence of some OCPs residues in the water- sediment media of the lake. It is mentionable that there is not a long series of pesticides data in the water column or in the sediment to do also a time series evaluation. However, compared to conventional grab samplings, passive sampling can allow measuring chemicals in low concentration which was the strong point of the applied data of this modeling.

Among the various physicochemical properties that contribute to the distribution and exchange of pollutants among the different media, air- 
Exploring the environmental exposure of the Lake Naivasha (Kenya) to pesticides residues using Multimedia fate modeling approach

water partitioning is important for more volatile compounds. For example, also pollutants that originate from air pollution, can contribute to water pollution. This evaluation is based on their $\mathrm{K}_{\mathrm{AW}}$ parameter and shows the importance of this factor to determine the affinity of the chemicals to the air or water bodies and vice versa (Kuwata and Lee 2017). Moreover, it is necessary to include the environmental properties also in the fate of the pollutant and the modeling results. For instance, the amount of evaporation loss has a invers relation to the depth of water in which the less water depth is, the more evaporation rate increases (Hughes, Mackay et al. 2012). Similarly, by increasing the content of suspended solids, more chemicals can be captured by the suspended particles and reduce the losses rate by evaporation. Moreover, by considering the environmental parameters (e.g., boundary conditions and the physicochemical properties of the pollutants), it can be understood that as these parameters vary, therefore the results of the model also can be influenced. Organochlorine pesticides residues are mostly persistent in environment and can remain in the nature (e.g., in aquatic phases) for a long period. However, their fate might be changed under the environmental variations that differ from the model predictions. In this study QWASI allowed an insight to the fate process of the studied OCPs and helped an actual concentrations predictions. Therefore, it can be used to do risk assessment for the environmental exposure to the pesticides residues. In different studies using QWASI model (Diamond, Bhavsar et al. 2005, Whelan 2013, Mackay, Hughes et al. 2014, Tong, Zhang et al. 2014) or similar studies that applied the mass modeling to explore the fate of the chemicals, the capability of this modeling approach was confirmed that can support this study. In these studies the sensitivity of the input data also was investigated that shows the importance of finding the most proper parameters and selecting accurate amounts. In the current case study, the sensitivity analysis showed that Koc had an important role in predicting the concentration which was in harmony with the study by Whelan (Whelan 2013). Finally, it is necessary to have a monitoring data by which the results of the modeling can be applied for long series.

\subsection{Conclusion}

The behaviour of the pesticides residues and the controlling processes in the environment are governed by different physicochemical properties. Finding the relationship between the influencing criteria can help in understanding the fate of pollutants. However, this is a complex issue, and a model, in which all of the factors are included, is needed to explore the mechanisms that are related to partitioning, degradation features and environmental properties in the dynamic environment 
conditions. In this study, the QWASI model was used to find out the fate of some OCPs residues (namely a-HCH, endosulfan-sulfate and Methoxychlor) in lake Naivasha. The lake was considered as a wellmixed environment in the modeling approach, and the data of the passive sampling campaign (Abbasi and Mannaerts 2018) as well as the environmental and physicochemical properties of the pesticides was used as the input data of the model. The physicochemical and the environmental data were also collected during the campaign or were found in the literatures. Because of the uncertainty that some of the parameters had, a sensitivity analysis and model calibration was accomplished. It was found that the model results were most sensitive to KOC and the half-lives of the pesticides' residues. In addition to these parameters, the coefficient values also had a meaningful effect on the output of the model and consequently the fate of the pollutants. All of the sensitive parameters were included in the calibration process in which the model could predict the fate of pesticide residues in the aquatic phase. Moreover, the results of modeling showed that because of the difference in the half-lives and the partitioning coefficients of the pesticides residues, there was a substantial difference between the fate of Methoxychlor and $\mathrm{a}-\mathrm{HCH}$ as well as endosulfan-sulfate. This difference was mostly expressed in volatilization from the water phase and sedimentation of the contaminants. The mass balance of the chemicals among different media showed the amount of partitioning of $\mathrm{a}-\mathrm{HCH}$ and endosulfan-sulfate to the sediment was similar and was less than $1 \%$, while this amount increased to almost $30 \%$ for Methoxychlor.

Finally, the QWASI model allowed understanding the distribution of the chemicals among different environmental media. This output allows exploring the environmental exposure of tropical lakes to pesticide residues. Using reliable chemical data was also of high importance. In this study, applying data of the passive sampling method, which can help in measuring the chemicals at very low concentrations, was a strong point in modelling the fate of pesticides residues.

Author Contributions: Yasser Abbasi designed and conducted the data collection, model calibration-validation and writing the paper. Chris Mannaerts (C.M.) and Yasser Abbasi developed the research objectives and conducting of methods. Chris Mannaerts also verified the model simulation results and contributed to editing the paper.

Funding: This research received no external funding.

Conflicts of Interest: The authors declare no conflict of interest. 
Exploring the environmental exposure of the Lake Naivasha (Kenya) to pesticides residues using Multimedia fate modeling approach 
Chapter 5 : Synthesis 


\subsection{Organochlorine pesticides application}

In spite of the risk of pollution, pesticides are still one of the main ways for controlling pests in agricultural and horticultural domains. But this can cause serious problems for the environment and human health. Therefore, it is needed to have reliable knowledge about their distribution and fate to minimize the risk of their pollution in soil, water, crop, biota and human. After application of pesticides in environment, their residues can move into different media such as sediment or soil particles, organic matter, crops and/or volatize to the air. This issue demonstrates the necessity of exploring relationships among different factors that affect the fate of pesticides.

Organochlorine pesticides (OCPs), that are synthetic compounds are used for preventing and killing pests for different aims such as in agricultural and domestic environments. These compounds contain strong bonds between chlorine and carbon which allows them to remain in the environment for a long time. Because of this feature, they can bio-accumulate in the tissue of animals and human body and consequently endanger their health. In fact, in past they were used widely in many countries but later the Stockholm Convention on POPs banned their application in the environment. Residues of the OCPs are mostly captured by the soil and sediment particles and biota, therefore these sample media are quite appropriate for monitoring them and exploring human and environmental exposure to their residues.

The main purpose of this study was exploring the transfer, fate and exposure of pesticide residues in the Malewa river network in the lake Naivasha basin using passive sampling and hydrologic modelling approach. Data from the passive sampling campaigns was used for calibration and validation of the model. Field surveys, laboratory, insitu experiments and modeling were combined to determine the exposure risk of different environmental compartments to micro pollutants.

\subsection{Pesticide monitoring by passive sampling}

In aquatic monitoring programs, grab sampling is usually the main way of collecting samples for contaminant analysis, which is usually done within a very short time span. Grab sampling usually provides a snapshot of contaminants content (Hernando et al. 2007; Vrana et al. 2005) and is also associated with logistical and practical difficulties including transportation, filtration, extraction, and storage. Moreover, by the grab sampling method as a way of monitoring pesticide pollution 
in aquatic environments, all the variations of the contaminants cannot be determined (Ahrens et al. 2015). In other words, it is not possible to determine the dynamic status of pollution accurately during low and high flows. Consequently, the results do not directly relate to the precise load of pollutants (Jordan et al. 2013). In spite of these facts, grab sampling is useful for finding information quickly. However, for covering fluctuations in flow and pollutant concentrations, increasing the sampling frequency and sample numbers is needed, which is expensive and time consuming while the results remain uncertain (Rozemeijer et al. 2010).

With regard to the challenges related to grab sampling, the passive sampling technique is considered as a promising alternative method for measuring pollutants in aquatic environments. In this method the contaminates are allowed to accumulate in the samplers which make it possible to determine very low concentrations of pollutants. Passive sampling provides means for continuous water quality monitoring from short term to long term (a week to some months) and allows determining time-weighted average (TWA) of contaminant concentrations (Ahrens et al. 2015). The difference of chemical potential between passive sampler media and the dissolved contaminants in the aquatic phase causes a partitioning of contaminants from water to the sampler (Allan et al. 2009). Moreover, in comparison with organisms, detecting pollutants using passive samplers is easier to understand (Smedes and Booij 2012). Therefore, passive sampling facilitates monitoring the pollution of surface and other water bodies and provides an alternative approach to other methods such as grab sampling and biomonitoring (Fox et al. 2010; Meyn et al. 2007; Munoz et al. 2010; Wille et al. 2011).

In this study the organochlorine pesticide (OCP) residues in the aquatic environment of the Lake Naivasha river basin (Kenya) was evaluated using passive sampling techniques. Silicone rubber sheet and Speedisk samplers were used to detect residues of a-HCH, $\beta-\mathrm{HCH}, \gamma-\mathrm{HCH}, \delta-$ $\mathrm{HCH}$, Heptachlor, Aldrin, Heptachlor Epoxide, pp-DDE, Endrin, Dieldrin, a-endosulfan, $\beta$-endosulfan, pp-DDD, Endrin aldehyde, pp-DDT, Endosulfan Sulfate and Methoxychlor in the Malewa river and Lake Naivasha. The residues of OCPs were determined using gas chromatography electron capture detection (GC-ECD) for the OCPs and gas chromatography-double mass spectrometry (GC-MSMS) for the reference compounds (PCBs). Measuring the OCP residues using the Silicone rubber samplers revealed the highest concentration of residues at the lake site, being the ultimate accumulation environment for surficial hydrological, chemical and sediment transport through the river basin. Middle Malewa had the second and Upper Malewa the third rank of total OCPs residues content. An evaluation of the different pesticide compound variations identified at the three sites revealed 
that Endosulfan Sulfate, a-HCH, Methoxychlor and Endrin aldehyde residues were still found at all sampling sites. However, the statistical analysis of one-way ANOVA for testing the differences of $\Sigma$ OCPs between the sampling sites showed that there were no significant differences from the Upper Malewa to the Lake site $(P<0.05)$. Finally, the finding of this study indicated that although the concentrations of the pesticides residues were lower than the maximum allowed concentrations by WHO, because of the importance of the studied area in providing a huge amount of food products, continued monitoring of pesticides residues in the catchment remains highly recommended.

\subsection{Modeling pollutants transport in the catchment}

Generally, the transport of chemical residues and sediment via runoff, causes concern about water quality in catchments. Residues of pollutants that are transported by runoff or by sediment particles endanger the quality of fresh water bodies in various regions in the world (Warren et al. 2003). Sediments also can affect different water quality factors such as turbidity, light penetration and dissolved oxygen. Moreover, they can transport the residues of the pollutants into water bodies (Vigiak et al. 2017). Assessment of runoff, sediment and pesticide residues loading of water resources, it can be helpful to protect aquatic life habitats against contamination risk. However, understanding and studying environmental pollution, measuring all soil erosion resources and sediment transport plus the chemical processes is a complicated process that is not feasible through the traditional ways (Odongo et al. 2013). Considering all of the hydrological factors and the dynamics of contaminant residues during the transport, shows the complexity of determining the transported sediment and pollutants. Therefore, applying hydrological models can be a very useful way to provide spatiotemporal information on sediment and chemical transport.

Using hydrological modeling has been increasing and can also support environmental planning. They allow to optimize the cost and time for monitoring the pesticides residues distribution (Chen et al. 2017). There are numerous models for simulating hydrological behavior and predicting various variables like runoff, sediment, and chemicals by considering climatic and land conditions (Ben Salah and Abida 2016). Among different models that are used for this aim, SWAT is a basin simulation model developed for simulation of the effects of practices carried out on land in heterogeneous watersheds. This model is a physically based semi-distributed model that can predict the impact of different practices on water and sediment and chemicals residues in watersheds. This model was applied in this study as the capability of 
this model has been confirmed in different studies for simulating discharge, sediment yield and agrochemicals transport (Abbaspour et al. 2007; Bannwarth et al. 2014; Chen et al. 2017; Dutta and Sen 2017; Ligaray et al. 2017; Luo et al. 2008; Mahzari et al. 2016; Folle 2010; Parker et al. 2007; Winchell et al. 2018).

This part of the study focused on hydrological modeling of runoff, sediment and pesticides residues in the Malewa river basin which is the largest river in the Lake Naivasha catchment. The purpose of the study was exploring the pesticide transport from the sub-basins and the upper catchment and their possible connection to lake Naivasha.

The SWAT-CUP tool was used to calibrate the model for discharge and suspended sediment simulations. The results of the calibration showed that there were different important parameters which govern the output of the model of which the curve number parameter proved the most sensitive to spatial changes. According the statistical evaluation of the model, the result of the calibration and validation periods of discharge were promising. The average monthly sediment production and the differences in sediment amounts in the sub-basins could be explained by precipitation, slope variation and land use properties in the basin. Moreover, it was concluded that the quality of the dataset in the modeling could have an important effect on the results as by the use of a digital turbidity sensor (DTS-12) the model could predict the sediment transport and distribution in the catchment. Additionally, simulating pesticides residues allowed a good insight into historical pesticide application in the basin. It was found that the amounts of pesticide from the Upper Malewa to the Downstream Malewa and finally to the lake had an increasing trend. Passive sampling also helped as an essential method to measure low concentrations of pesticide residues in the rivers and the lake. This method allowed us to have a high quality dataset by which the model was calibrated and this permitted us to produce more reliable results. However, as the data was limited, for further investigation of the fate and transport of pesticides, using longer series of data is recommended to overcome the uncertainty that arises from limited in-situ measurements.

\subsection{Fate of pesticides in the lake}

After emission of chemicals into the nature, they are distributed among different environmental media and the fate of the chemical residues is affected by different factors such as the basic properties of the chemicals (e.g., melting point, vapor pressure, partitioning coefficients between soil, sediment and water, biodegradation rate, etc.) and environmental factors (e.g., temperature, humidity, sunlight, etc.). In addition to this, the natural processes also change the interaction of the pollutants in an multimedia environment and cause more difficulty 
in predicting their fate. Consequently, it is more difficult to study the environmental exposure to the pollutants, which depends on their fate in the environment. For modeling the fate or transfer of the residues in a multimedia environment, it was needed to consider all the information related to the basic features and the environmental data needed. With regard to the difficulty of studying the pollutant dynamics in the environment (e.g., air, water, soil, sediment and biota), using multimedia models is necessary to predict the fate and transfer of the pesticides. As some of the chemicals are persistent against degradation and can remain in the environment for a long time, it was proposed to use models with a multimedia mass balance approach. For this aim, fugacity models can help by simplifying the process examinations. There are different models for such purposes among which the Quantitative Water Air Sediment Interaction (QWASI) fugacity model is one of the models that has been used to explore the chemical variations and fate (e.g., pesticides and heavy metals) by many researchers. Therefore, in this study, the fugacity multimedia model of QWASI was applied to estimate the environmental exposure to the studied pesticide residues.

It was found that the results of the model were affected by factors such as KOC and the half-lives of the pesticide residues as well as the parameters that consequently affected the fate of the pesticides residues. By considering all the sensitive parameters, the results of modeling showed that because of the difference in the half-lives and the partitioning coefficients of the pesticides residues, there was a substantial difference between the fate of the different pesticides. Finally, by applying the QWASI multimedia model, it was possible to understand the distribution of the pesticides residues among the different environmental compartments. This output allowed us to understand the Naivasha catchment basin environmental exposure to pesticide residues and see how the human health can be at risk. Moreover, using reliable data is also of high importance by which the model can be calibrated and validated for better prediction. In this study, applying data of the passive sampling method, which permits measuring the chemicals at very low concentrations, was an important asset for modelling the fate of pesticides residues.

\section{$5.5 \quad$ Future research}

For controlling and preventing the exposure of humans and the environment to pesticides pollution and their risk, a robust exploration of the spatial distribution and fate of pesticide residues is required. Both environmental factors and chemicals properties are the main governing drivers of the exposure and fate of chemicals residues. 
However, understanding and combining all these parameters is a complicated task. For example, exploring this issue at large scale is up to the land use-land cover, climate factors, precipitation and human activities that cause complicated conditions for measuring and predicting the distribution and fate of pesticides residues. In this study, passive sampling helped us to cover the variations of pesticides concentrations in different conditions (e.g., high and low flow rates). However, monitoring the pesticides contamination in the region needs to be more extended (both spatial and temporal) by measurements using this method. As residential areas as point source of pollution can also affect the quality of water resources, therefore it is highly recommended that in addition to the agricultural areas, these sources be also explored in future studies.

One of the major limitations of this study was the lack of historical quantitative organochlorine pesticides monitoring and reference or baseline data. There were some limited studies in the region that applied grab sampling (Gitahi et al. 2002). While for a better understanding of pesticide movement and fate, time series measurements considering all potential pollution sources is needed. In addition to this, applying models in this study helped to gain a closer insight to the environmental exposure to the pesticides residues. However, the quality of hydrological data was a challenge for calibration-validation of the hydrological model (SWAT). This issue can be improved by upgrading and renovating the hydrologic measuring stations. By improving the hydrological data, it is possible to get better results with a higher resolution at daily scale or hourly instead of monthly to find out more on the dynamics of pesticides in the region more precisely.

Moreover, awareness of the fate of pesticides is a key factor for decision making about pesticides application management. However, predicting their fate needs precise and detailed information. Some of these factors such as half-lives of pesticides residues, KOC, KAW, are reported based on reports that can differ from the studied conditions. Therefore, calibration and validating the model using long term measurements can allow achieving better fit between the model prediction and real measurements. 


\section{Bibliography}

Abbasi, Y., and C. M. Mannaerts. 2018. 'Evaluating organochlorine pesticide residues in the aquatic environment of the Lake Naivasha River basin using passive sampling techniques', Environ Monit Assess, 190: 1-12.

Abbasi, Y.; Mannaerts, C.M.; Makau, W. Modeling pesticide and sediment transport in the malewa river basin (kenya) using swat. Water 2019, 11, 1-20.

Abbaspour, K. C. 2015. 'SWAT-CUP: SWAT Calibration and Uncertainty Programs - A User Manual', Swiss Federal Institute of Aquatic Science and Technology, Eawag.

Abbaspour, K.C., E. Rouholahnejad, S. Vaghefi, R. Srinivasan, H. Yang, and B. Kløve. 2004. 'A continental-scale hydrology and water quality model for Europe: Calibration and uncertainty of a high-resolution large-scale SWAT model', J. Hydr, 524: 73352.

Abbaspour, Karim C., Jing Yang, Ivan Maximov, Rosi Siber, Konrad Bogner, Johanna Mieleitner, Juerg Zobrist, and Raghavan Srinivasan. 2007. 'Modelling hydrology and water quality in the pre-alpine/alpine Thur watershed using SWAT', J. Hydrol., 333: 413-30.

Ahrens, L., Daneshvar, A., Lau, A. E., \& Kreuger, J. (2015). Characterization of five passive sampling devices for monitoring of pesticides in water. Journal of Chromatography A, 1405, 111. doi:10.1016/j.chroma.2015.05.044.

Allan, I. J., Booij, K., Paschke, A., Vrana, B., Mills, G. A., \& Greenwood, R. (2009). Field performance of seven passive sampling devices for monitoring of hydrophobic substances. Environmental science \& technology, 43(14), 5383-90. doi: $10.1021 /$ es900608w.

Arnold, J.G., J.R. Kiniry, R. Srinivasan, J.R. Williams, E.B. Haney, and S.L. Neitsch. 2013. ' Soil \& Water Assessment Tool Inputoutput documentation', Texas Water Resources Institute, TR439.

Arnold, J.G., D. N. Moriasi, P. W. Gassman, K. C. Abbaspour, P. S. White, R. Srinivasan, C. Santhi, R. D. Harmel, A. van Griensven, M. W. Van Liew, N. Kannan, and M. K. Jha. 2012. 'SWAT: Model use, Calibration and Validation ', Am. Soc. Agr. Biol. Eng., 55: 1491-508.

Asres, Meqaunint Tenaw, and Seleshi B. Awulachew. 2010. 'SWAT based runoff and sediment yield modelling: a case study of the Gumera watershed in the Blue Nile basin', Ecohyd. \& Hydrobio., 10: 191-99. 
ATSDR (Agency for Toxic Substances and Disease Registry) 2005. 'Toxicological Profile for Hexachlorocyclohexane', U.S. DEPARTMENT OF HEALTH AND HUMAN SERVICES Public Health Service.

ATSDR, (Agency for Toxic Substances and Disease Registry). (2002a). Toxicological Profile for Methoxychlor. U.S. Department of Health and Human Services, Public Health Service.

ATSDR, (Agency for Toxic Substances and Disease Registry). (2002b). Toxicological Profile for DDT, DDE, and DDD. U.S. Department of Health and Human Services, Public Health Service.

ATSDR, (Agency for Toxic Substances and Disease Registry). (2005). Toxicological profile for alpha-, beta-, gamma-, and DeltaHexachlorocyclohexane. U.S. Department of Health and Human Services, Public Health Service.

Ayenew, T.; Becht, R.; Lieshout, A.M.V. Hydrodynamics of topographically closed lakes in the ethio-kenyan rift: The case of lakes awassa and naivasha. J. Spat. Hydrol. 2007, 7, 81100.

Bannwarth, M. A., W. Sangchan, C. Hugenschmidt, M. Lamers, J. Ingwersen, A. D. Ziegler, and T. Streck. 2014. 'Pesticide transport simulation in a tropical catchment by SWAT', Environ. Pollut., 191: 70-9.

Bao, L.J.; Maruya, K.A.; Snyder, S.A.; Zeng, E.Y. China's water pollution by persistent organic pollutants. Environ. Pollut. 2012, $163,100-108$.

Becht, R.; Odada, E.O.; Higgins, S. Lake naivasha experience and lessons learned brief. Int. Water Learn. Exch. Resour. Netw. 2010, 2, 277-298.

Ben Salah, Narjes Chaâbane, and Habib Abida. 2016. 'Runoff and sediment yield modeling using SWAT model: case of Wadi Hatab basin, central Tunisia', Arab. J. Geosc., 9: 1-12.

Bonnell, M.A. ; Zidek, A. ; Griffiths, A.; Gutzman, D. Fate and exposure modeling in regulatory chemical evaluation: New directions from retrospection. Environ. Sci. Process. Impacts 2018, 20, 20-31.

Booij, K., \& Smedes, F. (2010). An improved method for estimating in situ sampling rates of nonpolar passive samplers. Environmental Science and Technology, 44(17), 6789-6794. doi:10.1021/es101321v.

Booij, K., Hofmans, H. E., Fischer, C. V., \& Van Weerlee, E. M. (2003). Temperature-dependent uptake rates of nonpolar organic compounds by semipermeable membrane devices and lowdensity polyethylene membranes. Environmental Science and Technology, 37(2), 361-366. doi:10.1021/es025739i. 
Booij, K., Vrana, B., \& Huckins, J. N. (2007). Chapter 7 Theory, modelling and calibration of passive samplers used in water monitoring. Comprehensive Analytical Chemistry, 48(6), 141169. doi:10.1016/S0166-526X(06)48007-7.

Borah, D. K., and M. Bera. 2004. 'Watershed-scale hydrologic and nonpoint-source pollution models: Review of applications', Am. Soc. Agr. Eng., 47: 789-803.

Brockmeyer, B., Kraus, U. R., \& Theobald, N. (2015). Accelerated solvent extraction (ASE) for purification and extraction of silicone passive samplers used for the monitoring of organic pollutants. Environmental Science and Pollution Research. doi: $10.1007 / \mathrm{s} 11356-015-5192-1$

Buser, A.M.; MacLeod, M.; Scheringer, M.; Mackay, D.; Bonnell, M.; Russell, M.H.; DePinto, J.V.; Hungerbuhler, K. Good modeling practice guidelines for applying multimedia models in chemical assessments. Integr. Environ. Assess Manag. 2012, 8, 703708.

Carson, R. 1962. "Silent Spring". Mariner Books, HOUGHTON MIFFLIN HARCOURT, Boston New York.

Cessna, A.J. 2009. "Pesticides in the Environment: Real or Imagined." Agriculture and Agri-food Canada, Research Centre, Lethbridge, AB.

Chen, H., Y. Luo, C. Potter, P. J. Moran, M. L. Grieneisen, and M. Zhang. 2017. 'Modeling pesticide diuron loading from the San Joaquin watershed into the Sacramento-San Joaquin Delta using SWAT', Water Research, 121: 374-85.

Dasa, S.K., A.W.M. Nga, and B.J.C. Perera. 2013. 'Sensitivity analysis of SWAT model in the Yarra River catchment', 20th Inter. Cong. Mod. and Sim., Adelaide, Australia.

Diamond, M.L.; Bhavsar, S.P.; Helm, P.A.; Stern, G.A.; Alaee, M. Fate of organochlorine contaminants in arctic and subarctic lakes estimated by mass balance modelling. Sci. Total Environ. 2005, $342,245-259$.

Doppler, T., L. Camenzuli, G. Hirzel, M. Krauss, A. Lück, and C. Stamm. 2012. 'Spatial variability of herbicide mobilisation and transport at catchment scale: insights from a field experiment', Hydr. Earth Sys. Sci., 16: 1947-67.

Dutta, Subhasri, and Dhrubajyoti Sen. 2017. 'Application of SWAT model for predicting soil erosion and sediment yield', Sust. Water Res. Manag., 4: 447-68.

Fang, S.M.; Zhang, X.; Bao, L.J.; Zeng, E.Y. Modeling the fate of p,p'ddt in water and sediment of two typical estuarine bays in south china: Importance of fishing vessels' inputs. Environ. Pollut. 2016, 212, 598-604. 
Ficklin, Darren L., Yuzhou Luo, and Minghua Zhang. 2013. 'Watershed modelling of hydrology and water quality in the Sacramento River watershed, California', Hydrol. Proce., 27: 236-50.

Folle, SOLOMON MULETA 2010. 'SWAT Modeling of Sediment, Nutrients and Pesticides in the Le-Sueur River Watershed, South-Central Minnesota', PhD dissertation, Uniersity of Minesota.

Fox, J. T., Adams, G., Sharum, M., \& Steelman, K. L. (2010). Passive sampling of bioavailable organic chemicals in Perry County, Missouri cave streams. Environmental Science and Technology, 44(23), 8835-8841. doi:10.1021/es1019367

Gbeddy, G., Yeboah, P., Carboo, D., Doamekpor, L., Afful, S., Nartey, $V_{\text {., }}$ et al. (2012). Organochlorine pesticide residues in African catfish muscle, Nile tilapia Muscle and gills from the middle Volta basin, Kpando Torkor, Ghana and their potential health risks to humans. Elixir Agriculture, 49(July), 9724-9730.

Gitahi, S. M., Harper, D. M., Muchiri, S. M., Tole, M. P., \& Ng'ang'a, R. N. (2002). Organochlorine and organophosphorus pesticide concentrations in water, sediment, and selected organisms in Lake Naivasha (Kenya). Hydrobiologia, 488, 123-128. doi: $10.1023 / A: 1023386732731$

Gitahi, S.M.; Harper, D.M.; Muchiri, S.M.; Tole, M.P.; Ng'ang', R.N. Organochlorine and organophosphorus pesticide concentrations in water, sediment, and selected organisms in lake naivasha (kenya). Hydrobiologia 2002, 488, 123-128.

Górecki, T., \& Namieśnik, J. (2002). Passive sampling. TrAC Trends in Analytical Chemistry, 21(4), 276-291. doi:10.1016/S01659936(02)00407-7

Gramatica, P.; Di Guardo, A. Screening of pesticides for environmental partitioning tendency. Chemosphere 2002, 47, 947-956.

Guo, J.; Zhou, Y.; Zhang, B.; Zhang, J. Distribution and evaluation of the fate of cyclic volatile methyl siloxanes in the largest lake of southwest china. Sci. Total Environ. 2019, 657, 87-95.

Harman, C., Thomas, K. V., Tollefsen, K. E., Meier, S., Bøyum, O., \& Grung, M. (2009). Monitoring the freely dissolved concentrations of polycyclic aromatic hydrocarbons (PAH) and alkylphenols (AP) around a Norwegian oil platform by holistic passive sampling. Marine Pollution Bulletin, 58(11), 16711679. doi:10.1016/j.marpolbul.2009.06.022

Harper, David M., Edward H. J. Morrison, Michael M. Macharia, Kenneth M. Mavuti, and Caroline Upton. 2011. 'Lake Naivasha, Kenya: Ecology, Society and Future', Freshwater Reviews, 4: 89-114.

Hayo M.G. van der Werf I. "Assessing the Impact of Pesticides on the Environment." J. Agric. Food Chem 5: 81-96. 
Hernando, M. D., Lambropoulou, D., Konstantinou, I., Martinez Bueno, M. J., Gabrielides, D., Fernández-Alba, A. R., \& Albanis, T. (2007). Passive sampling techniques for monitoring organic contaminants in aquaculture environment. In Proceedings of the 10th International Conference on Environmental Science and Technology (pp. B276-B283).

Herrero-Hernández, E.; Andrades, M.S.; Álvarez-Martín, A.; PoseJuan, E.; Rodríguez-Cruz, M.S.; Sánchez-Martín, M.J. Occurrence of pesticides and some of their degradation products in waters in a spanish wine region. J. Hydrol. 2013, 486, 234-245.

Hu, M.; Liu, X.; Wu, X.; Dong, F.; Xu, J.; Chen, W.; Zheng, Y. Characterization of the fate and distribution of ethiprole in water-fish-sediment microcosm using a fugacity model. Sci. Total Environ. 2017, 576, 696-704.

Huang, Y.; Sun, X.; Liu, M.; Zhu, J.; Yang, J.; Du, W.; Zhang, X.; Gao, D.; Qadeer, A.; Xie, Y.; Nie, N. A multimedia fugacity model to estimate the fate and transport of polycyclic aromatic hydrocarbons (pahs) in a largely urbanized area, Shanghai, China. Chemosphere 2019, 217, 298-307.

Hughes, L.; Mackay, D.; Powell, D.E.; Kim, J. An updated state of the science eqc model for evaluating chemical fate in the environment: Application to d5 (decamethylcyclopentasiloxane). Chemosphere 2012, 87, 118124.

Jordan, P., Cassidy, R., Macintosh, K. a, \& Arnscheidt, J. (2013). Field and laboratory tests of flow-proportional passive samplers for determining average phosphorus and nitrogen concentration in rivers. Environmental science \& technology, 47(5), 2331-8. doi: $10.1021 /$ es304108e

Jung, J.E.; Kim, Y.K.; Song, J.H.; Lee, D.S. Development and evaluation of a dynamic multimedia model (ecorame) for local scale assessment of aquatic ecological exposure to chemicals originating from sources in environmental media. Sci. Total Environ. 2014, 500-501, 103-112.

Kannan, N., S. M. White, F. Worrall, and M. J. Whelan. 2006. 'Pesticide modelling for a small catchment using SWAT-2000', J. Environ. Sci. Health. B, 41: 1049-70.

Kaoga, J., G. Ouma, and P. Abuom. 2013. "Effect of Farm Pesticides on Water Quality in Lake Naivasha, Kneya." American Journal of Plant Physiology: 105-13.

Kaoga, J., Ouma, G., \& Abuom, P. (2013). Effect of Farm Pesticides on Water Quality in Lake Naivasha, Kneya. American Journal of Plant Physiology, 105-113. doi:10.3923/ajpp.2013.105.113 
Kapsi, M.; Tsoutsi, C.; Paschalidou, A.; Albanis, T. Environmental monitoring and risk assessment of pesticide residues in surface waters of the louros river (n.W. Greece). Sci. Total Environ. 2019, 650, 2188-2198.

Karickhoff, S.W. Semi empirical estimation of sorption of hydrophobic pollutants on natural sediments and soils. Chemosphere 1981, $10,833-846$.

Kaur, J.; DePinto, J.V.; Atkinson, J.F.; Verhamme, E.; Young, T.C. Development of a spatially resolved linked hydrodynamic and exposure model (lotox2) for pcbs in lake ontario. J. Great Lakes Res. 2012, 38, 490-503.

Keating, M. I. (1983). Tick control by chemical ixodicides in Kenya: A review 1912 to 1981 . Tropical Animal Health and Production, 15(1), 1-6. doi:10.1007/BF02250752

Khoadadi, M. 2009. "Determination of Residual Concentrations of Phosphorus and Carbamate Pesticides and Organiphosphate Pesticides in Drinking Water Sources in Hamedan." 12th National Conference of Environmental Health Iran, Shahid Beheshti University, Tehran.

Kim, H.S.; Lee, D.S. Influence of monitoring data selection for optimization of a steady state multimedia model on the magnitude and nature of the model prediction bias. Chemosphere 2017, 186, 716-724.

Kitaka, Nzula, David M. Harper, Kenneth M. Mavuti, and Nic Pacini. 2002. "Chemical Characteristics, with Particular Reference to Phosphorus, of the Rivers Draining into Lake Naivasha, Kenya." Hydrobiologia 488: 57-71.

Kong, X.; Liu, W.; He, W.; Xu, F.; Koelmans, A.A.; Mooij, W.M. Multimedia fate modeling of perfluorooctanoic acid (pfoa) and perfluorooctane sulphonate (pfos) in the shallow lake chaohu, china. Environ. Pollut. 2018, 237, 339-347.

Konstantinou, I.K.; Hela, D.G.; Albanis, T.A. The status of pesticide pollution in surface waters (rivers and lakes) of greece. Part i. Review on occurrence and levels. Environ. Pollut. 2006, 141, 555-570.

Kuwata, M.; Lee, W.-C. 1-octanol-water partitioning as a classifier of water soluble organic matters: Implication for solubility distribution. Aerosol Sci. Technol. 2017, 51, 602-613.

Kwadijk, C.J.; Korytar, P.; Koelmans, A.A. Distribution of perfluorinated compounds in aquatic systems in the netherlands. Environ. Sci. Technol. 2010, 44, 3746-3751.

Lang, C.; Tao, S.; Wang, X.; Zhang, G.; Fu, J. Modeling polycyclic aromatic hydrocarbon composition profiles of sources and receptors in the pear river delta, china. Environ. Toxicol. Chem. 2008, 27, 4-9. 
Ligaray, Mayzonee, Minjeong Kim, Sangsoo Baek, Jin-Sung Ra, Jong Chun, Yongeun Park, Laurie Boithias, Olivier Ribolzi, Kangmin Chon, and Kyung Cho. 2017. 'Modeling the Fate and Transport of Malathion in the Pagsanjan-Lumban Basin, Philippines', Water, 9: 1-18.

Liu, Y., W. Yang, Zh. Yu, I. Lung, and B. Gharabaghi. 2015. 'Estimating Sediment Yield from Upland and Channel Erosion at AWatershed Scale Using SWAT', Water Res. Manag., 29: 1399412.

Luo, Y., X. Zhang, X. Liu, D. Ficklin, and M. Zhang. 2008. 'Dynamic modeling of organophosphate pesticide load in surface water in the northern San Joaquin Valley watershed of California', Environ. Pollut., 156: 1171-81.

M. Meins, Frank. 2013. 'Evaluation of spatial scale alternatives for hydrological modelling of the Lake Naivasha basin, Kenya', MSc thesis, University of Twente, Netherlands.

Mackay, D. Finding fugacity feasible. Environ. Sci. Technol. 1979, 13, $1218-1224$.

Mackay, D. Multimedia Environmental Fate Models: The Fugacity Approach. Taylor \& Francis: New York, NY, USA, 2001.

Mackay, D.; Di Guardo, A.; Paterson, S.; Cowan, C.E. Evaluating the environmental fate of a variety of types of chemicals using the eqc model. Environ. Toxicol. Chem./SETAC 1996, 15, 16271637.

Mackay, D.; Hughes, L.; Powell, D.E.; Kim, J. An updated quantitative water air sediment interaction (qwasi) model for evaluating chemical fate and input parameter sensitivities in aquatic systems: Application to d5 (decamethylcyclopentasiloxane) and pcb-180 in two lakes. Chemosphere 2014, 111, 359-365.

Mackay, D.; Paterson, S.; Joy, M. A quantitative water, air, sediment interaction (QWASI) fugacity model for describing the fate of chemicals in rivers. Chemosphere 1983, 12, 1193-1208.

Mackay, D.; Shiu, W.-y.; Ma, K.-C.; Lee, C. Handbook of PhysicalChemical Properties and Environmental Fate For Organic Chemicals; Taylor \& Francis: New York, NY, USA, 2006.

Macleod, M.; Fraser, A.J.; Mackay, D. Evaluating and expressing the propagation of uncertainty in chemical fate and bioaccumulation models. Environ. Toxicol. Chem. 2002, 21, 700-709.

Mahzari, Samane, Farshad Kiani, Mojgansadat Azimi, and Farhad Khormali. 2016. 'Using SWAT Model to Determine Runoff, Sediment Yield and Nitrate Loss in Gorganrood Watershed, Iran', Ecopersia, 4: 1359-77.

Malone, R. W., G. Yagow, C. Baffaut, M. W. Gitau, Z. Qi, D. M. Amatya, P. B. Parajuli, J. V. Bonta, and T. R. Green. 2015. 
'Parameterization Guidelines and Considerations for Hydrologic Models', Am. Soc. Agri. Biolog. Eng., 58: 1681-703.

Mburu, Njoroge Simon, Munyao Thomas Matuku, Odipo Osano, and Chege Moses Gichuho. 2013. "Pesticide Preferences and Pattern of Use along the Shore of Lake Naivasha, Kenya." Greener Journal of Environmental Management and Public Safety 2: 115-20.

MCkay, M. D., R. J. Beckma, and W. J. Conover. 2000. 'A comparision of three methods for selelcting valuses of input variables in the analysis of output from a computer code', Am. Statist. Assoc. Am. Soci. Qualit, 42: 55-61.

Meyn, A., White, P. S., Buhk, C., \& Jentsch, A. (2007). Environmental drivers of large, infrequent wildfires: the emerging conceptual model. Progress in Physical Geography, 31(3), 287-312. doi: $10.1177 / 0309133307079365$

Mohamed, A.-M.O.; Paleologos, E.K. Fate and effects of pollutants on the land environment. In Fundamentals of Geoenvironmental Engineering, Elsevier Butterworth-Heinemann, 2018; pp. 239281.

Moncada, J. 2001. "Spatial Distribution of Pesticide Contamination Potential around Lake Naivasha, Kenya." Wrs MSc: 110.

Monteyne, E., Roose, P., \& Janssen, C. R. (2013). Application of a silicone rubber passive sampling technique for monitoring PAHs and PCBs at three Belgian coastal harbours. Chemosphere, 91(3), 390-8. doi:10.1016/j.chemosphere.2012.11.074

Moriasi, D. N., M. W. Gitau, N. Pai, and P. Daggupati. 2015. 'Hydrologic and water quality models: performance measures and evaluation criteria', ASABE, 58: 1763-85.

Moriasi, D.N.; Gitau, M.W.; Pai, N.; Daggupati, P. Hydrologic and water quality models: Performance measures and evaluation criteria. Trans. ASABE 2015, 58, 1763-1785.

Munoz, I., Martinez Bueno, M. J., Aguera, A., \& Fernandez-Alba, A. R. (2010). Environmental and human health risk assessment of organic micro-pollutants occurring in a Spanish marine fish farm. Environmental Pollution, 158(5), 1809-1816. doi:10.1016/j.envpol.2009.11.006

Mutuku, M., Njogu, P., \& Nyagah, G. (2014). Assessment of Pesticide Use and Application Practices in Tomato Based Agrosystems in Kaliluni Sub Location, Kathiani District, Kenya. JAGST, 16(2), 34-44.

'National Center for Biotechnology Information. PubChem Compound Database;

$\mathrm{CID}=3224$ https://pubchem.ncbi.nlm.nih.gov/compound/3224 (accessed Dec 8, 2018).'. 
National Center for Biotechnology Information. PubChem Database. Endosulfan Sulfate, $C I D=13940$, https://pubchem.ncbi.nlm.nih.gov/compound/Endosulfansulfate, Accessed on Apr. 13, 2020.

Ndungu, Jane Njeri. 2014. Assessing Water Quality in Lake Naivasha. http://purl.org/utwente/doi/10.3990/1.9789036537001.

Neitsch, S.L., J.G. Arnold, J.R. Kiniry, and J.R. Williams. 2011. 'Soil \& Water Assessment Tool, Theoretical Documentation ', Texas Water Resources Institute Technical Report No. 406.

NJOGU, PAUL MWANGI. 2011. "Assessment of Pollution and Prediction of Environmental Risks of Organochlorine Pesticides on Aquatic Communities in Lake Naivasha, Kenya." A Thesis submitted in fulfillment for the Degree of Doctor Philosophy in Environmental Technology in the Jomo Kenyatta University of Agriculture and Technology.

Odada, Eric O. et al. 2003. "Environmental Assessment of the East African Rift Valley Lakes." Aquatic Sciences 65(3): 254-71.

Odongo, V. O., D. W. Mulatu, F. K. Muthoni, P. R. van Oel, F. M. Meins, C. van der Tol, A. K. Skidmore, T. A. Groen, R. Becht, J. O. Onyando, and A. van der Veen. 2014. 'Coupling socio-economic factors and eco-hydrological processes using a cascademodeling approach', J. Hydrol., 518: 49-59.

Odongo, V. O., J. O. Onyando, B. M. Mutua, P. R. van Oel, and R. Becht. 2013. 'Sensitivity analysis and calibration of the Modified Universal Soil Loss Equation (MUSLE) for the upper Malewa Catchment, Kenya', Inter. J. Sedim. Res., 28: 368-83.

Onyango, J., Kreuzinger, N., \& Kitaka, N. (2015). Pesticides Residues Contamination in Lake Naivasha catchment, Kenya. AV Akademikerverlag.

Onyango, J., Kreuzinger, N., Yillia, P., \& Kitaka, N. (2014). Potential Risks of Pesticide Application in Kenya : Case of Lake Naivasha Catchment. In 7th International Young Water Professional Conference. Taipei, Chinese Taiwan.

Onyango, J.; Kreuzinger, N.; Kitaka, N. Pesticides Residues Contamination in Lake Naivasha Catchment, Kenya; AV Akademikerverlag, Saarland, Germany; 2015; p. 112.

Panuwet, P., W. Siriwong, T. Prapamontol, P. B. Ryan, N. Fiedler, M. G. Robson, and D. B. Barr. 2012. 'Agricultural Pesticide Management in Thailand: Situation and Population Health Risk', Environ. Sci. Policy, 17: 72-81.

Parker, Ronald, J.G. Arnold, Michael Barrett, Lawrence Burns, Lee Carrubba, S.L. Neitsch, N.J. Snyder, and R. Srinivasan. 2007. 'Evaluation of three watershed-scale pesticide environmental transportat and fate models', J. Am. Water Res. Assoc., 43. 
PCPB, (Pest Control Products Board). (2008). List of Pest Control Products Provisionally Registered by the Pest Control Products Board for use in Kenya. Nairobi, Kenya.

Qiu, Linjing, Fenli Zheng, and Runsheng Yin. 2012. 'SWAT-based runoff and sediment simulation in a small watershed, the loessial hilly-gullied region of China: capabilities and challenges', Int. J. Sedim. Res., 27: 226-34.

Renschler, C.S., C. M. Mannaerts, and B. Diekkruger. 1999. 'Evaluating spatial and temporal variability in soil erosion riskrainfall erosivity and soil loss ratios in Andalusia, Spain', Catena, 34: 209-25.

Rozemeijer, J., Van Der Velde, Y., De Jonge, H., Van Geer, F., Broers, H. P., \& Bierkens, M. (2010). Application and evaluation of a new passive sampler for measuring average solute concentrations in a catchment scale water quality monitoring study. Environmental Science and Technology, 44(3), 13531359. doi: $10.1021 /$ es903068h

Rusina, T. P., Smedes, F., Koblizkova, M., \& Klanova, J. (2010). Calibration of silicone rubber passive samplers: Experimental and modeled relations between sampling rate and compound properties. Environmental Science and Technology, 44(1), 362367. doi:10.1021/es900938r

Saltelli, A.; Ratto, M.; Tarantola, S.; Campolongo, F. Sensitivity analysis practices: Strategies for model-based inference. Reliab. Eng. Syst. Saf. 2006, 91, 1109-1125.

Schuol, Jürgen, Karim C. Abbaspour, Raghavan Srinivasan, and Hong Yang. 2008. 'Estimation of freshwater availability in the West African sub-continent using the SWAT hydrologic model', J. Hydrol., 352: 30-49.

Scopel, C. 'SWAT: Soil \& Water Assessment Tool', ArcGIS Blog, Available online: https://www.esri.com/arcgisblog/products/product/water/swat-soil-water-assessmenttool/ (accessed on 15 Feb. 2018).

Seth, R.; Mackay, D. Fugacity Modeling to Predict Long-Term Environmental Fate of Chemicals From Hazardous Spills; Canadian Environmental Modelling Centre, Trent University: Peterborough Ontario, PC, Canada, 2001; pp. 1-12.

Shen, Z. Y., Y. W. Gong, Y. H. Li, Q. Hong, L. Xu, and R. M. Liu. 2009. 'A comparison of WEPP and SWAT for modeling soil erosion of the Zhangjiachong Watershed in the Three Gorges Reservoir Area', Agri. Water Manag., 96: 1435-42.

Smedes, F., \& Booij, K. (2012). Guidelines for passive sampling of hydrophobic contaminants in water using silicone rubber samplers. ICES Techniques in Marine Environmental Sciences No. 52. 
Smedes, F., Bakker, D., \& Weer, J. de. (2010). The use of passive sampling in WFD monitoring. Rijkswaterstaat Centre for Water Management, Deltares Project No. 1202337-004.

Spruill, C. A., S. R. Workman, and J. L. Taraba. 2000. 'Simulation of daily stream discharge from small watersheds using the SWAT model', Am. Soc. Agri. Biolog. Eng., 1: 1431-39.

'STOCKHOLM CONVENTION ON PERSISTENT ORGANIC POLLUTANTS (POPs), Text and Annexes'. 2009. The Secretariat of the Stockholm Convention on Persistent Organic Pollutants.

Stoof-Leichsenring, K.R.; Junginger, A.; Olaka, L.A.; Tiedemann, R.; Trauth, M.H. Environmental variability in lake naivasha, kenya, over the last two centuries. J. Paleolimnol. 2011, 45, 353-367.

Tarras-Wahlberg, Håkan, Mark Everard, and David M. Harper. 2002. "Geochemical and Physical Characteristics of River and Lake Sediments at Naivasha, Kenya." Hydrobiologia 488(i): 27-41.

Tiryaki, Osman, and Cemile Temur. 2010. "The Fate of Pesticide in the Environment." 4(10): 29-38.

Tong, Y.; Zhang, W.; Chen, C.; Chen, L.; Wang, W.; Hu, X.; Wang, $\mathrm{H} . ; \mathrm{Hu}, \mathrm{D} . ; \mathrm{Ou}, \mathrm{L} . ;$ Wang, X.; Wang, Q. Fate modeling of mercury species and fluxes estimation in an urban river. Environ Pollut 2014, 184, 54-61.

Toth, S.J. , Buhler, W.G. 2009. "Environmental Effects of Pesticides." Department of Entomology and Horticultural Science, North Carolina State University.

Traum, Jonathan A., Steven P. Phillips, George L. Bennett, Celia Zamora, and Loren F. Metzger. 2014. 'Documentation of a Groundwater Flow Model (SJRRPGW) for the San Joaquin River Restoration Program Study Area, California', Sci. Investi. Rep. 2014-5148 (USGS).

UNEP. Stockholm Convention on ( POPs ) Text and Annexes; Published by the Secretariat of the Stockholm Convention on Persistent Organic Pollutants; Geneva, Switzerland; 2009, 1-56.

Vigiak, O., A. Malago, F. Bouraoui, M. Vanmaercke, F. Obreja, J. Poesen, H. Habersack, J. Feher, and S. Groselj. 2017. 'Modelling sediment fluxes in the Danube River Basin with SWAT', Sci Total Environ, 599-600: 992-1012.

Vrana, B., Allan, I. J., Greenwood, R., Mills, G. a., Dominiak, E., Svensson, K., et al. (2005). Passive sampling techniques for monitoring pollutants in water. TrAC - Trends in Analytical Chemistry, 24(10), 845-868. doi:10.1016/j.trac.2005.06.006

Waite, D.T. et al. 2002. "Environmental Concentrations of Agricultural Herbicides: 2,4-D and Triallate." J. Environ. Qual., 31: 129-44.

Wang, R.; Cao, H.; Li, W.; Wang, W.; Wang, W.; Zhang, L.; Liu, J.; Ouyang, H.; Tao, S. Spatial and seasonal variations of polycyclic 
aromatic hydrocarbons in haihe plain, china. Environ. Pollut. 2011, 159, 1413-1418.

Wang, Wenbin, Shlomo P. Neuman, Tzungmow Yao, and Peter J. Wierenga. 2003. 'Simulation of Large-Scale Field Infiltration Experiments Using a Hierarchy of Models Based on Public, Generic, and Site Data', Vadose Zone J., 2: 297-312.

Wang, Y.; Khan, S.J.; Fan, L.; Roddick, F. Application of a qwasi model to produce validated insights into the fate and transport of six emerging contaminants in a wastewater lagoon system. Sci. Total Environ. 2020, 721, 137676.

Warren, N., I.J. Allan, J.E. Carter, W.A. House, and A. Parker. 2003. 'Pesticides and other micro-organic contaminants in freshwater sedimentary environments-a review', Appl. Geochem., 18: 159-94.

Weber, J., C. J. Halsall, D. Muir, C. Teixeira, J. Small, K. Solomon, M. Hermanson, H. Hung, and T. Bidleman. 2010. 'Endosulfan, a global pesticide: a review of its fate in the environment and occurrence in the Arctic', Sci. Total. Environ., 408: 2966-84.

Webster, E.; Lian, L.; Mackay, D.; Harvey, C. Application of the Quantitative Water Air Sediment Interaction (QWASI) Model to the Great Lakes, Canadian Environmental Modelling Centre Trent University, Peterborough, Ontario, Canada; 2006.

Whelan, M.J. Evaluating the fate and behaviour of cyclic volatile methyl siloxanes in two contrasting north american lakes using a multi-media model. Chemosphere 2013, 91, 1566-1576.

WHO. (2011). WHO guidelines for drinking-water quality. WHO chronicle, (Fourth Edition). doi:10.1016/S14620758(00)00006-6

Wille, K., Claessens, M., Rappé, K., Monteyne, E., Janssen, C. R., De Brabander, H. F., \& Vanhaecke, L. (2011). Rapid quantification of pharmaceuticals and pesticides in passive samplers using ultra high performance liquid chromatography coupled to high resolution mass spectrometry. Journal of Chromatography $A$, 1218(51), 9162-9173. doi:10.1016/j.chroma.2011.10.039.

Winchell, M. F., N. Peranginangin, R. Srinivasan, and W. Chen. 2018. 'Soil and Water Assessment Tool model predictions of annual maximum pesticide concentrations in high vulnerability watersheds', Integr. Environ. Assess. Manag., 14: 358-68.

Wu, X.; Davie-Martin, C.L.; Steinlin, C.; Hageman, K.J.; Cullen, N.J.; Bogdal, C. Understanding and predicting the fate of semivolatile organic pesticides in a glacier-fed lake using a multimedia chemical fate model. Environ. Sci. Technol. 2017, 51, 1175211760.

Xu, F.-L.; Qin, N.; Zhu, Y.; He, W.; Kong, X.-Z.; Barbour, M.T.; He, Q.-S.; Wang, Y.; Ou-Yang, H.-L.; Tao, S. Multimedia fate 
modeling of polycyclic aromatic hydrocarbons (pahs) in lake small baiyangdian, northern china. Ecol. Model. 2013, 252, 246-257.

$\mathrm{Xu}, \mathrm{S}$; ; Kropscott, B. Method for simultaneous determination of partition coefficients for cyclic volatile methylsiloxanes and dimethylsilanediol. Anal. Chem. 2012, 84, 1948-1955.

Xu, Tang Zhen. 1999. "Water Quality Assessment and Pesticide Fate Modeling in the Lake Naivasha Area , Kenya." MSc Thesis, University of Twente, Netherlands.

Zettam, Amin, Amina Taleb, Sabine Sauvage, Laurie Boithias, Nouria Belaidi, and José Sánchez-Pérez. 2017. 'Modelling Hydrology and Sediment Transport in a Semi-Arid and Anthropized Catchment Using the SWAT Model: The Case of the Tafna River (Northwest Algeria)', Water, 9: 1-18. 


\section{Summary}

In spite of the pollution risk of pesticides, it is still one of the important methods for protecting agriculture and horticultural products against pests. However, the use of pesticides continues to cause anxiety due to the potential harmful effects of pesticides on the environment and on human health. Therefore, increased awareness and knowledge of micro-pollutants (incl. pesticide residues), their spatial distribution and location, and their fate can help to better understand the hazards and risks associated to chemical pollutants in soil, water, crops and biota. During application of pesticide to agricultural cropland, some of it may be adsorbed to sediments, organic matter, soil particles, biota and crops and/or may volatize to the air. Pesticides are also subject to biodegradation by microorganisms. Therefore, in order to determine the distribution and fate of pesticides in the environment, it is necessary to evaluate, next to their accurate concentration, any relevant factors and variation of pesticides fate in the environment.

This study is about pollution and fate of pesticide residues in the lake Naivasha basin where intensive agricultural activity has caused worries about micro-pollutants and contamination of the lake environment and surrounding ecosystem. The Lake Naivasha catchment is located in the eastern part of the Rift Valley region in Kenya with a basin area of approx. 3,400 km2. The eastern Rift has a tropical equatorial highland climate with two dry and two rainy seasons. The upper and middle parts of the catchment are mostly subjected to smallholder mixed farming for producing various crops. Moreover, there are various local dwellings, villages and towns all around the catchment that influence the rivers and lake water quality located in the lower catchment. Input from upstream into the Lake includes streamflow from the Malewa, Karati and Gilgil rivers plus other surface runoff and sub-surface flows that drain from the catchment and ultimately reach the lake. As the Malewa river accounts for approximately $80 \%$ of the water inflow into Lake Naivasha, the passive sampling stations were installed in the Upper Malewa, Middle Malewa river and in the Lake waterbody.

Although the potential pollution of different agro-chemicals (e.g. pesticides and fertilizers) has been explored in some earlier studies in the basin, a comprehensive evaluation of environmental exposure to residues coming from pesticide application by using new in-situ sampling techniques and models in the Naivasha basin was deemed necessary. The scientific challenge of this study was to determine the exposure risk of lake Naivasha to pesticide residues, and to identify the sources of the chemicals and their fate by using a combined passive sampling, hydrological modelling and eco-partitioning approach. To meet this challenge, the following objectives were defined: The first 
objective deals with application of passive sampling techniques for studying and measuring the micro-pollutants in the aquatic environment of the lake Naivasha basin. The main challenge of this objective was the spatial distribution of the passive sampling locations for achieving adequate information and data about pesticide concentrations in the river network and lake Naivasha. In the second instance, a simulation of pesticide transport and their fate in the river network of the Naivasha basin was undertaken and the effect of different hydrological conditions was analysed. The main aim of this objective was exploring the transfer of pesticides through the river network from the upper and middle parts of the basin to the lake by using a hydrologic modelling approach. Finally, the last objective was evaluating the micro-pollutants distribution in the lake Naivasha basin by using an environmental ecosystem partitioning approach. The main theory of this objective was that applied pesticides could be washed from crops and soil to riparian areas and transferred further to the rivers and the Lake, but usually have a strong preference for an ecosystem compartment i.e. air, soil, water, biota. It means that pesticide pollution of agricultural areas affects not only the water quality of rivers and the lake in the basin, but ultimately also can affect biota (plants, fish) and therefore presents a health risk and hazard. This objective identified how any of the environmental compartments of the lake basin are exposed to the investigated pesticide residues.

In the first part of the study, the idea was that the passive sampling techniques could improve the discovery and assessment of very low concentrations by continuous collecting the contaminants, which usually go undetected with classic and once-off time-point grab sampling. The aim of this study was to evaluate organochlorine pesticide (OCP) residues in the aquatic environment of the lake Naivasha river basin (Kenya) using passive sampling techniques. Silicone rubber sheet and Speedisk samplers were used to detect residues of $a-H C H, \beta-H C H, \gamma-H C H, \delta-H C H$, Heptachlor, Aldrin, Heptachlor Epoxide, pp-DDE, Endrin, Dieldrin, a-endosulfan, $\beta$ endosulfan, pp-DDD, Endrin aldehyde, pp-DDT, Endosulfan Sulfate and Methoxychlor in the Malewa river and Lake Naivasha. After solvent extraction from the sampling media, the residues were analyzed using gas chromatography electron capture detection (GC-ECD) for the OCPs and gas chromatography- double mass spectrometry (GC-MSMS) for the PCB reference compounds. Measuring the OCP residues using the Silicone rubber samplers revealed the highest concentration of residues ( $\Sigma$ OCPs of $81( \pm 18.9 \mathrm{SD}) \mathrm{ng} / \mathrm{L}$ to be at the lake site, being the ultimate accumulation environment for surficial hydrological, chemical and sediment transport through the river basin. The total OCP residue sums changed to $71.5( \pm 11.3 \mathrm{SD}) \mathrm{ng} / \mathrm{L}$ for the Middle Malewa and $59( \pm 12.5 S D) \mathrm{ng} / \mathrm{L}$ for the Upper Malewa river sampling sites. The 
concentration sums of OCPs detected using the Speedisk samplers at the Upper Malewa, Middle Malewa and the Lake Naivasha sites were 28.2( $\pm 4.2 \mathrm{SD}) \mathrm{ng} / \mathrm{L}, 31.3( \pm 1.8 \mathrm{SD}) \mathrm{ng} / \mathrm{L}$ and $34.2( \pm 6.4 \mathrm{SD}) \mathrm{ng} / \mathrm{L}$, respectively. An evaluation of the different pesticide compound variations identified at the three sites revealed that Endosulfan Sulfate, $\mathrm{a}-\mathrm{HCH}$, Methoxychlor and Endrin aldehyde residues were still found at all sampling sites. However, the statistical analysis using one-way ANOVA for testing the differences of $\Sigma O C P$ s between the sampling sites for both the Silicone Rubber sheet and Speedisk samplers showed that there were no significant differences from the Upper Malewa to the Lake site $(P<0.05)$. Finally, the finding of this study indicated that continued monitoring of pesticide residues in the catchment remains highly recommended.

In the second step of this study, the SWAT model as an integrated hydrological model was applied to evaluate the transport of pesticide residues. The idea was improving our understanding of the dynamics of pesticide transport in the Malewa river and lake Naivasha, a major fresh water resource of high socio-economic importance. In this study, the Soil and Water Assessment Tool (SWAT) model was used to simulate the discharge of sediment and pesticides (notably the organochlorine or OCP residues of a-HCH, Methoxychlor and endosulfan-sulfate) into the Malewa river sub-basin. Model sensitivity analysis, calibration and validation were performed for both daily and monthly time steps using the Sequential Uncertainty Fitting version 2 (SUFI-2) algorithm of the SWAT-CUP tool. Water level gauge data as well as a DTS-12 digital turbidity sensor for suspended sediment transport were used for the SWAT calibration. Pesticide residues were measured at Upper and Down Malewa locations using a passive sampling technique and their quantity was determined using laboratory Gas Chromatography. The sensitivity analysis results showed that curve number (CN2), USLE soil erodibility factor (USLE-K) and pesticide application efficiency (AP_EF) formed the most sensitive parameters for discharge, sediment and pesticide simulations, respectively. In addition, SWAT model calibration and validation showed better results for monthly discharge simulations than for daily discharge simulations. Similarly, the results obtained for the monthly sediment calibration demonstrated more match between measured and simulated data as compared to the simulation at daily steps. Comparison between the simulated and measured pesticide concentrations at upper Malewa and down Malewa locations demonstrated that although the model mostly overestimated pesticide loadings, there was a positive association between the pesticide measurements and the simulations. Higher concentrations of pesticides were found between May and mid-July. The similarity between measured and simulated pesticides shows the potential of the SWAT 
model as evaluation modelling tool for upstream to downstream suspended sediment and pesticide transport in catchments.

Finally, distribution of pesticide residues in the environment, their transport and final fate is one of the most important environmental challenges. Fate of pesticides in the complex environments, especially in aquatic phases such as lakes and rivers, is governed by the main physicochemical properties of the contaminants and the surrounding environmental properties. In this study, a multimedia mass modeling approach using the Quantitative Water Air Sediment Interaction (QWASI) model was applied to explore the fate of organochlorine pesticide residues of Methoxychlor, a-HCH and endosulfan-sulfate in the lake Naivasha (Kenya). The required physicochemical data of the pesticides such as molar mass, vapour pressure, air-water partitioning coefficient (KAW), solubility, and the Henry's law constant were provided as the inputs of the model. The environmental data also were collected using field measurements and taken from the literature. The sensitivity analysis of the model was applied using a One-At-a-Time (OAT) approach and calibrated using measured pesticide residues by the passive sampling method. Finally, the calibrated model was used to estimate the fate and partitioning of the pesticide residues in different media of the lake. The result of sensitivity analysis showed the five most sensitive parameters were KOC, log Kow, half-life of the pollutants in water, half-life of the pollutants in sediment, and KAW. The variations of outputs for the three studied pesticide residues against inputs were noticeably different. For example, the range of changes in the concentration of a-HCH residue was between $96 \%$ to $102 \%$, while for Methoxychlor and endosulfan-sulfate it was between $65 \%$ to $125 \%$. The results of calibration demonstrated that the model was calibrated reasonably with the R2 of 0.65 and RMSE of 16.4. It was found that Methoxychlor had a mass fraction of almost $70 \%$ in the water column and almost $30 \%$ of mass fraction in the sediment. In contrast, endosulfan-sulfate had highest most fraction in the water column $(>99 \%)$ and just a negligible percentage in the sediment compartment. a-HCH also had the same situation like endosulfansulfate (e.g., $99 \%$ and $1 \%$ in water and sediment, respectively). Finally, it was concluded that the application of QWASI in combination with data from the passive sampling measurement technique allowed an improved insight to the fate processes of the studied OCPs and helped actual concentration estimates. Therefore, the results of this study can also be used to perform risk assessment and investigate the environmental exposure of other pesticide residues and chemicals. 


\section{Samenvatting}

Ondanks het vervuilings- en gezondheidsrisico van pesticiden, blijft het een van de belangrijkste methoden om land- en tuinbouwproducten tegen ongedierte en ziektes te beschermen. Het gebruik van pesticiden blijft echter zorgen baren vanwege de mogelijke nadelige effecten van pesticiden op het milieu en op de menselijke gezondheid. Daarom kan een groter bewustzijn en kennis van de verspreiding van microverontreinigende stoffen (inclusief residuen van pesticiden) en hun uiteindelijke bestemming, bijdragen om het gevaar en het risico van chemische verontreinigende stoffen in bodem, water, gewassen en biota beter te begrijpen. Tijdens de toepassing van pesticiden op landbouwgewassen, kan een deel ervan worden geadsorbeerd op organisch materiaal, bodemdeeltjes, biota en gewassen, kan vervluchtigen in de lucht en/of wordt afgebroken door microorganismen. Om de verspreiding en de uiteindelijke bestemming van pesticiden en hun residuen in het milieu te bepalen, is het daarom noodzakelijk om, naast hun nauwkeurige bepaling, alle relevante factoren en variatie van de bestemming van pesticiden in het milieu te evalueren.

Deze studie gaat over het vervuilingsrisico van pesticide residuen rond het Naivasha meer in Kenia, waarin intensieve landbouwactiviteiten zorgen hebben veroorzaakt over de mogelijke verontreiniging van het meer. Het stroomgebied van "lake Naivasha" ligt in het oostelijke deel van de Rift Valley-regio in Kenia met een oppervlakte van ongeveer $3.400 \mathrm{~km} 2$. De oostelijke Rift heeft een tropisch equatoriaal klimaat met twee droge en twee regenseizoenen. De bovenste en middelste delen van het stroomgebied worden gekenmerkt door kleinschalige gemengde landbouw voor het produceren van verschillende gewassen. Bovendien zijn er veel lokale woonkernen, dorpen en kleine steden in het stroomgebied die de rivieren en de waterkwaliteit van het meer in het lagere stroomgebied ook beïnvloeden. Water en sediment afvoer naar het meer omvat water van de rivieren Malewa, Karati en Gilgil plus afvloeiing aan de oppervlakte en vanuit het grondwater, die vanuit het stroomgebied het meer kan bereiken. Aangezien de Malewa rivier ongeveer $80 \%$ van de instroom in Lake Naivasha uitmaakt, werden de "passive sampler" bemonsteringslocaties geïnstalleerd in de bovenstroomse of Upper Malewa, de Middle Malewa rivier en het meer.

Hoewel het vervuilingspotentieel van verschillende agrochemicaliën (bijv. pesticiden en meststoffen) in studies in het stroombekken al meer is onderzocht, was een uitgebreide evaluatie van de 
milieublootstelling aan microcontaminanten en residuen afkomstig van de toepassing van pesticiden met behulp van nieuwe nauwkeurige insitu bemonsteringstechnieken en modellen in het Naivasha-bekken nog niet uitgevoerd. De wetenschappelijke uitdaging van deze studie was om het blootstellingsrisico van het Naivasha meer aan micro verontreinigende stoffen te bepalen, de bronnen van de chemicaliën en hun uiteindelijke bestemming te identificeren door middel van een gecombineerde benadering van "passive sampler" bemonstering, hydrologische modellering en ecosysteem partitie. Om deze uitdaging aan te gaan, werden de volgende doelstellingen gedefinieerd: de eerste doelstelling betreft de toepassing van "passive sampling" water en sediment bemonsteringstechnieken voor het meten van zeer lage concentraties van microverontreinigingen in de aquatische omgevingen van het Naivasha stroombekken. De belangrijkste uitdaging van deze doelstelling was de ruimtelijke verdeling van de bemonsteringslocaties voor het verkrijgen van adequate informatie en gegevens over de concentraties van pesticiden in het riviernetwerk en het Naivasha meer.

In tweede instantie werd een simulatie worden uitgevoerd van het transport van microverontreinigingen in het riviernetwerk van het Naivasha stroombekken en werd het effect van verschillende hydrologische omstandigheden geanalyseerd. Het belangrijkste doel van deze doelstelling was het onderzoeken van het mogelijk transport en de overdracht van pesticiden door het rivier netwerk vanuit de bovenstroomse gebieden, naar het meer met behulp van een hydrologische modelbenadering.

Ten slotte was de laatste doelstelling het evalueren van de verdeling van microverontreinigingen in het bekken van het Naivasha meer door middel van een ecosysteem partitie of milieucompartimenten benadering. De achterliggende theorie van deze doelstelling was dat toegepaste pesticiden op gewassen en grond naar het water systeem kunnen worden uitgewassen en verder via de rivieren naar het meer kunnen worden overgebracht, maar sterke voorkeur vertonen voor bepaalde ecosysteem compartimenten e.g. lucht, water, bodem en sediment of biota zoals vissen en planten. Deze doelstelling identificeerde welke van de milieucompartimenten van het meer bekken worden blootgesteld aan de residuen van verschillende bestrijdingsmiddelen.

In het eerste deel van de studie was het idee dat de "passive sampling" bemonsteringstechnieken de detectie van lage concentraties kunnen verbeteren door gedurende een bepaalde tijd continu verontreinigingen te bemonsteren, die meestal onopgemerkt blijven met klassieke en eenmalige monstername. Het doel was het evalueren van residuen van organochloorpesticiden (OCP) in het aquatisch milieu 
van het stroomgebied van het Naivasha meer met behulp van deze nauwkeurige "passive sampling" bemonsteringstechnieken. Siliconenrubberfolie en Speedisk monsternemers werden gebruikt om residuen van $\mathrm{a}-\mathrm{HCH}, \beta-\mathrm{HCH}, \gamma-\mathrm{HCH}, \delta-\mathrm{HCH}$, Heptachlor, Aldrin, Heptachlor Epoxide, pp-DDE, Endrin, Dieldrin, a-endosulfan, $\beta$ endosulfan, pp-DDD, Endrin aldehyde, pp-DDT, Endosulfansulfaat en methoxychloor te detecteren in de Malewa rivier en Naivasha meer. $\mathrm{Na}$ oplosmiddelextractie uit de bemonsteringsmedia werden de residuen geanalyseerd met gaschromatografie elektronenvangst detectie (GCECD) voor de OCP's en gaschromatografie- dubbele massaspectrometrie (GC-MSMS) voor de PCB-referentieverbindingen. Het meten van het OCP residuen met behulp van siliconenrubbermonsternemers vertoonden de hoogste concentratie van residuen ( $\Sigma$ OCP's van 81 ( $\pm 18,9 \mathrm{SD}) \mathrm{ng} / \mathrm{L}$ ) op de locatie van het meer, zijnde de ultieme accumulatieomgeving voor hydrologisch, chemisch en sedimenttransport van het stroomgebied. De totale OCPresidusommen werden begroot op 71,5 ( \pm 11,3 SD) $\mathrm{ng} / \mathrm{L}$ voor de Midden-Malewa en 59 ( $\pm 12,5$ SD) ng/L voor de bemonsteringslocaties van de Boven-Malewa. De concentratiesommen van OCP's die werden gedetecteerd met behulp van de Speedisk-samplers op de locaties Upper Malewa, Middle Malewa en Lake Naivasha waren 28,2 ( \pm 4,2 SD) ng/L, 31,3 ( $\pm 1,8 S D) n g / L$ en 34,2 ( $\pm 6,4 S D) n g / L$, respectievelijk. Een evaluatie van de verschillende variaties van pesticidenverbindingen die op de drie locaties zijn geïdentificeerd, onthulde dat residuen van endosulfan-sulfaat-, a- $\mathrm{HCH}-$, methoxychloor- en endrine-aldehyde residuen nog steeds op alle bemonsteringsplaatsen werden gevonden. De statistische Anova analyse van de verschillen tussen $\Sigma$ OCP's tussen de bemonsteringslocaties voor zowel de siliconenrubberplaat als de Speedisk-monsternemers, toonde echter aan dat er geen statistisch significante verschillen waren tussen de Upper Malewa en de Lake-site $(P<0,05)$. De bevindingen van dit eerste onderzoek wezen er op dat monitoring van residuen van bestrijdingsmiddelen in het stroomgebied sterk aanbevolen blijft.

In de tweede stap van deze studie werd het SWAT hydrologisch model toegepast om het transport van residuen van bestrijdingsmiddelen te evalueren. Het idee was om de dynamiek van het transport van pesticiden in de Malewa rivier te begrijpen en de invloed van de bovenstroomse gebieden op de waterkwaliteit van het Naivasha meer, een belangrijke zoetwaterbron, die van cruciaal socio-economisch belang is in dit gebied, te bepalen. Het "Soil and Water Assessment Tool" (SWAT) model gebruikt om de afvoer van sediment en pesticiden (met name de organochloorresiduen van a-HCH, methoxychloor en endosulfan-sulfate) in het stroomgebied van Malewa te simuleren. Modelgevoeligheidsanalyse, kalibratie en validatie werden uitgevoerd 
voor zowel dagelijkse als maandelijkse tijdsstappen met behulp van het "Sequential Uncertainty Fitting" versie-2 (SUFI-2) algoritme van de SWAT-CUP tool. Voor de SWAT kalibratie werden gegevens over de waterstanden en debieten in de rivieren en eigen metingen van een DTS-12 digitale troebelheidssensor voor de bepaling van zwevend sedimenttransport gebruikt. Residuen van bestrijdingsmiddelen werden gemeten op locaties in de bovenstroom en benedenloop van de Malewa met behulp van de "passive sampling" bemonsteringstechniek en hun hoeveelheid werd bepaald met behulp van gaschromatografie in het laboratorium (zie ook boven). De resultaten van de model gevoeligheidsanalyse toonden aan dat het "Curve Number" afvoergetal (CN2), de "USLE-K" bodemerodibiliteitsfactor en pesticide toepassingsefficiëntie (AP_EF) de meest gevoelige parameters vormden voor respectievelijk applicatie, sediment en chemisch transport bij de pesticide simulaties. Bovendien lieten de kalibratie en validatie van het SWAT model betere resultaten zien voor maandelijkse simulaties dan voor dagelijkse. Evenzo toonden de resultaten die werden verkregen voor de maandelijkse sediment kalibratie meer overeenstemming tussen gemeten en gesimuleerde gegevens in vergelijking met de simulatie in dagelijkse stappen. Vergelijking tussen de gesimuleerde en gemeten pesticide concentraties in de boven- en benedenstroomse locaties van de Malewa toonde aan dat hoewel het model de pesticide beladingen van het water overschatte, er een positieve associatie was tussen de pesticide metingen en de simulaties. Tussen mei en half juli werden hogere concentraties bestrijdingsmiddelen aangetroffen. De gelijkenis tussen gemeten en gesimuleerde bestrijdingsmiddelen toont het potentieel van het SWAT model als eerste evaluatiemodel voor zwevend sediment en hydrologisch chemisch transport in stroomgebieden.

Ten slotte is de uiteindelijke verdeling van residuen van bestrijdingsmiddelen in het milieu en hun opslag in oppervlakte waterlichamen en ecosystemen een van de belangrijkste milieuuitdagingen. De eindbestemming van pesticide residuen in complexe omgevingen, vooral in aquatische milieus zoals meren en rivieren, wordt in grote mate bepaald door de eigenschappen van de verontreinigingen en de eigenschappen en klimaat van de omgeving. In deze studie werd een multimedia massamodellering toegepast met behulp van het "Quantitative Water Air Sediment Interaction" (QWASI) model om het lot van organochloor residuen van bestrijdingsmiddelen van methoxychloor, a-HCH en endosulfan sulfaat in het meer Naivasha (Kenia) te onderzoeken. Als input voor het model werden de vereiste fysisch en chemische eigenschappen van de pesticiden bepaald, zoals molaire massa, dampspanning, lucht-waterverdelingscoëfficiënt (KAW), oplosbaarheid en de Henry verdelingscoefficient en de 
biologische afbreekbaarheid i.e. halfwaardetijd in water en sediment. De omgevingsgegevens werden verzameld met behulp van veldmetingen en ook uit de literatuur gehaald. De gevoeligheidsanalyse van het model werd uitgevoerd door middel van een "One At a Time" (OAT) benadering en gekalibreerd met gemeten bestrijdingsmiddelen residuen vanuit de "passive sampling" bemonstering. Ten slotte werd het gekalibreerde model gebruikt om de bestemming en de verdeling van de bestrijdingsmiddelen residuen in verschillende media van het meer te schatten. Het resultaat van gevoeligheidsanalyse toonde aan dat de vijf meest gevoelige parameters, KOC, log Kow, halfwaardetijd van de verontreinigende stoffen in water, halfwaardetijd van de verontreinigende stoffen in sediment en KAW waren. De variaties van de output voor de drie bestudeerde residuen ten opzichte van de inputs waren merkbaar verschillend. Bijvoorbeeld de verschillen in de concentratie van a-HCH residu was tussen $96 \%$ en $102 \%$, terwijl het voor methoxychloor en endosulfan sulfaat tussen $65 \%$ en $125 \%$ lag. De resultaten van de kalibratie toonden aan dat het model redelijk gekalibreerd was met de R2 van 0.65 en RMSE van 16.4. Het bleek dat methoxychloor een massafractie had van bijna $70 \%$ in de waterkolom en $30 \%$ massafractie in het sediment. Endosulfan sulfaat had daarentegen de hoogste fractie in de waterkolom (> 99\%) en slechts een verwaarloosbaar percentage in het sedimentcompartiment. a-HCH had ook dezelfde situatie als endosulfan sulfaat (bijv. respectievelijk $99 \%$ en $1 \%$ in water en sediment). Ten slotte werd geconcludeerd dat de toepassing van QWASI in combinatie met de "passive sampling" bemonsteringstechniek een beter inzicht gaf in het bestemmingsproces van de bestudeerde OCP's en hielp bij daadwerkelijke concentratievoorspellingen. Daarom kunnen de resultaten van deze studie ook worden gebruikt om een risicobeoordeling uit te voeren en de milieublootstelling van residuen van bestrijdingsmiddelen beter te onderzoeken, ook in tropische streken. 


\section{Appendix}

1- Calculating the passive samplers:

Calculation of the pesticides was using the equations that were mentioned in Chapter 2. For this aim, the data were analyzed using an Excel sheet that was provided by Deltares (Utrecht, Netherlands). The samplers were calculated based on the PRC data and Kpw coefficients as follow:

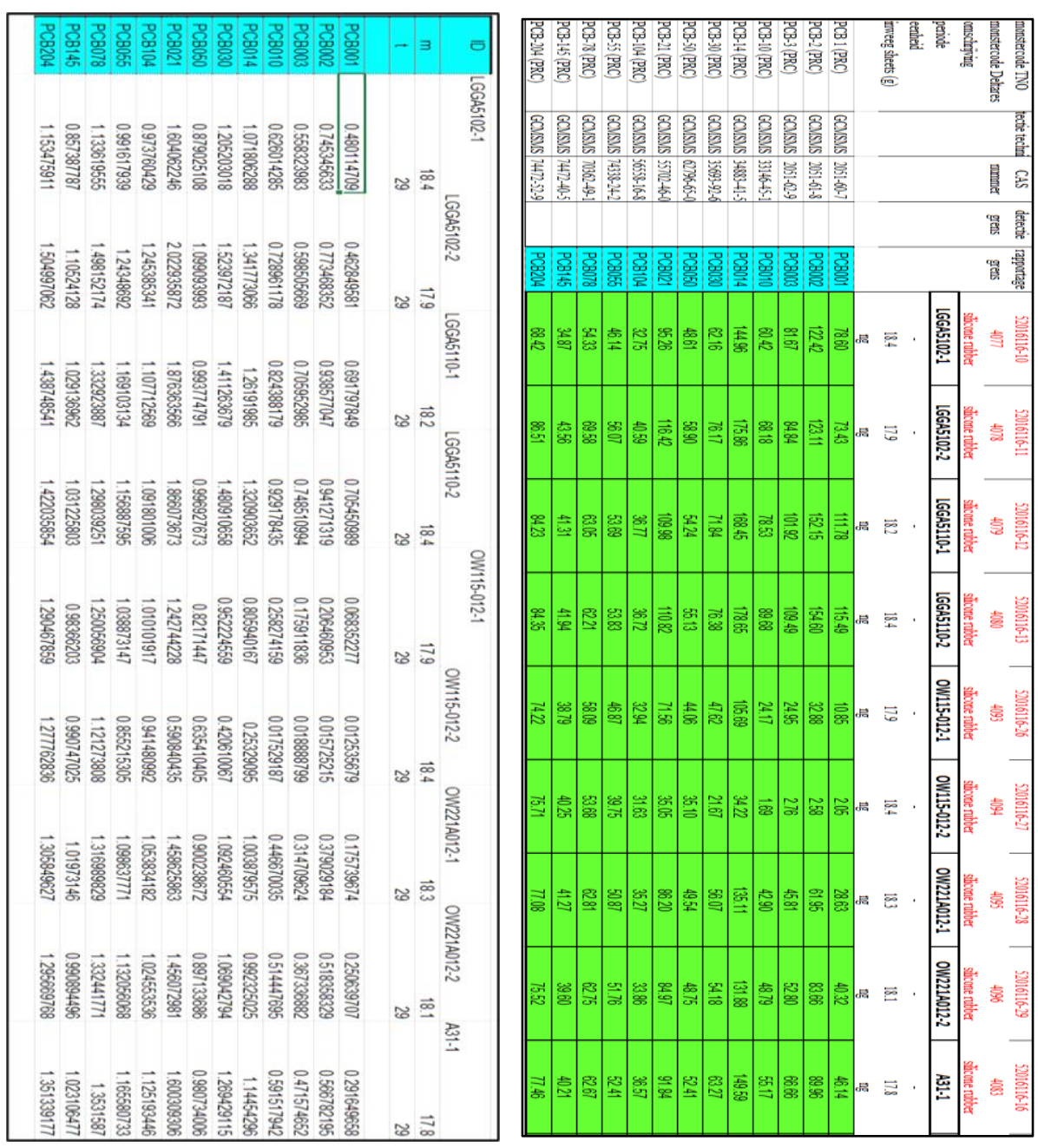




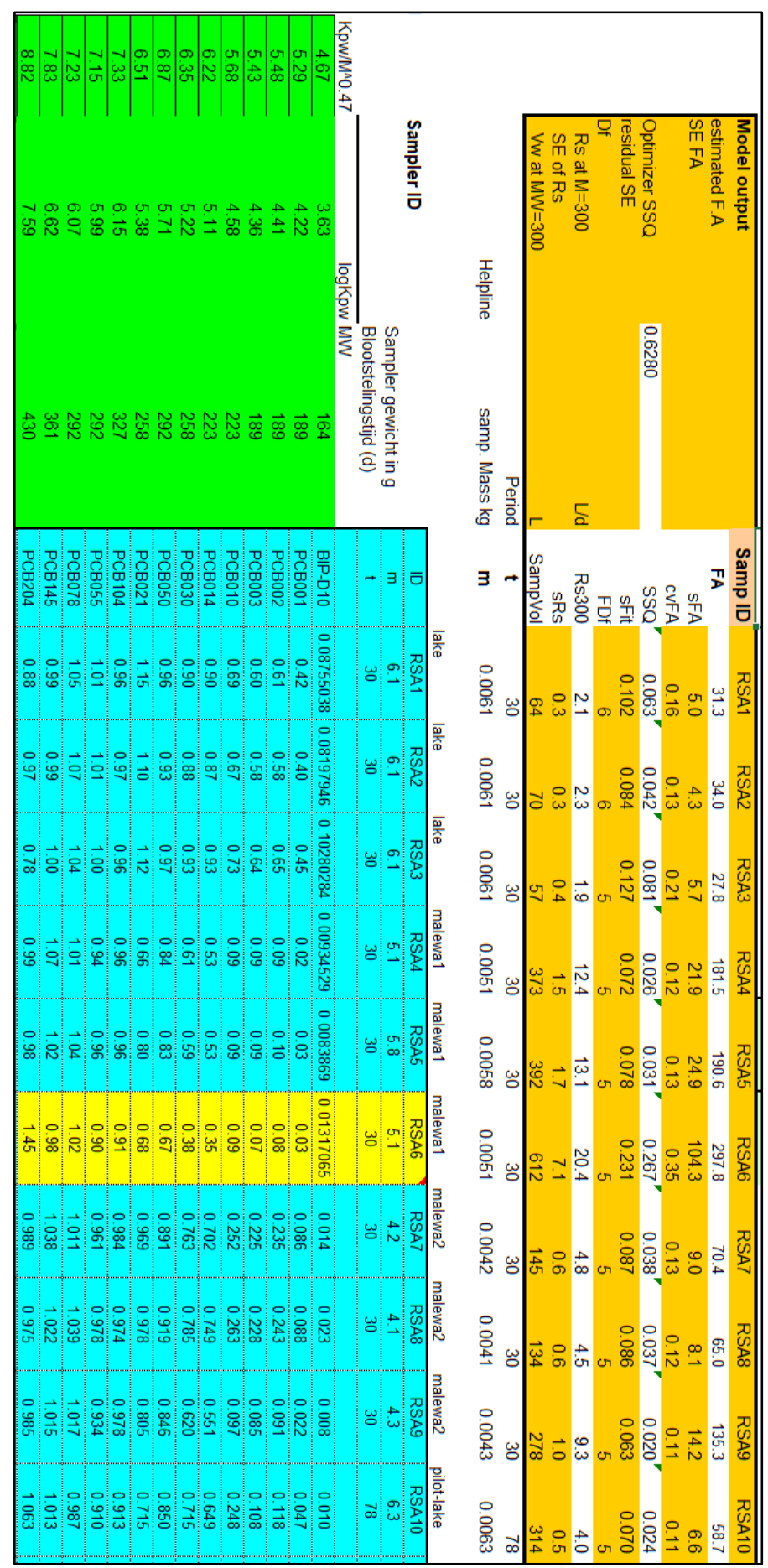

Figure 0-1-Calculating the passive sampling 


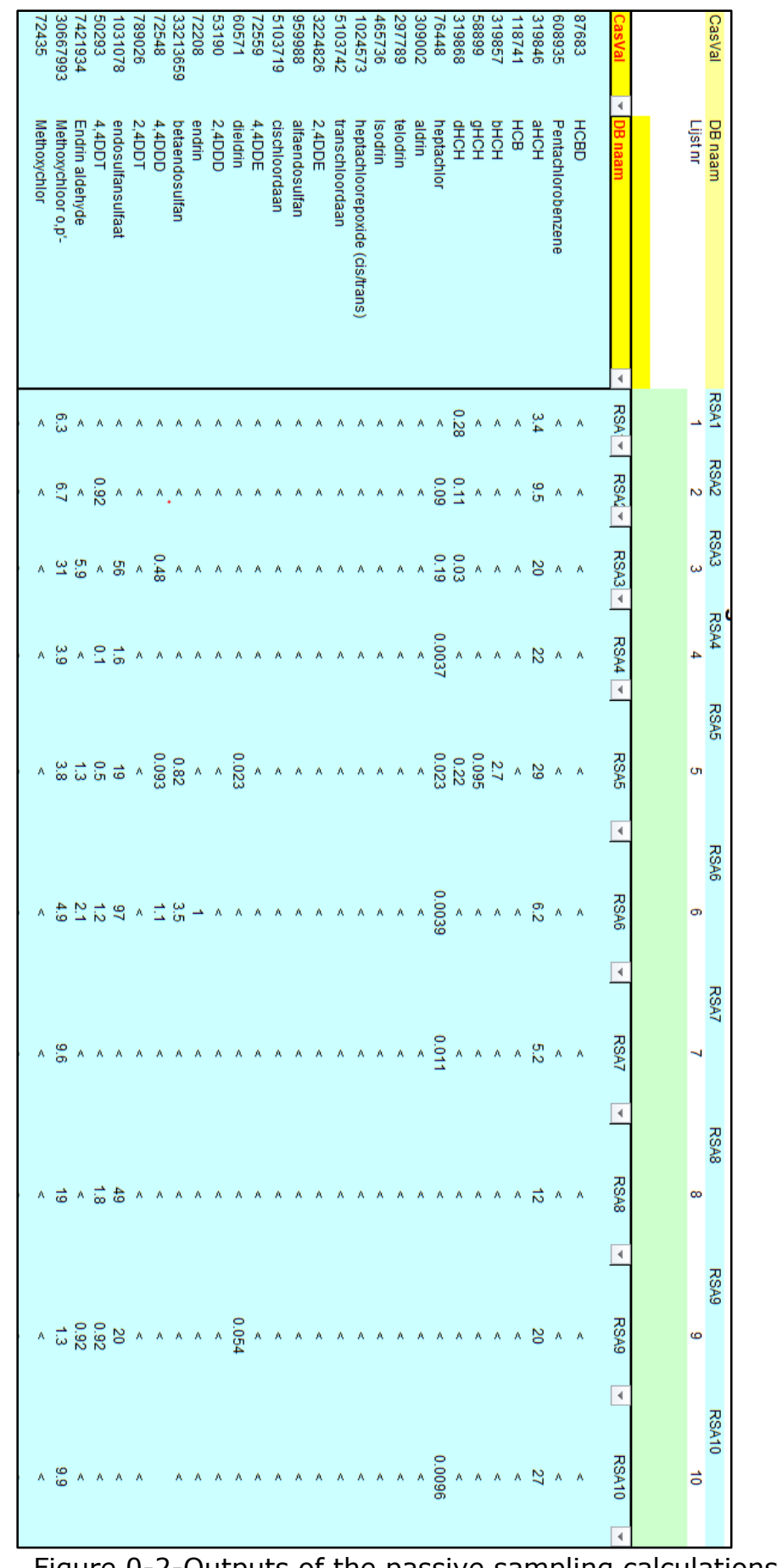

Figure 0-2-Outputs of the passive sampling calculations 
2- Preparation and setting SWAT model:

The model needed several data sets. One of the important inputs of the model was hydrological information. The general workflow of the modeling was as below:

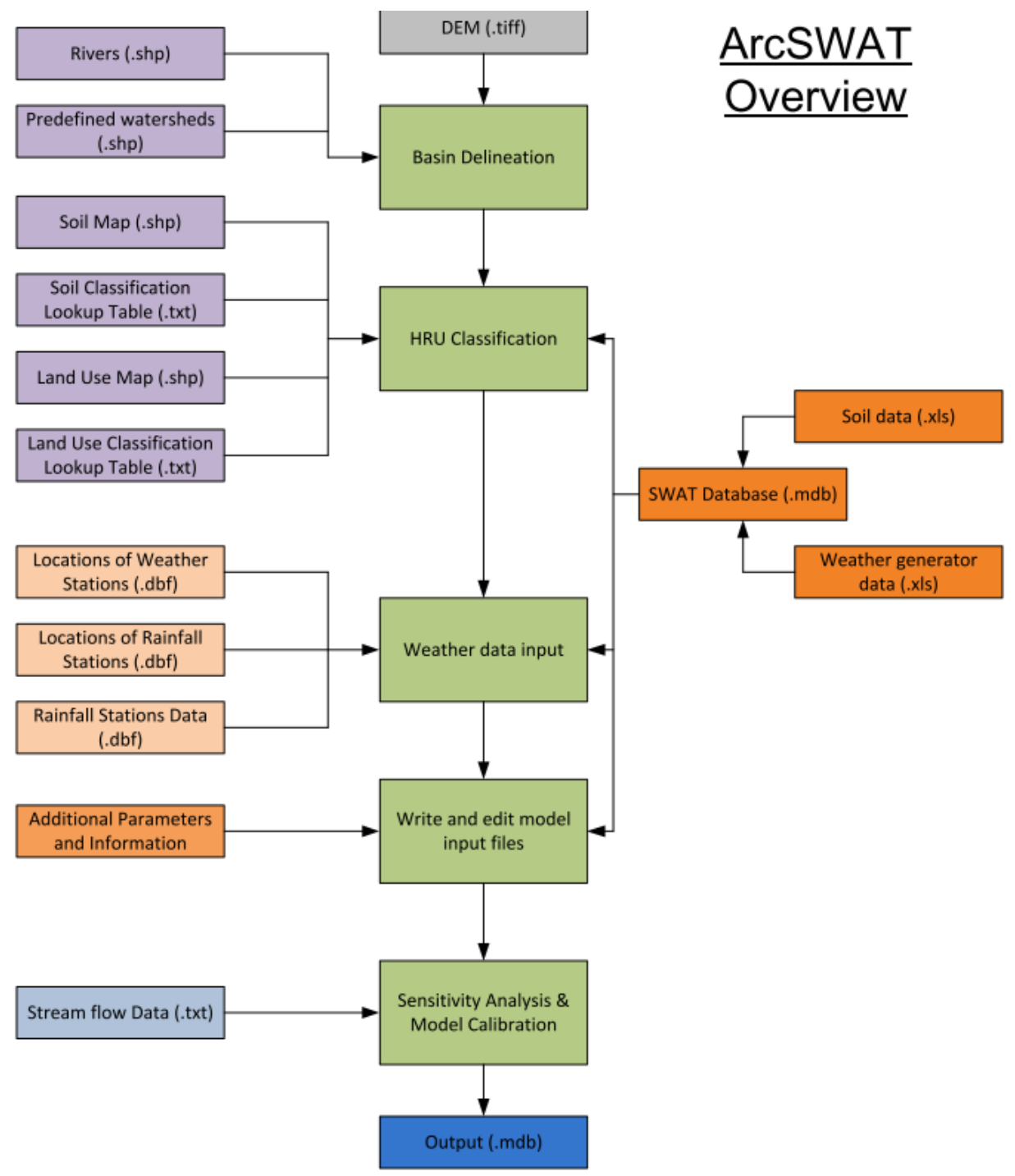

Figure 0-3- The modeling process algorithm in ArcSWAT

The river gauge stations were as follow in the initial model setting: 


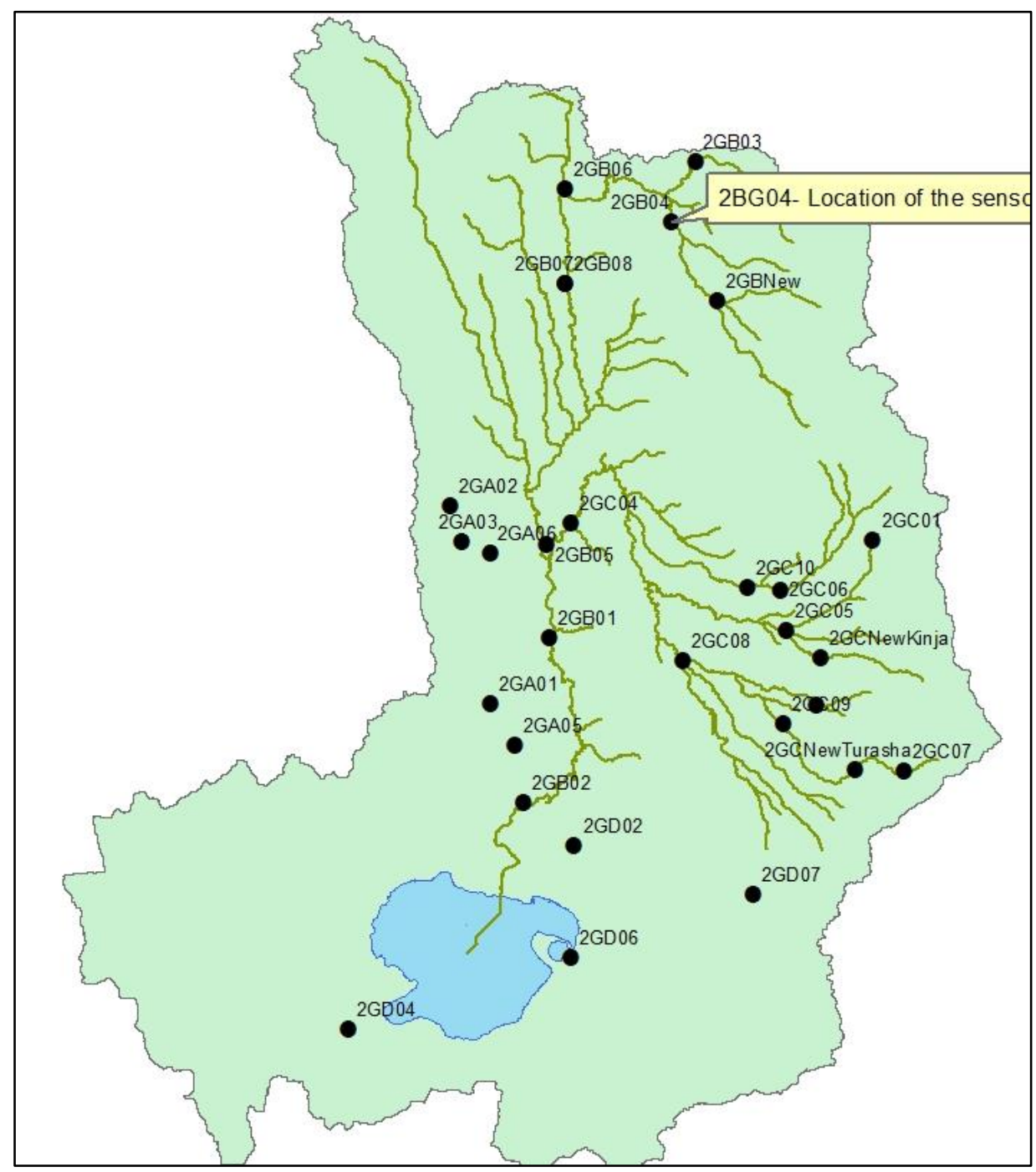




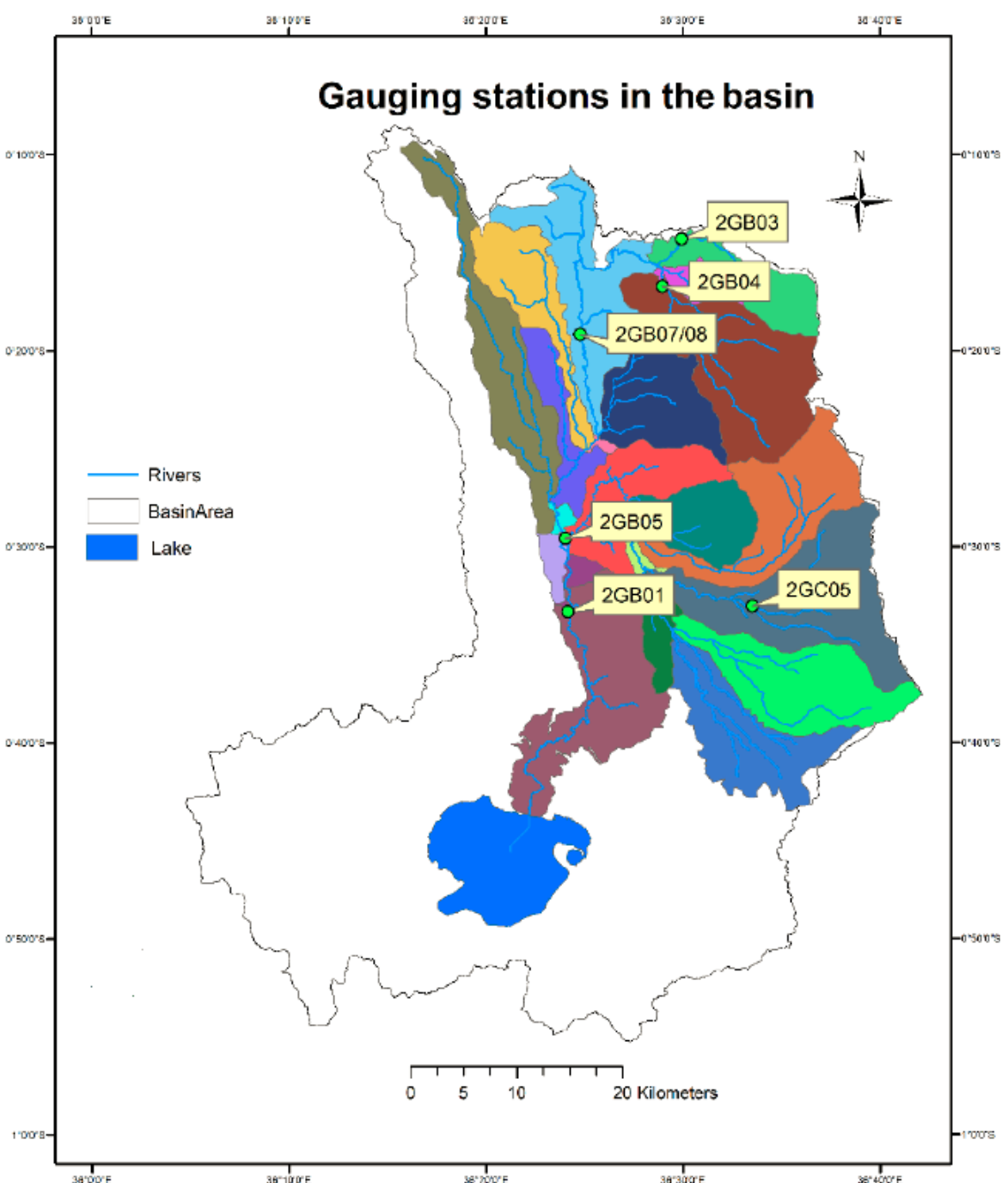

Figure 0-4- Flow gauging stations in both all the basin (up) and Mallewa river basin (down)

- The water flow in different gauge stations were converted from water depth to flow rates based on the following table and graph provided by Water Resources Management Authority in Naivasha: 
Table 0-1- Rating coefficients of $Q=a(H-b)^{c}$ equation

\begin{tabular}{|l|ccc|}
\hline Station & Coefficient a & Coefficient b & Coefficient c \\
\hline 2GA01 & 1.15 & 0.10 & 1.99 \\
\hline 2GA03 & 2.08 & 0.00 & 1.65 \\
\hline 2GA05 & 1.37 & 0.20 & 1.20 \\
\hline 2GA06 & 0.05 & 0.00 & 0.40 \\
\hline 2GB01 & 28.26 & 0.00 & 1.77 \\
\hline 2GB03 & 5.16 & 0.00 & 2.23 \\
\hline 2GB04 & 7.19 & 0.00 & 1.67 \\
\hline 2GB05 & 7.62 & 0.29 & 1.70 \\
\hline 2GB07 & 3.63 & 0.00 & 2.85 \\
\hline 2GB08 & 9.82 & 0.00 & 2.52 \\
\hline 2GC04 & 13.55 & 0.00 & 2.16 \\
\hline 2GC05 & 4.47 & 0.00 & 1.52 \\
\hline 2G07 & 4.04 & 0.00 & 3.63 \\
\hline 2GC10 & 1.65 & 0.02 & 2.50 \\
\hline 2GD02 & 7.72 & 0.01 & 2.87 \\
\hline 2GD07 & 5.68 & 0.09 & 2.18 \\
\hline
\end{tabular}

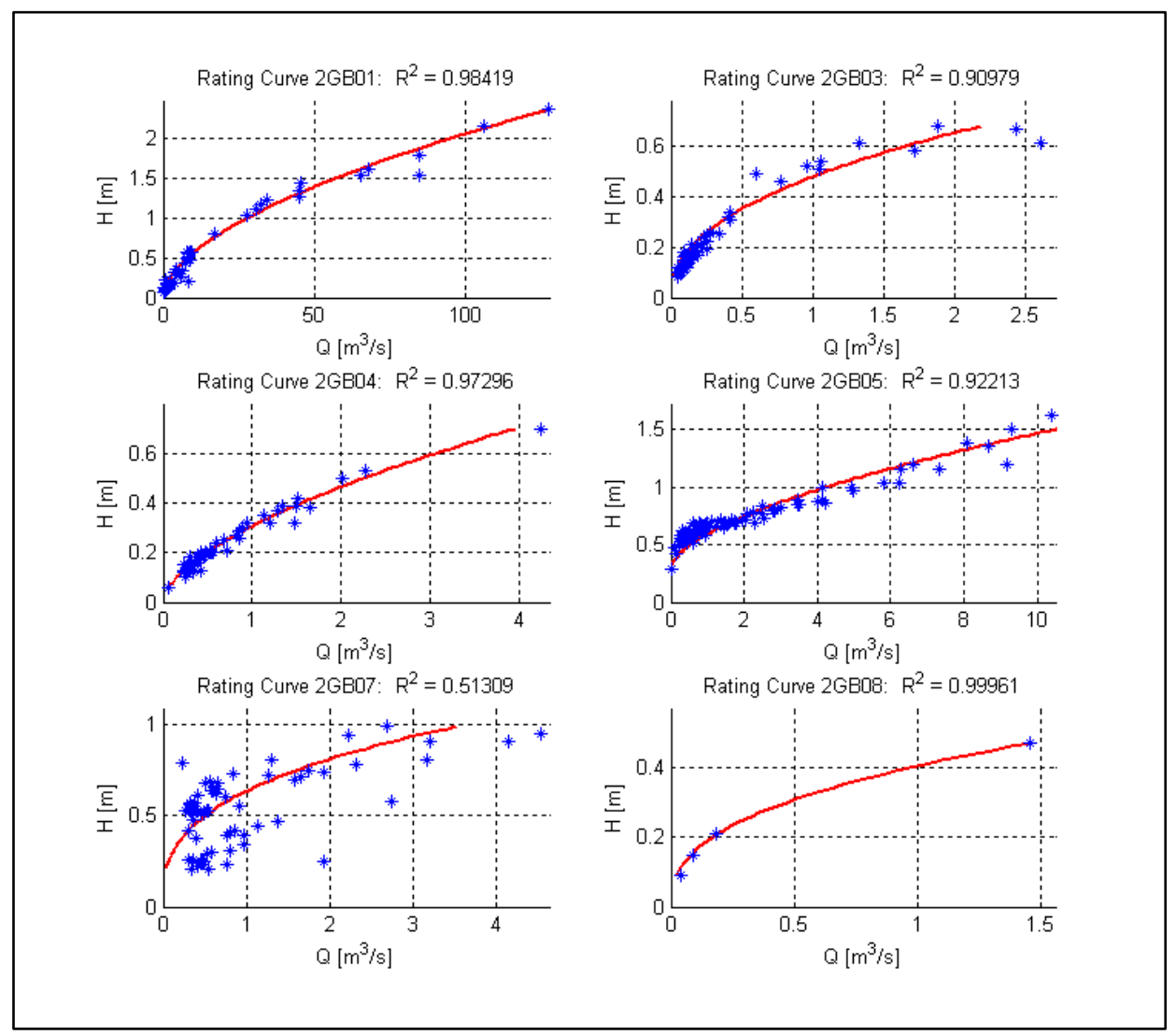

Figure 0-5-Rating curves coefficients based on $\mathrm{Q}=\mathrm{a}(\mathrm{H}-\mathrm{b}) \mathrm{c}$ equation 
- Land use- land cover of the basin was as follow:

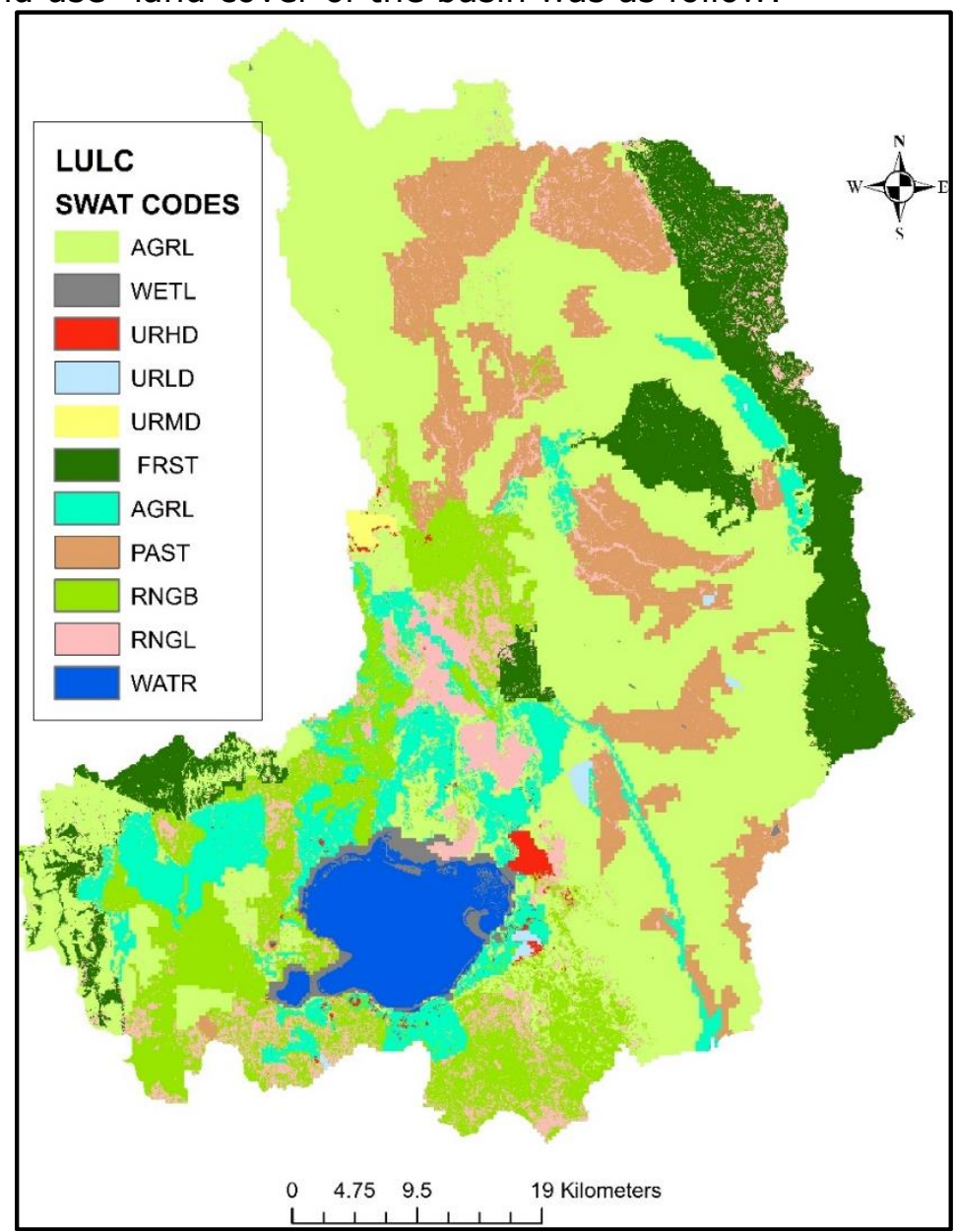

Figure 0-6-Land use-Land cover in Naivasha basin 
- The $20 m$ resolution DEM was used in a grid format then projected to UTM projection. The following map shows the DEM used in this research:

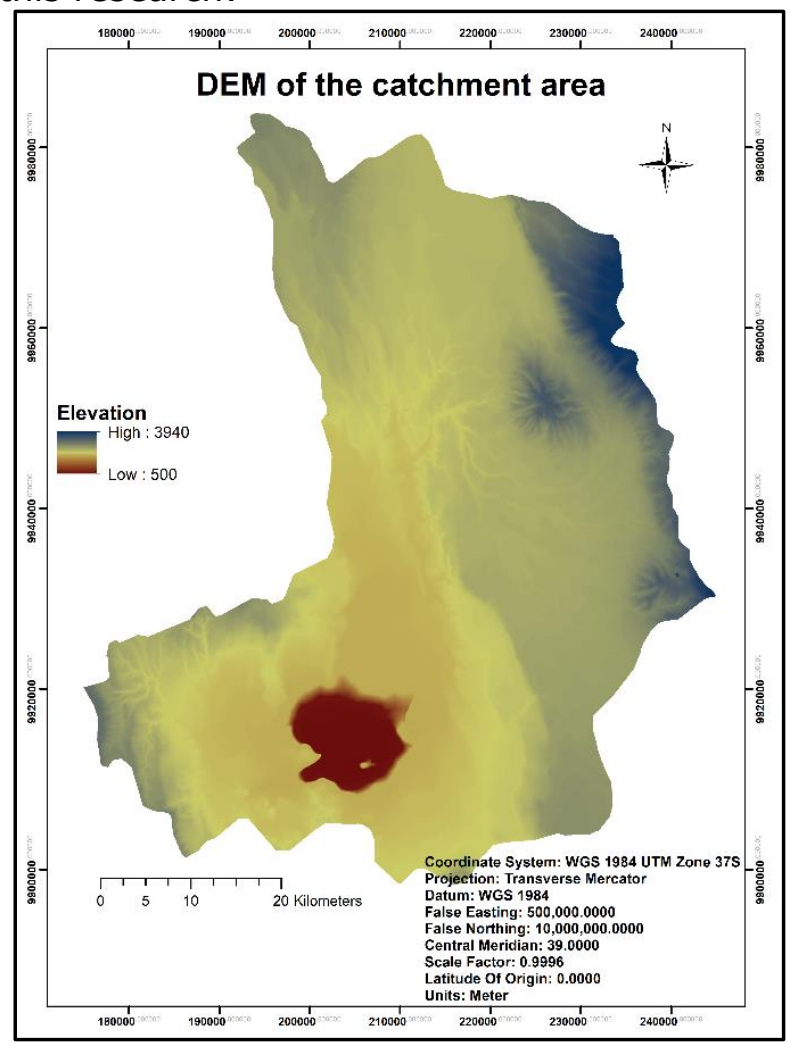

Figure 0-7- DEM of the L. Naivasha Basin used in modeling 
- The soil properties of the basin was explored in earlier studies. The texture of the soil samples was mainly clay loam. The soil map of the area was like this:

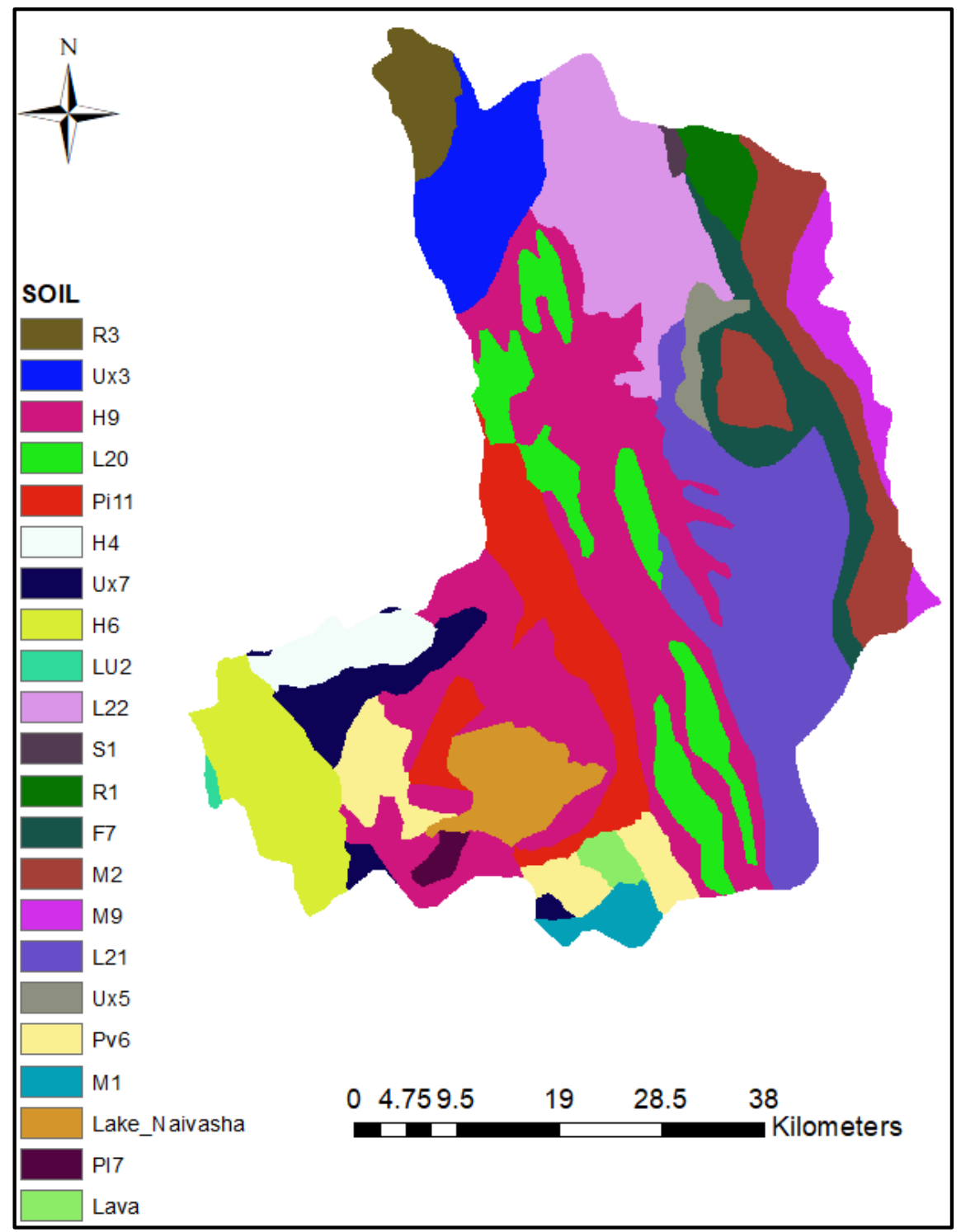

Figure 0-8-Soil map of Naivasha basin 


\section{Biography}

Yasser Abbasi was born on $8^{\text {th }}$ of November 1984 in Kermanshah, Iran. He received BSc. (2004-2008) in soil and water engineering at Razi University (Kermanshah, Iran) and followed the MSc study at University of Tehran (20082010) with the focus on the water quality and quantity subjects. After graduation, he started his career in different engineering consultancy companies on the supervision of various water-related projects. In 2014, he was awarded an

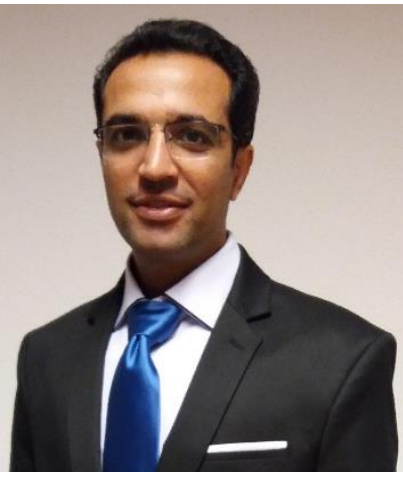
Erasmus Mundus Scholarship (SALAM project) to continue his Ph.D. research in the Faculty of Geo-Information Science and Earth Observation (ITC), University of Twente. The outcomes of the Ph.D. study are represented in this thesis and also were published in different journals and conferences as the following titles:

1. Y. Abbasi, C.M. Mannaerts. Exploring the Environmental Exposure to Methoxychlor, $\mathrm{a}-\mathrm{HCH}$ and Endosulfan-sulfate Residues in Lake Naivasha (Kenya) Using a Multimedia Fate Modeling Approach. International Journal of Environmental Research and Public Health 17 (8), 2727.

2. Y. Abbasi, C.M. Mannaerts, W Makau. Modeling pesticide and sediment transport in the malewa river basin (kenya) using swat, Water 11 (1), 87.

3. Y. Abbasi, C.M. Mannaerts. Evaluating organochlorine pesticide residues in the aquatic environment of the Lake Naivasha River basin using passive sampling techniques. Environmental monitoring and assessment 190 (6), 349.

4. Y. Abbasi, C.M. Mannaerts. Monitoring pesticides residues in water resources of the Lake Naivasha catchment using passive sampling. 4thWorld Congress on Civil, Structural, and Environmental Engineering (CSEE'19) Rome, Italy -April 7-9, 2019.

5. Y. Abbasi, C.M. Mannaerts. Watershed modeling of sediment and chemical transport in the Malewa river basin, Kenya. 2nd Annual Congress on Soil and Water Sciences 2018 (Berlin) : New strategies and approaches in Soil and Water resources to effective adaptability on Earth. 